\title{
Leitlinie der Deutschen Gesellschaft für Ernährungsmedizin (DGEM) in Zusammenarbeit mit der GESKES, der AKE, der DGN und der DGG Klinische Ernährung in der Neurologie Teil des laufenden S3-Leitlinienprojekts Klinische Ernährung
}

\author{
Guideline of the German Society for Nutritional Medicine (DGEM) \\ in cooperation with the GESKES, the AKE, the DGN and the DGG \\ Clinical Nutrition in Neurology - Part of the Ongoing S3-Guideline Project Clinical Nutrition
}

Autoren

Institute
R. Wirth ${ }^{1}$, R. Dziewas ${ }^{2}$, M. Jäger ${ }^{3}$, T. Warnecke ${ }^{2}$, C. Smoliner ${ }^{4}$, K. Stingel ${ }^{5}$, A. H. Leischker ${ }^{6}$ und das DGEM Steering Committee*

Die Institute sind am Ende des Artikels gelistet.

Schlüsselwörter
Leitlinie
Schlaganfall
Morbus Parkinson
Chorea Huntington
Multiple Sklerose
Dysphagie
Keywords
guideline
stroke
Parkinson's disease
Chorea Huntington
Multiple Sclerosis
dysphagia

Bibliografie

Dol http://dx.doi.org/

10.1055/s-0033-1343317

Online-Publikation: 18.7.2013

Aktuel Ernahrungsmed 2013;

38: e49-e89

(c) Georg Thieme Verlag KG

Stuttgart · New York

ISSN 0341-0501

\section{Korrespondenzadresse}

Dr. Andreas Leischker, M. A.

Alexianer Krefeld $\mathrm{GmbH}$, Klinik für Allgemeine Innere Medizin und Altersmedizin

Oberdießemer Straße 136

47805 Krefeld

Tel.: 02151/334-1211

Fax: 02151/334-3680

andreas.leischker@alexianer-

krefeld.de

\section{Zusammenfassung \\ $\nabla$}

Fragestellung: Neurologische Erkrankungen können zu Schluckstörungen mit konsekutiver Aspiration führen und gehen mit einem erhöhten Risiko für Mangelernährung einher. Die vorliegende Leitlinie soll evidenzbasierte Empfehlungen zur klinischen Ernährung in der Neurologie geben. Der akute Schlaganfall, der Morbus Parkinson, die Chorea Huntington und die Multiple Sklerose wurden als neurologische Erkrankungen ausgewählt, da hier die Ernährung eine besondere Rolle spielt.

Methodik: Es wurde eine systematische Literaturrecherche zur Ernährung bei den genannten Krankheitsbildern durchgeführt. Die Ergebnisse wurden in einer interdisziplinären Arbeitsgruppe aus Neurologen und Ernährungsmedizinern diskutiert. Auf dieser Basis wurden von der Arbeitsgruppe Empfehlungen erarbeitet, die auf der Konsensuskonferenz am 14. September 2011 vorgestellt, diskutiert und z.T. modifiziert wurden. Die modifizierten Empfehlungen wurden am 16. Juni 2012 auf einer 2. Konsensuskonferenz verabschiedet.

Ergebnisse: Die Leitlinie enthält 75 Empfehlungen zur Ernährung von Patienten mit neurologischen Erkrankungen. Bei Erkrankungen, die zu einer Dysphagie führen, sollten zeitnah ein Screening und ein Assessment auf Dysphagie erfolgen. Ausgehend von den erhobenen Befunden ist die Ernährung entsprechend zu modifizieren. Dies reicht von Texturmodifikationen über Sondenernährung bis zur Notwendigkeit einer parenteralen Ernährung. Patienten mit Morbus Parkinson und Chorea Huntington haben bereits in frühen Krankheitsstadien ein erhöhtes Risiko für Mangelernährung. Um diese zu vermeiden, werden auch hier ein regelmäßiges Screening, Assess-

\footnotetext{
* DGEM Steering Committee: Bischoff SC, Lochs H, Wei-
} mann A, Adolph M, Ockenga J, Sieber C.

\section{Abstract \\ $\nabla$}

Purpose: Neurologic diseases can lead to swallowing disorders. This may cause aspiration during oral intake of food and fluid and involves a higher risk for malnutrition. The present guideline is supposed to give evidence-based recommendations for clinical nutrition in neurology. Acute stroke, Parkinson's disease, Chorea Huntington and Multiple Sclerosis were chosen because here nutrition can become an import issue. Methods: A systematic literature search about nutrition and the mentioned disease patterns was conducted. The results were discussed in an interdisciplinary working group that consisted of neurologists and physicians with expertise for nutritional medicine. On this basis the working group developed recommendations, which were presented, discussed and partly modified at the consensus conference on September $14^{\text {th }}, 2011$. The revised form of these recommendations was passed at a second consensus conference on June $16^{\text {th }}, 2012$.

Results: The guideline includes 75 recommendations for patients with neurologic diseases. If the existing disease leads to dysphagia, screening and assessment of dysphagia should be performed early. Nutritional intervention has to be adapted according to medical findings. This ranges from texture modification and tube feeding to necessity for parenteral nutrition. Patients with Morbus Parkinson and Chorea Huntington have a higher risk for malnutrition already in early stages of disease. Regular screening, assessment and, if needed, nutritional interventions are recommended to avoid malnutrition. When using L-Dopa-containing medication the interactions with food proteins have to be taken into account. There is no adequate scientific evidence for the application of specific diets or nutritional supplements in Multiple Sclerosis, therefore such interventions cannot be recommended in general. 
ment und bei Bedarf entsprechende ernährungsmedizinische Interventionen empfohlen. Bei der Einnahme von L-Dopa-haltigen Medikamenten ist auf die Interaktion mit eiweißhaltiger Nahrung zu achten. Bei Multipler Sklerose liegt für den Einsatz von „Spezialdiäten“ oder Nahrungssupplementen keine ausreichende wissenschaftliche Evidenz vor, sie werden deshalb generell nicht empfohlen.

Schlussfolgerung: Durch ein frühzeitiges Screening und Assessment auf Dysphagie und auf Mangelernährung kann die Ernährung von Patienten mit neurologischen Erkrankungen optimiert werden. Die Texturmodifikation von Speisen und Getränken, Trinknahrung, Ernährung über nasogastrale Sonden, über PEGSonden, PEJ-Sonden und parenterale Ernährung stellen mögliche ernährungsmedizinische Interventionen dar. Sämtliche Interventionen sollten bei entsprechender Indikation frühzeitig eingeleitet werden.

\section{Einleitung}

$\nabla$

Neurologische Erkrankungen können zu Schluckstörungen führen. Eine orale Nahrungs- und Flüssigkeitsaufnahme bei bestehender Schluckstörung kann zur Aspiration führen. Je nach Ausprägung der Schluckstörung kann durch Texturmodifikationen (z.B. durch Andicken von Getränken oder das Vermeiden krümeliger Konsistenzen) das Risiko für eine Aspiration deutlich gesenkt werden. Fehlende oder verminderte orale Nahrungsaufnahme bei neurologischen Erkrankungen geht mit dem Risiko einer Mangelernährung einher. Bei einigen neurologischen Erkrankungen (z. B. Morbus Parkinson, Chorea Huntington) besteht ein erhöhter Energiebedarf.

Ziel der vorliegenden Leitlinie ist es, für wichtige neurologische Erkrankungen bei denen die Ernährung eine besondere Relevanz hat, konkrete evidenzbasierte Handlungsempfehlungen zu geben. Als besonders relevante Erkrankungen wurden der akute Schlaganfall, der Morbus Parkinson, die Chorea Huntington und die Multiple Sklerose ausgewählt.

\section{Methodik}

$\nabla$

Die vorliegende Arbeit ist eine Weiterentwicklung und Aktualisierung der DGEM-Leitlinie „Enterale Ernährung bei Patienten mit Schlaganfall“ [1]. Neben der enteralen Ernährung bei Patienten mit Schlaganfall werden in der Leitlinie auch Empfehlungen ausgesprochen, die die parenterale Ernährung bei Schlaganfallpatienten betreffen. Des Weiteren wird in der Leitlinie auf die neurologischen Erkrankungen Morbus Parkinson, Chorea Huntington und Multiple Sklerose eingegangen. Es handelt sich hierbei um einen Teil des angemeldeten Leitlinienvorhabens „Klinische Ernährung“ (AWMF-Registernummer 073/019).

Neben den aufgeführten Autoren waren Prof. Jürg Kesselring (Rehabilitationszentrum Valens, Schweiz), PD Dr. med. Elmar W. Busch (Evangelische Kliniken Gelsenkirchen GmbH, Deutschland) und Dr. Ronny Beer (Universität Innsbruck, Österreich) ebenso aktiv in der Arbeitsgruppe „Neurologie“ tätig. Sie waren jedoch selbst nicht direkt an der Texteerstellung beteiligt. Die Methodik ist im Leitlinienreport des Leitlinien-Updates Klinische Ernährung ausführlich beschrieben. Suchstrategie und Evidenztabellen sind im kapitelspezifischen Teil des Leitlinienreports (Anhang 4: Arbeitsgruppe Neurologie) hinterlegt. Der Leitlinienreport ist über die Internetseite der Arbeitsgemeinschaft der Wissenschaft-
Conclusion: Nutrition for patients with neurologic diseases can be optimized by early screening and assessment of dysphagia and malnutrition. The texture modification of food and drinks, oral nutritional supplements, nutrition through a nasogastric tube, PEG tube, PEJ tube and parenteral nutrition are possible nutritional medical interventions. All indicated interventions shoud be introduced early.

lichen Medizinischen Fachgesellschaften e.V. (AWMF) abrufbar (www.awmf.org, AWMF-Registernummer 073/019). Ein Auszug zum methodischen Vorgehen bei dem Leitlinien-Update Klinische Ernährung wurde bereits in der Aktuellen Ernährungsmedizin veröffentlicht [2]. Neben dem Empfehlungsgrad wird auch die Outcome-Bewertung bei den Empfehlungen mitangegeben (Biomedizinische Endpunkte [BM], Patientenzentriertes Outcome $[\mathrm{PC}]$, Gesundheitsökonomische Parameter [HE], Medizinische Entscheidungsfindung [DM], Mehr-Komponenten-Outcome-Modelle [MC]) [3].

Ein Entwurf der Leitlinie ging folgenden Selbsthilfegruppen zur Kommentierung zu: die Deutsche Huntington-Hilfe, die Deutsche Parkinson Vereinigung (dPV), die Deutsche Multiple Sklerose Gesellschaft (DMSG) und die Stiftung Deutsche Schlaganfallhilfe.

\section{Ernährungstherapie bei Patienten mit akutem Schlaganfall $\nabla$}

3.1 Screening und Assessment von Schluckstörungen bei Schlaganfallpatienten

3.1.1 Einleitung

Schlaganfälle im Großhirn, Kleinhirn oder Hirnstamm können den Schluckvorgang in vielfältiger Art beeinträchtigen. So können Hirnläsionen die willkürliche Kontrolle des Kauvorgangs und des Transports des Nahrungsbolus während der oralen Vorbereitungsphase und der oralen Transportphase stören [4]. Kortikale Läsionen, die sich in den Gyrus praecentralis erstrecken, sind mit kontralateralen Störungen der motorischen Kontrolle von Gesicht, Lippen und Zunge verknüpft [5]. Läsionen, die zu Beeinträchtigungen kognitiver Funktionen wie Konzentration und selektiver Aufmerksamkeit führen, können ebenfalls die Kontrolle des Schluckakts beeinträchtigen [6]. Bei Hirnstamminsulten kommt es typischerweise zu den schwersten Schluckstörungen; bei ihnen ist die Sensibilität von Mund, Zunge und Wange sowie die Auslösbarkeit der pharyngealen Schluckphase beeinträchtigt und sie verursachen eine Störung der Larynxelevation, des Glottisschlusses und der Relaxation des M. cricopharyngeus [7].

In der Akutphase des Schlaganfalls leiden 30-50\% der Patienten an einer Schluckstörung, während deren Inzidenz in der chronischen Phase 6 Monate nach Insult auf ca. 10\% sinkt. Betroffene Patienten sind nicht nur anfällig für Dehydratation und Mangelernährung, sondern es besteht auch ein erhöhtes Risiko für die 


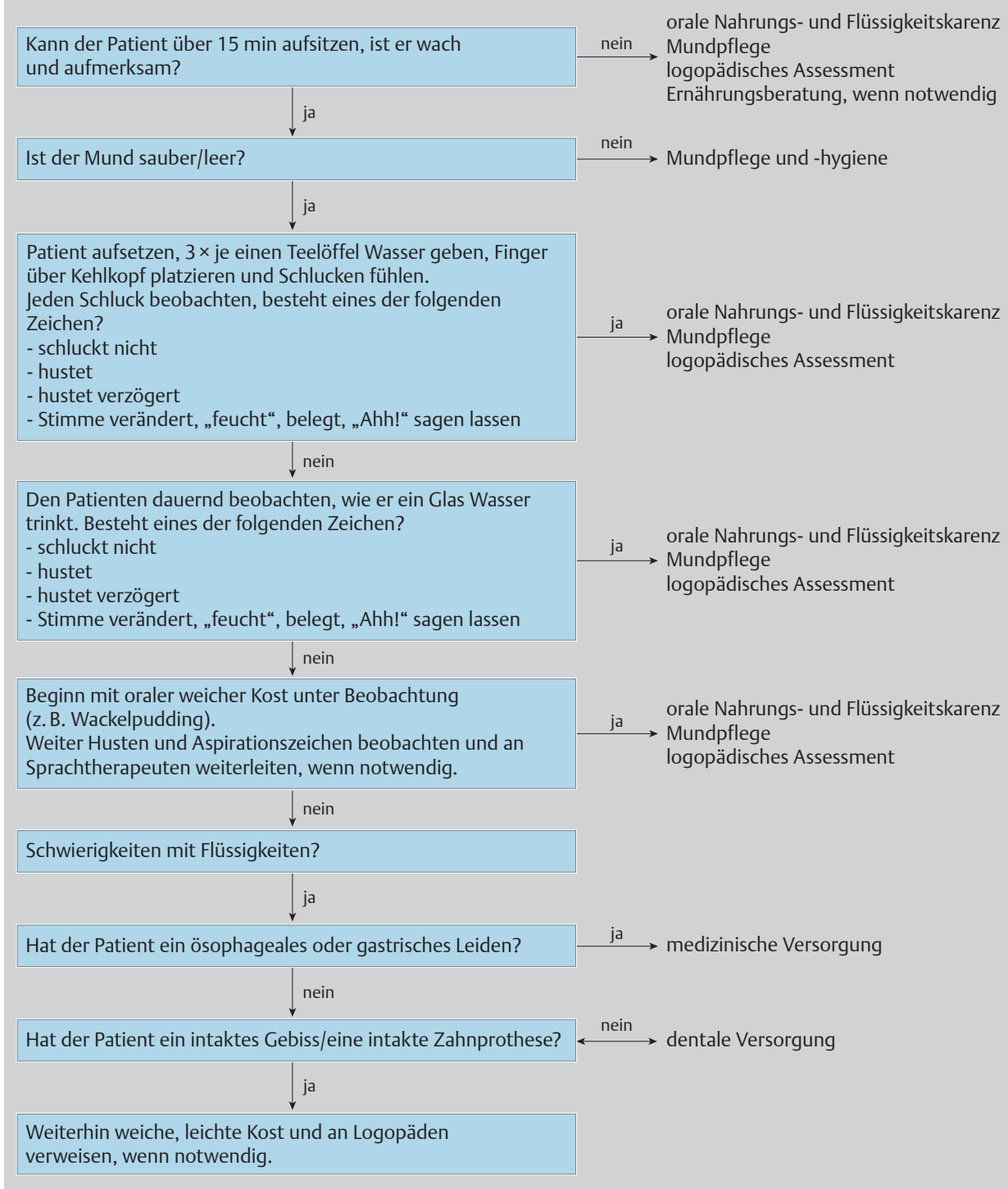

Abb. 1 Wasserschlucktest (WaterSwallowing-Test, WST). Quelle: Department of Speech and Language Therapy, Raigmore Hospital, Inverness.
Entwicklung einer Aspirationspneumonie. Verschiedene Studien haben bei dysphagischen Schlaganfallpatienten ein um das 12fache erhöhtes Risiko für diese Komplikation gezeigt, die in bestimmten Patientengruppen sogar bei bis zu 30\% der Betroffenen auftreten kann [8-12]. Deshalb weisen Patienten mit einem akuten Schlaganfall mit zusätzlicher Schluckstörung eine im Vergleich zu nichtdysphagischen Schlaganfallpatienten signifikant erhöhte Morbidität und Mortalität während der Akutphase auf $[13,14]$.

Aus diesen prognostischen Gründen kommt der frühzeitigen Detektion der schlaganfallbedingten Dysphagie eine erhebliche klinische Bedeutung zu.

3.1.2 Welche Methoden sollten für das Dysphagiescreening angewandt werden? Wie sollte das Aspirationsrisiko bewertet werden?

\section{Empfehlung 1:}

Ein standardisiertes Dysphagiescreening sollte bei allen Schlaganfallpatienten durchgeführt werden.

[B (BM); starker Konsens]
Kommentar: Unter ausschließlicher Berücksichtigung der verfügbaren wissenschaftlichen Studien wäre hier formal der Empfehlungsgrad C angemessen. Unter Berücksichtigung klinischer Expertenerfahrung wurde diese Empfehlung auf Beschluss der Konsensuskonferenz mit Grad B eingestuft.

Die folgenden Methoden wurden für akute Schlaganfallpatienten empfohlen und bewertet:

1. Wasserschlucktest (Water-Swallowing-Test, WST). In der Literatur findet sich eine Vielzahl von vorgeschlagenen Testprotokollen, die sich v.a. hinsichtlich der gewählten Flüssigkeitsmenge unterscheiden [15-21]. Entsprechend den Leitlinien der Scottish Intercollegiate Guideline Network kann ein 50 mLWST für die täglichen Routinetests empfohlen werden. Der Test beginnt mit einer Untersuchung der Mundhöhle und der Zähne. Anschließend werden dem Patienten kleine Wassermengen verabreicht (3-mal 1 Teelöffel). Ist der Patient in der Lage, diese ohne Anzeichen von Aspiration zu schlucken, wird eine größere Menge von etwa $50 \mathrm{~mL}$ verabreicht [22]; (ब Abb.1).

Der Wassertest sollte nicht durchgeführt werden, wenn der Patient nicht aufgesetzt werden und in dieser Position mindestens 15 Minuten wach und kooperationsfähig bleiben kann. Zu jedem Zeitpunkt der Testdurchführung bedingen 
Tab. 1a Multiple-Consistency-Test (Gugging Swallowing Screen). Teil 1: Voruntersuchung/indirekter Schlucktest.

\begin{tabular}{|c|c|c|}
\hline & ja & nein \\
\hline $\begin{array}{l}\text { Vigilanzniveau (Patient ist für mindestens } \\
15 \text { Minuten wach) }\end{array}$ & $1 \square$ & $0 \square$ \\
\hline willkürliches Husten (2-mal kräftiges Husten) & $1 \square$ & $0 \square$ \\
\hline \multicolumn{3}{|l|}{ Schlucken des eigenen Speichels } \\
\hline - erfolgreich & $1 \square$ & $0 \square$ \\
\hline - oraler Speichelverlust & $0 \square$ & $1 \square$ \\
\hline $\begin{array}{l}\text { - Stimmveränderung (belegt, rau, gurgelnd, } \\
\text { schwach) }\end{array}$ & $0 \square$ & $1 \square$ \\
\hline \multirow[t]{2}{*}{ SUMME } & & (5) \\
\hline & $\begin{array}{l}\text { (1- } \\
\text { Unt } \\
5: w\end{array}$ & $\begin{array}{l}\text { rführende } \\
\text { ng* }^{*} \\
\text { it Teil 2) }\end{array}$ \\
\hline
\end{tabular}

Tab. 1b Teil 2: Direkter Schlucktest.

\begin{tabular}{|c|c|c|c|}
\hline \multirow[t]{2}{*}{ Reihenfolge } & $\Rightarrow$ & $\Rightarrow$ & 3 \\
\hline & halbfest & flüssig & fest \\
\hline \multicolumn{4}{|l|}{ Schluckakt } \\
\hline - nicht möglich & $0 \square$ & $0 \square$ & $0 \square$ \\
\hline - verzögert & $1 \square$ & $1 \square$ & $1 \square$ \\
\hline - regelrecht & $2 \square$ & $2 \square$ & $2 \square$ \\
\hline \multicolumn{4}{|c|}{$\begin{array}{l}\text { Husten (vor während oder } \\
\text { bis zu } 3 \text { Minuten nach dem } \\
\text { Schlucken) }\end{array}$} \\
\hline \multirow{2}{*}{$\begin{array}{l}- \text { ja } \\
\text { - nein }\end{array}$} & $0 \square$ & $0 \square$ & $0 \square$ \\
\hline & $1 \square$ & $1 \square$ & $1 \square$ \\
\hline \multicolumn{4}{|c|}{ oraler Bolusverlust } \\
\hline- ja & $0 \square$ & $0 \square$ & $0 \square$ \\
\hline - nein & $1 \square$ & $1 \square$ & $1 \square$ \\
\hline \multicolumn{4}{|c|}{ Stimmveränderung } \\
\hline- ja & $0 \square$ & $0 \square$ & $0 \square$ \\
\hline - nein & $1 \square$ & $1 \square$ & $1 \square$ \\
\hline \multirow[t]{2}{*}{ SUMME I } & $\ldots$ & $\ldots(5)$ & $\ldots(5)$ \\
\hline & $\begin{array}{l}\text { (1-4: wei- } \\
\text { terführende } \\
\text { Untersu- } \\
\text { chung* } \\
\text { 5: weiter mit } \\
\text { Flüssigkeit) }\end{array}$ & $\begin{array}{l}\text { (1-4: wei- } \\
\text { terführende } \\
\text { Untersu- } \\
\text { chung* } \\
\text { 5: weiter mit } \\
\text { fester Kon- } \\
\text { sistenz) }\end{array}$ & $\begin{array}{l}\text { (1-4: wei- } \\
\text { terführende } \\
\text { Untersu- } \\
\text { chung* } \\
\text { 5: Normal- } \\
\text { befund) }\end{array}$ \\
\hline
\end{tabular}

* CBA (Clinical Bedside Assessment) oder apparative Dysphagiediagnostik klinische Aspirationshinweise, wie eine veränderte Stimmqualität und Hustenreiz, einen Testabbruch ( $\bullet$ Abb. 1). Die Testgabe von Flüssigkeit unterbleibt auch dann, wenn der Patient seinen eigenen Speichel nicht schlucken kann.

Das Ergebnis des Wassertests ist wie folgt zu interpretieren: Für den Fall, dass klinische Aspirationszeichen während der Testdurchführung detektiert werden, gilt der Test als positiv. Eine orale Ernährung soll dann wegen der bestehenden Aspirationsgefährdung nicht erfolgen und weitere Diagnostik ist zu initiieren (s.u.). Absolviert der Patient problemlos alle Schritte des WST, gilt dieser als negativ. Auch wenn der Test in diesem Fall anzeigt, dass eine orale Ernährung begonnen werden kann, können aus dem WST methodenbedingt keine Diätempfehlungen abgeleitet werden.

2. Multiple-Consistency-Test. Der als Gugging Swallowing Screen (GUSS) publizierte Mehrkonsistenzentest überwindet das genannte fundamentale Problem des Wassertests, dass sich aus einem unauffälligen Testergebnis keine differenzierte Handlungsanweisung bzgl. des anzustrebenden Kostaufbaus ableiten lässt [23]. Der GUSS ist als schrittweises Verfahren konzipiert, das eine Einstufung der Dysphagie erlaubt und getrennte Beurteilungen für nichtflüssige und flüssige Konsistenzen ermöglicht. Bei der Testdurchführung wird zunächst die Fähigkeit des Patienten überprüft, seinen Speichel zu schlucken. Anschließend werden schrittweise und in der genannten Reihenfolge die Konsistenzen halbfest, flüssig und fest getestet. Auf jeder Stufe des Tests ist die Untersuchung abzubrechen, wenn klinische Aspirationszeichen zu verzeichnen sind oder der Schluckakt verspätet initiiert wird ( $\bullet$ Tab.1a-c).

Auf Grundlage dieses Tests wird die Dysphagie in eine von 4 Kategorien eingeordnet (schwere, mäßige, leichte oder keine Dysphagie). Für jeden Schweregrad wird eine spezielle Diät empfohlen.

3. Schluck-Provokations-Test (Swallowing-Provocation-Test, SPT). Der SPT prüft isoliert die Auslösbarkeit des Schluckreflexes, fokussiert sich somit auf die unwillkürliche Phase des Schluckakts und unterscheidet sich daher grundlegend von den anderen Bedside-Tests. Zur Testdurchführung wird ein dünner Katheter, z. B. eine Säuglingsernährungssonde, transnasal eingeführt und im Oropharynx platziert. Anschließend wird ein Bolus von 0,4 mL destilliertem Wasser oder steriler, physiologischer Kochsalzlösung über den Katheter an die Rachenhinterwand injiziert. Als Ergebnis des SPTs wird die Reflexantwort beurteilt. Diese gilt als physiologisch und somit

\begin{tabular}{|c|c|c|c|}
\hline Ergebnis & & Schweregrad & Empfehlung \\
\hline 20 & $\begin{array}{l}\text { halbfeste, flüssige und } \\
\text { feste Konsistenz erfolg- } \\
\text { reich }\end{array}$ & $\begin{array}{l}\text { keine oder leichte Dys- } \\
\text { phagie mit minimalem } \\
\text { Aspirationsrisiko }\end{array}$ & $\begin{array}{l}\text { - normale Kost } \\
\text { - Flüssigkeit ohne Einschränkung (initial unter } \\
\text { Aufsicht speziell geschulten Personals) }\end{array}$ \\
\hline $15-19$ & $\begin{array}{l}\text { halbfeste und flüssige } \\
\text { Konsistenz erfolgreich, } \\
\text { feste Konsistenz nicht } \\
\text { erfolgreich }\end{array}$ & $\begin{array}{l}\text { leichte Dysphagie mit } \\
\text { niedrigem Aspirations- } \\
\text { risiko }\end{array}$ & $\begin{array}{l}\text { - pürierte oder weiche Kost } \\
\text { - Flüssigkeiten schluckweise } \\
\text { - apparative Dysphagiediagnostik (FEES, VFSS) } \\
\text { - logopädische Mitbeurteilung }\end{array}$ \\
\hline $10-14$ & $\begin{array}{l}\text { halbfeste Konsistenz } \\
\text { erfolgreich, flüssige } \\
\text { Konsistenz nicht erfolg- } \\
\text { reich }\end{array}$ & $\begin{array}{l}\text { mäßige Dysphagie mit } \\
\text { Aspirationsrisiko }\end{array}$ & $\begin{array}{l}\text { - geringe Mengen pürierte Kost } \\
\text { - zusätzlich Ernährung via NGT oder parenteral } \\
\text { - Flüssigkeiten andicken } \\
\text { - Tabletten mörsern } \\
\text { - apparative Dysphagiediagnostik (FEES, VFSS) } \\
\text { - logopädische Mitbeurteilung }\end{array}$ \\
\hline $0-9$ & $\begin{array}{l}\text { Voruntersuchung oder } \\
\text { halbfeste Konsistenz } \\
\text { nicht erfolgreich }\end{array}$ & $\begin{array}{l}\text { schwere Dysphagie mit } \\
\text { hohem Aspirationsrisiko }\end{array}$ & $\begin{array}{l}\text { - keine orale Ernährung } \\
\text { - Ernährung via NGT oder parenteral } \\
\text { - apparative Dysphagiediagnostik (FEES, VFSS) } \\
\text { - logopädische Mitbeurteilung }\end{array}$ \\
\hline
\end{tabular}

Tab.1c Teil 3: Auswertung. 
unauffällig, wenn innerhalb von 3 Sekunden nach Stimulation der Schluckreflex ausgelöst wird. Wird dieser gar nicht oder später als 3 Sekunden getriggert, so gilt er als pathologisch verzögert und der Patient als aspirationsgefährdet.

Die grundsätzliche Bedeutung des Dysphagiescreenings bei Patienten mit akutem Schlaganfall wurde in den letzten Jahren durch verschiedene, methodisch heterogene Studien untermauert. So zeigten Odderson et al., dass die Implementierung eines Dysphagiescreenings in einer Einrichtung im Zeitverlauf zu einem Rückgang der Pneumonierate führte [20]. In mehreren prospektiven Beobachtungsstudien war ein pathologisches Dysphagiescreening mit einer erhöhten Inzidenz an Pneumonien assoziiert [24, 25] bzw. die Durchführung eines Dysphagiescreenings war unabhängig mit einer Reduktion infektiöser Komplikationen verknüpft $[25,26]$. Schließlich wiesen Hinchey et al. in einer prospektiven, multizentrischen Beobachtungsstudie ( $n=$ 2532) nach, dass Einrichtungen, die ein formales Dysphagiescreening etabliert hatten, gegenüber solchen ohne ein derart formalisiertes Diagnostikum, hiervon durch eine signifikant niedrigere Pneumonierate und Mortalität profitierten [27].

Trotz dieser überzeugenden Studienlage wird die Bedeutung des Dysphagiescreenings, besonders die des einfachen Wassertests, durch wiederholte kritische Betrachtungen der Aussagekraft dieses Instruments relativiert. So wiesen Ramsey et al. sowie Bours et al. in ihren Metaanalysen darauf hin, dass die Sensitivität der Wassertests für die Detektion von Aspirationen im Vergleich zur röntgenbasierten VFSS (Videofluoroskopic Swallowing Study) oder der endoskopischen FEES (Fiberoptic Endoscopic Evaluation of Swallowing) in fast allen Studien deutlich unter $80 \%$ lag $[28,29]$. Auch Spezifität, positiver und negativer prädiktiver Wert wiesen überwiegend unzureichende Werte auf [28, 29]. Diese Beobachtung wurde in einer aktuellen Studie bestätigt, die auf einen modifizierten Wassertest zurückgriff, bei dem anstelle des Wassers Röntgenkontrastmittel verwandt wurde, um im Anschluss an den Schlucktest das potenzielle Aspirat direkt in einer Röntgenaufnahme des Thoraxes nachzuweisen. Trotz dieses gegenüber dem einfachen Wassertest optimierten Vorgehens lagen Sensitivität und Spezifität für die Detektion des Aspirationsrisikos im Vergleich zur VFSS nur bei 0,47 und 0,72 [30]. Der nach dem Protokoll des GUSS durchgeführte Mehrkonsistenzentest wurde bisher in einer prospektiven Studie evaluiert [23]. Gegenüber der FEES als objektives Beurteilungsverfahren ergaben sich bei der Verwendung eines Punktwerts von 14 oder weniger als Marker für eine Aspirationsgefährdung ( $\bullet$ Tab. 1a) eine Sensitivität von $100 \%$ und eine Spezifität von $50 \%$. Damit erscheint dieser Test zuverlässiger in dem Erkennen von aspirationsgefährdeten Schlaganfallpatienten zu sein als die verschiedenen Varianten des einfachen Wassertests. Als nachteilig ist die relativ niedrige Spezifität zu beurteilen, aus deren Konsequenz Patienten zurückhaltender oralisiert bzw. häufiger mit einer nasogastralen Sonde versorgt werden dürften als tatsächlich erforderlich. Neben einer Bestätigung dieses Befundes in zukünftigen, unabhängigen Studien bleibt auch der eine Aspirationsgefährdung anzeigende Schwellenwert zu überprüfen.

Im Anschluss an kleinere, retrospektive Studien [31, 32] wurde der SPT in einer prospektiven Studie an Patienten mit akutem Schlaganfall evaluiert [33]. Verglichen mit der FEES als objektives Diagnostikum erreichte der SPT eine Sensitivität von 74,1\% und eine Spezifität von $100 \%$. Falsch negative Befunde ergaben sich v.a. bei Patienten, die eine stark gestörte orale Phase aufwiesen und infolge des resultierenden, ausgeprägten Leakings eine prädeglutitive Penetration oder Aspiration zeigten. Während die mutmaßlich hohe Spezifität dieses Tests den SPT zu einem idealen Kombinationspartner für andere Screeninginstrumente macht, spricht die eingeschränkte Sensitivität eindeutig gegen eine alleinige Verwendung des SPTs zum Dysphagiescreening. In zukünftigen Studien ist daher zu untersuchen, ob die Validität des Dysphagiescreenings durch die Einbindung des SPTs relevant verbessert werden kann.

Die Messung der Sauerstoffsättigung parallel zur Dysphagieevaluation wird von mehreren Autoren als sinnvolle Ergänzung des Screenings vorgeschlagen [34-38]. Allerdings sind inzwischen mehrere Studien publiziert, die die Aussagekraft der Pulsoximetrie zur Aspirationsdetektion erheblich in Zweifel ziehen [30, $39-41]$. So lagen im Vergleich zur VFSS, Sensitivität und Spezifität des Parameters „Sättigungsabfall um $>2 \%$ “ in der aktuellsten Studie zu diesem Thema z.B. bei 33\% und 62\%. Auch eine Kombination des Wassertests mit der Pulsoximetrie brachte mit einer Sensitivität von $60 \%$ und einer Spezifität von $41 \%$ keine ausreichende Verbesserung dieses Ergebnisses. Zusammenfassend kann daher die Verwendung der Pulsoximetrie im Rahmen des Dysphagiescreenings nicht empfohlen werden.

Schließlich wurde darauf hingewiesen, dass eine gestörte Rachensensibilität ein geeigneter Prädiktor für ein Aspirationsrisiko bei Schlaganfallpatienten sein kann [42]. Es gibt jedoch nur eine ältere Studie mit einigen methodischen Einschränkungen, die diesen Ansatz stützt [19]. Deshalb, und in Übereinstimmung mit den Schlussfolgerungen von Bours u. Kollegen [29], wird eine Prüfung der Rachensensibilität als Screeningverfahren für schlaganfallbedingte Dysphagie nicht empfohlen.

\subsubsection{Bei welchen Patienten ist ein Dysphagieassessment indiziert?}

\section{Empfehlung 2:}

Bei allen Patienten mit einem pathologischen Screeningbefund sollte ein weiterführendes Assessment der Schluckfunktion durchgeführt werden.

[B (BM); starker Konsens]

\section{Empfehlung 3:}

Patienten ohne pathologischen Screeningbefund, bei denen aber andere etablierte klinische Prädiktoren für das Vorliegen einer Dysphagie bzw. deren Komplikationen vorhanden sind, wie insbesondere ein insgesamt schweres neurologisches Defizit, eine Dysarthrie, eine Aphasie oder eine ausgeprägte faziale Parese, sollten ebenfalls einem weiterführenden Assessment zugeführt werden. [B (BM); starker Konsens]

Kommentar: Unter ausschließlicher Berücksichtigung der verfügbaren wissenschaftlichen Studien wäre hier formal der Empfehlungsgrad $C$ angemessen. Unter Berücksichtigung klinischer Expertenerfahrung wurden beide Empfehlungen auf Beschluss der Konsensuskonferenz mit Grad B eingestuft.

Aufgrund der unzureichenden Sensitivität der meisten beschriebenen Screeningverfahren oder aufgrund fehlender Replikationsstudien sollten Patienten mit unauffälligem Befund des Dysphagiescreenings ein weiterführendes Assessment durchlaufen, sofern andere klinische Prädiktoren einer Schluckstörung vorhanden sind, wie insbesondere ein schweres neurologisches Defizit, eine ausgeprägte Dysarthrie oder Aphasie oder eine deutliche faziale Parese [24, 43, 44]. 


\begin{tabular}{|c|c|c|}
\hline FEDSS-Protokoll & Hauptbefunde & klinische Konsequenz \\
\hline Speichel & Penetration/Aspiration & $\begin{array}{l}\text { keine Oralisierung, Magensonde, } \\
\text { Schutzintubation erwägen (Score 6) }\end{array}$ \\
\hline$\downarrow$ & & \\
\hline $\begin{array}{c}\text { halbfeste } \\
\text { Konsistenzen }\end{array}$ & $\begin{array}{l}\text { Penetration/Aspiration ohne oder } \\
\text { insuffizienter Schutzreflex }\end{array}$ & $\begin{array}{l}\text { keine Oralisierung, Magensonde } \\
\text { (Score 5) }\end{array}$ \\
\hline \multicolumn{3}{|l|}{$\downarrow$} \\
\hline $\begin{array}{c}\text { halbfeste } \\
\text { Konsistenzen }\end{array}$ & $\begin{array}{l}\text { Penetration/Aspiration mit } \\
\text { suffizientem Schutzreflex }\end{array}$ & $\begin{array}{l}\text { Magensonde, Oralisierung während } \\
\text { logopädischer Therapie (Score 4) }\end{array}$ \\
\hline$\downarrow$ & & \\
\hline Flüssigkeit & $\begin{array}{l}\text { Penetration/Aspiration ohne oder } \\
\text { insuffizienter Schutzreflex }\end{array}$ & $\begin{array}{l}\text { Magensonde, Oralisierung während } \\
\text { logopädischer Therapie (Score 4) }\end{array}$ \\
\hline \multicolumn{3}{|l|}{$\downarrow$} \\
\hline Flüssigkeit & $\begin{array}{l}\text { Penetration/Aspiration mit } \\
\text { suffizientem Schutzreflex }\end{array}$ & $\begin{array}{l}\text { passierte Kost oral, } \\
\text { Flüssigkeit intravenös (Score 3) }\end{array}$ \\
\hline \multicolumn{3}{|l|}{$\downarrow$} \\
\hline $\begin{array}{c}\text { feste } \\
\text { Konsistenzen }\end{array}$ & $\begin{array}{l}\text { Penetration/Aspiration oder hochgradige } \\
\text { Residuen in Valleculae und/oder Sinus piriformes }\end{array}$ & $\begin{array}{l}\text { passierte Kost und } \\
\text { Flüssigkeit oral (Score 2) }\end{array}$ \\
\hline \multicolumn{3}{|l|}{$\downarrow$} \\
\hline $\begin{array}{c}\text { feste } \\
\text { Konsistenzen }\end{array}$ & $\begin{array}{l}\text { keine Penetration/Aspiration und keine hochgradigen } \\
\text { Residuen in Valleculae und/oder Sinus piriformes }\end{array}$ & $\begin{array}{l}\text { weiche Kost und } \\
\text { Flüssigkeit oral (Score 1) }\end{array}$ \\
\hline
\end{tabular}

Abb. 2 Fiberoptic Endoscopic Dysphagia Severity Scale (FEDSS).

\subsubsection{Welche Verfahren sollten für das Dysphagie- assessment angewandt werden?}

\section{Empfehlung 4:}

Clinical Bedside Assessment (CBA): Das CBA kann von speziell ausgebildeten Fachkräften, z. B. von Logopäden, nach einem standardisierten Verfahren (z. B. nach den von Logemann oder Bartolome veröffentlichen Protokollen) durchgeführt werden.

[C (BM); starker Konsens]

\section{Empfehlung 5:}

Apparatives Dysphagieassessment: Aufgrund der Limitationen des CBAs, besonders im Hinblick auf die Detektion stiller Aspirationen und die Möglichkeit, die Effektivität logopädisch-therapeutischer Interventionen zu überprüfen, kann ergänzend die zeitnahe Durchführung einer zuverlässigen und kosteneffektiven Zusatzdiagnostik erwogen werden.

[C (BM); Konsens]

\section{Empfehlung 6:}

Das Dysphagieassessment sollte so früh wie möglich erfolgen. [KKP; starker Konsens]

Kommentar: Das von Logemann veröffentlichte CBA umfasst 28 Punkte und wurde auf seine Interrater- und Intraraterreliabilität untersucht [45]. Alternativ können andere standardisierte Verfahren wie das Bartolome-Protokoll in Betracht gezogen werden [46].

Die videofluoroskopische Schluckuntersuchung (VFSS=VideoFluoroscopic Swallowing Study) galt lange als Goldstandard der apparativen Dysphagiediagnostik. Mithilfe dieses radiologischen Verfahrens ist der gesamte Schluckablauf einschließlich der Öffnung des oberen Ösophagussphinkters und der ösophagealen Phase in höchster Bildqualität darstellbar. Bei der Untersuchung aspirationsgefährdeter Patienten lassen sich durch die Verwendung von nichtionischem Kontrastmittel pulmonale Komplikationen vermeiden [47]. Art und Schweregrad der Dysphagie, die
Wirksamkeit von Konsistenzanpassungen und Haltungsänderungen sowie die Effektivität von Haltungsänderungen und spezifischen Schlucktechniken können mithilfe der VFSS differenziert beschrieben und beurteilt werden [48]. Penetrationen und Aspirationen werden mithilfe der validierten Penetrations-Aspirations-Skala von Rosenbek et al. bewertet [49].

Bei der FEES (Flexible Endoscopic Evaluation of Swallowing) wird zur direkten Visualisierung des Schluckakts ein flexibles NasoPharyngo-Laryngoskop transnasal in den Pharynx eingeführt. Aktuelle Studien legen nahe, dass die FEES auch bei Patienten mit einem akuten Schlaganfall eine sichere, reliable und prädiktive Methode zur Dysphagieevaluation darstellt [50-52]. So kommt es während der FEES bei akuten Schlaganfallpatienten auch innerhalb von 24 Stunden nach Thrombolyse zu keiner klinisch relevanten Verschlechterung kardiorespiratorischer Parameter oder dem Auftreten schwerwiegender Komplikationen wie vasovagaler Reaktionen oder einer interventionsbedürftigen Epistaxis [51].

Vorteile der FEES gegenüber der VFSS im Kontext des akuten Schlaganfalls sind, dass die Untersuchung am Patientenbett erfolgen kann, auch motorisch schwer betroffene, bettlägerige und wenig kooperative Patienten untersuchbar sind, die Möglichkeit zu kurzfristigen und im Bedarfsfalle häufigen Verlaufsuntersuchungen besteht und der Speichel des Patienten visualisierbar ist $[53,54]$. Nachteile der FEES gegenüber der VFSS sind, dass der Schluckakt nicht vollständig erfasst wird und intradeglutitiv die Sicht für einen kurzen Moment durch das sog. „White-Out“ versperrt ist [55]. Trotz dieser methodenimmanenten Schwäche belegen 2 aktuelle Studien, dass die FEES gegenüber der VFSS sensitiver für die Detektion von Residuen, Penetrationen und Aspirationen ist $[56,57]$. 


\subsubsection{Wie oft sollte das Dysphagieassessment wiederholt} werden?

\section{Empfehlung 7:}

Während der ersten Krankheitstage kann das CBA bei dysphagischen Schlaganfallpatienten täglich wiederholt werden. Bleibt die Schluckstörung weiter bestehen, kann ein CBA dann 2-mal wöchentlich sowie vor der Entlassung erfolgen. Weist das CBA auf eine Besserung oder Verschlechterung der Schluckfähigkeit hin, kann eine apparative Zusatzuntersuchung in Erwägung gezogen werden (entweder FEES oder VFSS).

[C (BM); starker Konsens]

\section{Empfehlung 8:}

Bleibt die Schluckstörung nach der Entlassung bestehen, kann das Assessment einmal monatlich über einen Zeitraum von 6 Monaten nach Auftreten des Schlaganfalls durchgeführt werden. [C (BM); starker Konsens]

Kommentar: Besonders in den ersten 1-2 Wochen nach Schlaganfall kommt es bei einer Vielzahl von Patienten, insbesondere bei solchen mit supratentoriellem Schlaganfall, zu einer durchgreifenden Besserung der Dysphagie [11, 15, 17, 58]. Andererseits können z.B. Rezidivinsulte, die sich bei 5-10\% der Patienten innerhalb der 1. Woche ereignen [59], auch zu einer Verschlechterung der Schluckfunktion führen. Aus diesem Grund ist eine regelmäßige klinisch-logopädische Beurteilung der Dysphagie erforderlich. Auch aus therapeutischer Sicht ist eine regelmäßige logopädische Behandlung schon in der Frühphase nach Schlaganfall indiziert. Wie Carnaby et al. in einer prospektiven randomisierten Studie zeigen konnten, ist die Implementierung einer täglichen logopädischen Therapieeinheit mit einer Reduktion infektiöser Komplikationen und rascheren Verbesserung der Schluckfunktion assoziiert [60].

\subsubsection{Wie sollte die Dysphagie im Rahmen des Assessments graduiert werden?}

\section{Empfehlung 9:}

Das Assessment kann über die Feststellung des Vorliegens oder Nichtvorliegens einer schlaganfallbedingten Dysphagie hinaus, zu einer abgestuften Schweregradeinschätzung der Schluckstörung gelangen, aus der sich unmittelbar protektive und rehabilitative Maßnahmen ergeben und insbesondere die Ernährungsform des Patienten festgelegt werden kann.

[C (BM); starker Konsens]

Kommentar: Das primäre Ziel von CBA und/oder der apparativen Dysphagiediagnostik (VFSS oder FEES) in der Akutphase des Schlaganfalls ist es, anhand der erhobenen Befunde den initialen Schweregrad der Dysphagie festzulegen. Eine Graduierung der akuten schlaganfallbedingten Dysphagie ist erforderlich, um unmittelbar protektive und rehabilitative Maßnahmen einleiten zu können sowie einen Ausgangswert für Verlaufsuntersuchungen zur Verfügung zu haben [23, 61, 62].

Darüber hinaus gibt es erste wissenschaftliche Evidenz dafür, dass der initiale Dysphagieschweregrad einen unabhängigen Prädiktor für das funktionelle Outcome (modified Rankin Scale) nach 3 Monaten darstellt [50,63]. Je nach angewandter Untersuchungsmethode stehen zur Graduierung verschiedene Skalen zur Verfügung (z.B. GUSS oder Fiberoptic Endoscopic Dysphagia Se- verity Scale [FEDSS], Abb.2). Aufgrund fehlender Vergleichsstudien, kann derzeit keine Empfehlung gegeben werden, welche der in der Literatur beschriebenen, semiquantitativen Dysphagieskalen am besten zur Schweregradeinteilung der akuten schlaganfallbedingten Dysphagie geeignet sind.

\subsection{Kann Sondenernährung die Prognose bei Schlaganfallpatienten verbessern?}

\subsubsection{Bei welchen Schlaganfallpatienten kann}

Sondenernährung die Prognose verbessern?

In der akuten Schlaganfallphase benötigen 8,5-29\% der Schlaganfallpatienten eine Sondenernährung [64]. Dabei stellt sich die Frage, welche Schlaganfallpatienten von Sondenernährung besonders profitieren können. Es könnte sich hierbei um Patienten handeln, die bereits zum Zeitpunkt des Schlaganfalls mangelernährt sind oder um Patienten, bei denen es voraussichtlich zu Mangelernährung kommt. Schlaganfallpatienten mit einer Bewusstseinstrübung, Dysphagie und schweren Lähmungen sind in ihrer Nahrungsaufnahme erheblich eingeschränkt und haben deshalb ein hohes Risiko für Mangelernährung.

Der 2. Teil der FOOD-Studie zeigte bei 859 dysphagischen Schlaganfallpatienten einen Trend zu einer 5,5\% geringeren Mortalität bei früher Sondenernährung mit einem Beginn innerhalb von 7 Tagen gegenüber einem späteren Beginn. Der Unterschied war jedoch statistisch nicht signifikant $(p=0,09)[65,66]$. Die Aussagekraft der Studie wird dadurch eingeschränkt, dass Patienten nur dann in die Studie eingeschlossen wurden, wenn der behandelnde Arzt sich der angemessenen Ernährungstherapie für den Patienten nicht sicher war. Somit wurden keine Patienten mit klarer Indikation für eine frühe Sondenernährung berücksichtigt. Es gibt keine Angaben dazu, wie viele Patienten nicht berücksichtigt wurden und welches die Gründe dafür waren. Trotzdem dokumentiert die FOOD-Studie einen Vorteil für Patienten mit früher Sondenernährung. Das weist deutlich auf den potenziellen Nutzen eines frühen Beginns der Sondenernährung hin sowie auf einen Nutzen der Sondenernährung bei dysphagischen Schlaganfallpatienten an sich. Es bleibt jedoch unklar, bei welchen Schlaganfallpatienten genau Sondenernährung die Prognose verbessern kann.

\subsubsection{Profitieren bewusstseinsgetrübte Patienten} und beatmete Schlaganfallpatienten von einer Sondenernährung?

\section{Empfehlung 10:}

Patienten mit einer Bewusstseinstrübung und beatmete Patienten benötigen meist über einen längeren Zeitraum eine künstliche Ernährung und können deshalb frühzeitig mit Sondenernährung versorgt werden.

[C (BM); starker Konsens]

Kommentar: Zu diesem Thema gibt es keine systematischen Untersuchungen. Da Patienten mit einer relevanten Bewusstseinsstörung regelhaft künstlich ernährt werden müssen, stellt sich nur die Frage, ob eine parenterale oder eine enterale Ernährung vorzuziehen ist und welches das geeignete Vorgehen ist.

Es existieren keine systematischen Untersuchungen zum Vergleich von parenteraler und enteraler Ernährung bei Schlaganfallpatienten. Aufgrund der vorliegenden Daten zu anderen schwer kranken Patientengruppen kann jedoch von einem Vorteil der Sondenernährung bei Schlaganfallpatienten ausgegangen werden [67]. Nach der ESPEN-Leitlinie für enterale Ernährung in 
der Geriatrie finden sich weniger infektiöse Komplikationen und ergeben sich geringere Kosten [68]. Eine Auswirkung auf die Sterblichkeit wurde bislang nicht nachgewiesen [69].

\subsubsection{Profitieren Patienten mit voraussichtlich länger anhaltenden Schluckstörungen von einer enteralen Ernährung über eine Ernährungssonde?}

\section{Empfehlung 11:}

Patienten mit einer voraussichtlich länger als 7 Tage anhaltenden schweren Dysphagie sollten Sondenernährung erhalten. [KKP; starker Konsens]

Kommentar: Je nach Diagnoseverfahren leiden 23-78\% aller Schlaganfallpatienten an einer relevanten Dysphagie [14, 70]. Dies führt häufig innerhalb der ersten Tage nach Schlaganfall zu Aspirationen. Nach einer Studie von Daniels et al. kommt es bei den meisten Patienten zu einer stillen Aspiration [71]. Die Schwere des Schlaganfalls, eine Aphasie sowie Dysphasie und Läsionen des frontalen Kortex und der Inselregion sowie Hirnstammläsionen sind Prädiktoren für eine anhaltende Dysphagie (>14 Tage) [14, 72]. Klinische Erfahrung, diagnostische Beurteilung und die genannten Faktoren ermöglichen die Identifikation derjenigen Patienten, die voraussichtlich über einen längeren Zeitraum eine Sondenernährung benötigen.

Patienten mit Schluckstörungen sind einem hohen Risiko für Aspirationen und Aspirationspneumonien ausgesetzt und die Gefahr, eine Mangelernährung zu entwickeln ist hoch. Aspirationspneumonien können allerdings während der Akutphase nach Schlaganfall durch Sondenernährung nicht verhindert werden [43, 73, 74]. Die Rate der Aspirationspneumonien steigt bei enteraler Ernährung jedoch auch nicht an [65]. Für die Langzeittherapie nach Schlaganfall zeigte eine prospektive Beobachtungsstudie über ein Jahr, dass Patienten mit gestörtem Husten- oder Schluckreflex, die oral ernährt wurden $(n=48)$, eine signifikant höhere Rate an Pneumonien aufwiesen als Patienten, die über eine nasogastrale Sonde ernährt wurden (54,3 vs. $13,2 \%$; $n=52$ ) [75]. Nur in einer Untergruppe bettlägeriger Patienten mit nasogastraler Sondenernährung war die Pneumonierate vergleichbar hoch (64\%). Das Aspirationsrisiko an sich stellt keine eindeutige Indikation für Sondenernährung dar. Nur für die Langzeittherapie von Patienten mit gutem Funktionsstatus scheint die Sondenernährung das Risiko einer Aspirationspneumonie zu senken. Neben dem Risiko für Aspirationen und Aspirationspneumonien sind Patienten mit persistierender Dysphagie auch von Mangelernährung bedroht. Da Mangelernährung die Prognose verschlechtert und zu einer höheren Komplikationsrate führt, muss sie vermieden werden [76, 77]. Aus diesem Grund sollten Patienten mit dem Risiko einer anhaltenden Dysphagie über eine Sonde ernährt werden.

\subsection{Wann sollte bei Schlaganfallpatienten mit Schluck- störungen mit der Ernährungstherapie begonnen werden?}

\section{Empfehlung 12:}

Schwere Schluckstörungen, bei denen keine ausreichende orale Nahrungsaufnahme möglich ist und die voraussichtlich länger als eine Woche anhalten, können eine frühzeitige enterale Sondenernährung erfordern (innerhalb von 72 Stunden).

[C (BM; HE); starker Konsens]
Kommentar: Aus praktischer Sicht ist es bei den meisten Patienten nicht möglich, mit der Sondenernährung bereits am 1. Behandlungstag zu beginnen, v.a. in ungewissen Situationen mit möglichen Komplikationen wie Hirnblutungen oder notwendiger Beatmung. Auf der anderen Seite hat ein frühzeitiger Beginn der enteralen Ernährung bei akuten Erkrankungen eine Reihe von Vorteilen: die Barrierefunktion der Darmmukosa bleibt intakt und der Übertritt von Darmbakterien in den Blutkreislauf wird somit verringert. Bei operierten Intensivpatienten traten bei enteraler Ernährung im Vergleich mit parenteraler Ernährung weniger Sepsisepisoden auf [78, 79]. Insgesamt wurden bei kritisch kranken Patienten bei Sondenernährung weniger Komplikationen durch Infekte beobachtet als bei parenteraler Ernährung [80]. Jedoch könnte enterale Ernährung bei kritisch kranken Patienten das Risiko für eine Aspirationspneumonie in der Akutphase erhöhen [81].

In den ESPEN-Leitlinien zur enteralen Ernährung in der Intensivmedizin wird frühzeitige enterale Ernährung (innerhalb <24 Stunden) bei kritisch kranken Patienten empfohlen, die voraussichtlich nicht innerhalb von 3 Tagen vollständig oral ernährt werden können [67]. Für diese Empfehlung wurde Empfehlungsgrad $\mathrm{C}$ vergeben, da keine der Studien den Kriterien einer randomisierten kontrollierten Prüfung entsprach und die Anzahl der untersuchten Patienten in den einzelnen Studien zu klein war. Die Studien, auf die sich diese Empfehlungen stützen, umfassten hauptsächlich operierte Intensivpatienten und nur sehr wenige Schlaganfallpatienten.

In einem gemischten Patientenkollektiv (38\% Schlaganfallpatienten) war die Mortalität geringer und die Verweildauer kürzer, wenn die enterale Ernährung innerhalb von 5 Tagen begonnen wurde. Eine signifikante Verminderung der Mortalität zeigte sich jedoch nur in der Altersgruppe der Schlaganfallpatienten von über 65 Jahren. Bei jüngeren Patienten war der günstige Effekt einer frühzeitigen Ernährung ( $<5$ Tage nach Schlaganfall) weniger ausgeprägt [82]. Ältere Patienten stellen eine Risikogruppe für Mangelernährung dar. Daher sollte bei ihnen besonders auf einen frühzeitigen Beginn der enteralen Ernährung geachtet werden.

In einer retrospektiven Analyse der Daten von Schlaganfallpatienten untersuchten Nyswonger und Helmchen, welchen Einfluss eine innerhalb von 72 Stunden nach Aufnahme begonnene enterale Ernährung im Vergleich zu einem späteren Beginn ( $>72$ Stunden nach Aufnahme) hatte [83]. Patienten mit einer frühen enteralen Ernährung hatten eine signifikant kürzere Krankenhausverweildauer als Patienten, bei denen die enterale Ernährung erst später begonnen wurde (durchschnittliche Hospitalisierung 20,1 vs. 29,8 Tage). In einer Studie von Dávalos konnte eine frühzeitige enterale Ernährung die Verschlechterung des Ernährungszustands innerhalb der ersten Wochen nach Aufnahme ins Krankenhaus nicht verhindern [84]. Eine Cochrane-Analyse aus dem Jahre 1999 konnte keine randomisierte kontrollierte Studie zum besten Zeitpunkt für den Beginn einer enteralen Ernährung ermitteln [85]. Die Studie von Nyswonger und Helmchen wurde nicht berücksichtigt, da sie nicht randomisiert war. Die einzige randomisierte kontrollierte Studie zum Beginn der Ernährung von Schlaganfallpatienten ist die „Early versus Avoid"-Untersuchung innerhalb der FOOD-Studie, die 2005 veröffentlicht wurde $[65,66]$. Es handelt sich um die Studie mit der für diese Fragestellung größten Fallzahl (859 Patienten). Nach der Randomisierung wurde mit der Sondenernährung entweder so bald wie möglich begonnen, oder das Legen einer Sonde wurde um mindestens 7 Tage zurückgestellt. Während dieses Zeitraums 
wurde intravenös oder subkutan Flüssigkeit verabreicht. Ob die enterale Ernährung über PEG-Sonde oder nasogastrale Sonde erfolgen sollte, entschied der behandelnde Arzt. Bei 429 Patienten wurde eine nasogastrale Sonde gewählt und in nur 10 Fällen eine PEG-Sonde. Die Patientengruppe, deren enterale Ernährung innerhalb von 7 Tagen nach Aufnahme begann, verzeichnete eine Verminderung der Mortalität um 5,8\%, was allerdings statistisch nicht signifikant war $(\mathrm{p}=0,09)$. Der Anteil der mit schlechtem Ergebnis überlebenden Patienten war größer in der Gruppe mit frühzeitigem Ernährungsbeginn (definiert als 4 oder 5 auf der Rankin-Skala). Möglicherweise handelt es sich bei Patienten mit „schlechtem Outcome“ um Patienten, die bei einem verzögerten Beginn der Ernährung verstorben wären. Dies bleibt allerdings Spekulation. Pneumonien traten in der Patientengruppe, die früh enteral ernährt wurde, nicht häufiger auf. Gastrale Blutungen waren bei frühzeitigem Beginn häufiger als bei verzögertem Beginn der Sondenernährung. In die Studie wurden nur Patienten aufgenommen, bei denen sich der behandelnde Arzt bezüglich des Ernährungsbeginns nicht sicher war. Der Ernährungszustand wurde nicht durch ein standardisiertes Screening erfasst, sondern nur informell durch den behandelnden Arzt. Neben einigen anderen Mängeln der Studie wurde die verabreichte Menge an Sondennahrung nicht dokumentiert.

Es wird empfohlen, bei den Patienten, deren Schluckbeschwerden voraussichtlich mehr als 7 Tage anhalten werden und die daher keine ausreichende orale Nahrungsaufnahme erreichen werden, frühzeitig mit enteraler Ernährung zu beginnen. Da die einzige randomisierte Studie (FOOD-Studie) methodische Schwächen hat, bekommt diese Empfehlung den Grad C.

\subsection{Wie sollte Sondennahrung verabreicht werden?}

3.4.1 Wann ist eine PEG-Sonde und wann eine nasogastrale Sonde indiziert?

\section{Empfehlung 13:}

Falls eine ausreichende orale Nahrungsaufnahme in der Akutphase des Schlaganfalls nicht möglich ist, soll die Sondenkost vorzugsweise über eine nasogastrale Sonde verabreicht werden. [A (BM); starker Konsens]

\section{Empfehlung 14:}

Ist enterale Ernährung voraussichtlich über einen längeren Zeitraum erforderlich (>28 Tage), soll eine PEG-Sonde in einer klinisch stabilen Phase gelegt werden (nach 14-28 Tagen).

[A (BM); starker Konsens]

\section{Empfehlung 15:}

Beatmete Schlaganfallpatienten sollten frühzeitig eine PEG-Sonde erhalten.

[B (BM); starker Konsens]

\section{Empfehlung 16:}

Wird eine nasogastrale Sonde vom Patienten abgelehnt oder nicht toleriert und ist die künstliche Ernährung voraussichtlich länger als 14 Tage erforderlich, sollte frühzeitig eine PEG-Sonde in Betracht gezogen werden.

[ $B^{*}(B M)$; starker Konsens]

Alternativ sollte in dieser Situation die Anwendung eines nasalen Sondenhalters in Erwägung gezogen werden.

[B (BM); starker Konsens]
Kommentar: *Unter ausschließlicher Berücksichtigung der verfügbaren wissenschaftlichen Studien wäre hier formal der Empfehlungsgrad C angemessen. Unter Berücksichtigung zusätzlicher klinischer Expertenerfahrung wurde diese Empfehlung auf Beschluss der Konsensuskonferenz mit Grad B eingestuft.

Dysphagien aufgrund eines ischämischen Insults bilden sich in 73 - 86\% der Fälle innerhalb von 7 - 14 Tagen zurück $[15,58,86]$. Es ist daher lohnenswert, zunächst eine enterale Ernährung in Betracht zu ziehen, die weniger invasiv ist als die perkutane endoskopische Gastrostomie (PEG). Bisher existieren nur 2 prospektive randomisierte kontrollierte Interventionsstudien, die die Ernährung über eine nasogastrale Sonde mit der Ernährung über eine PEG-Sonde nach Schlaganfall vergleichen.

In einer Studie von Norton et al. mit 30 Schlaganfallpatienten wiesen die 16 Patienten der PEG-Gruppe 6 Wochen nach Intervention einen besseren Ernährungszustand, eine geringere Mortalität und eine kürzere Krankenhausverweildauer auf [87]. Es ist jedoch zu beachten, dass es sich bei der Studienpopulation um schwer beeinträchtigte ältere Schlaganfallpatienten mit einem Durchschnittsalter von 79 Jahren handelte. Alle Patienten waren bei Krankenhausaufnahme bewusstlos, hatten eine Hemiplegie und der durchschnittliche Barthel-Index lag bei unter 3 Punkten (auf einer Skala von 0-20 Punkten).

In der FOOD-Studie fanden sich im Hinblick auf den Endpunkt „Tod nach 6 Monaten“ bei 321 dysphagischen Schlaganfallpatienten keine Unterschiede zwischen Ernährung per PEG- und nasogastraler Sonde $[65,66]$. In diese Studie waren vorwiegend ältere Patienten eingeschlossen (Durchschnittsalter 76 Jahre). Bei Aufnahme konnten $16 \%$ der Patienten beide Arme heben, 3\% konnten ohne Hilfe laufen und 25\% erreichten auf der Glasgow-KomaSkala normale Werte, sodass es sich um mittelschwer bis schwer beeinträchtigte Patienten handelte. Nach 6 Monaten wiesen Patienten mit nasogastraler Sonde gegenüber Patienten mit früher PEG-Ernährung ein signifikant (7,8\%) geringeres Risiko hinsichtlich der kombinierten Endpunkte „Tod und/oder schlechter Funktionsstatus“ auf. Einschränkender Faktor für die Studie war, dass ausschließlich Patienten eingeschlossen wurden, bei denen sich der behandelnde Arzt bezüglich der besten Ernährungstherapie unsicher war. Leider gibt die Studie keine Auskunft darüber, wie viele Patienten pro Zentrum nicht in die Studie eingeschlossen wurden und aus welchen Gründen dies nicht geschah. Des Weiteren wurde die Sonde bei in die PEG-Gruppe randomisierten Patienten deutlich später gelegt als dies bei Patienten mit nasogastraler Sonde der Fall war. 80\% der Patienten mit nasogastraler Sonde erhielten die Sonde am 1. Tag nach der Randomisierung. In der PEG-Gruppe wurden nur 70\% der Sonden innerhalb von 4 Tagen gelegt, $80 \%$ wurden innerhalb von 14 Tagen nach Schlaganfall gelegt. Die meisten Patienten in dieser Studie wurden aus Kliniken in Großbritannien rekrutiert, wo die Wartezeit für eine Sondenplatzierung mehrere Tage betrug. Die Tatsache, dass die Intervention nicht direkt nach der Randomisierung möglich war, schränkt die Vergleichbarkeit der beiden Studiengruppen ein.

Die Auswirkungen einer verzögerten Ernährungstherapie sind aus anderen Studien bekannt, u.a. auch aus dem „Early versus Avoid“-Teil der FOOD-Studie. Die Autoren der FOOD-Studie beschreiben eine Häufung von Dekubitalgeschwüren in der PEGGruppe. Zwei mögliche Begründungen für den Unterschied werden angegeben: Einerseits könnten die Patienten mit PEG-Sonde weniger mobil gewesen sein aufgrund der im Bauchbereich liegenden Sonde und deshalb eine höhere Dekubitus-Rate aufweisen; andererseits ist es denkbar, dass Patienten mit einer PEG- 
Sonde anders gepflegt wurden (z. B. weniger intensiv) als solche mit einer nasogastralen Sonde. Im letzteren Fall wäre das schlechtere funktionelle Ergebnis in der PEG-Gruppe nicht durch den enteralen Zugang und die Ernährung verursacht worden, sondern durch die unterschiedliche Behandlung und Pflege der Patienten. Aufgrund der Einschlusskriterien müssen die Ergebnisse der FOOD-Studie kritisch betrachtet werden. Sie können nicht uneingeschränkt auf die Gesamtgruppe der dysphagischen Schlaganfallpatienten übertragen werden.

In einer weiteren prospektiven randomisierten Studie von Park et al. mit einer Gruppe von 40 Patienten mit persistierender neurologischer Dysphagie, die 10 Schlaganfallpatienten einschloss, zeigte sich ein besserer Ernährungszustand in der PEG-Gruppe als in der nasogastral ernährten Gruppe [88]. An Tag 28 erfüllten 18 von 19 Patienten der nasogastral ernährten Gruppe die Kriterien für einen „Behandlungsmisserfolg“, aufgrund dessen auf eine Ernährung über eine PEG-Sonde umgestellt wurde. Das Endresultat konnte aufgrund der geringen Anzahl von verbleibenden Patienten der Gruppe mit nasogastraler Sonde nicht beurteilt werden. Dies zeigt die häufigen praktischen Probleme mit nasogastralen Sonden, die oft von den Patienten nicht toleriert werden. Insgesamt ist die Dislokation von nasogastralen Sonden und die daraus resultierende unzureichende enterale Ernährung ein erhebliches Problem. Zwei Studien über Nasensondenhaltesysteme (nasal loop/bridle) an Schlaganfallpatienten zeigten, dass Nasensondenhaltesysteme sicher sind, gut toleriert werden und zu einer effizienteren enteralen Ernährung führen [89, 90]. In der Gruppe mit Nasensonden-Haltesystem einer neueren randomisierten kontrollierten Studie wurde ein Anstieg des durchschnittlich verabreichten Flüssigkeits- und Sondenkostvolumens um $17 \%$ beobachtet, ohne dass Unterschiede im Outcome nach 3 Monaten festgestellt wurden [90].

Eine 2005 von Kostadima et al. veröffentlichte randomisierte Studie zeigte, dass eine frühzeitige Ernährung (innerhalb von 24 Stunden) über PEG bei 41 beatmeten Patienten mit Schlaganfall oder Kopfverletzungen, der Ernährung mit nasogastraler Sonde wegen der geringeren Inzidenz beatmungsassoziierter Pneumonien überlegen war [91]. Es fand sich jedoch kein signifikanter Unterschied bezüglich Verweildauer und Mortalität. Diese Studie erlaubt Rückschlüsse auf die Behandlung beatmeter Schlaganfallpatienten, da Schlaganfallpatienten mit $61 \%$ vertreten waren. Besonders bei beatmeten Schlaganfallpatienten, bei denen eine längerfristige künstliche Ernährung (>14 Tage) wahrscheinlich ist, sollte eine frühzeitige Ernährung über PEG einer nasogastralen Sondenernährung wegen der geringeren Rate an Beatmungspneumonien $[69,91]$ vorgezogen werden.

Bei Schlaganfallpatienten mit ungünstiger Prognose sollten ethische Erwägungen eine wichtige Rolle spielen. Im Zweifelsfall kann eine semiinvasive Ernährung mit nasogastraler Sonde als potenziell reversibler 1 . Schritt angeraten sein. Die Indikation für eine künstliche Ernährung sollte täglich neu überdacht werden und besonders vor einer Überweisung in eine Pflegeeinrichtung oder auf eine Palliativstation erneut beurteilt werden. Sondenernährung kann eingestellt werden, wenn es keine Indikation mehr dafür gibt, was in einer palliativen Situation sehr wahrscheinlich ist. Bei Patienten mit einer unsicheren Prognose sollte die Anlage einer PEG-Sonde kein Kriterium für die Aufnahme in die Rehabilitation oder eine Pflegeeinrichtung sein, besonders wenn eine nasogastrale Sonde gut toleriert wird. Hierfür kann auch die aktuelle DGEM-Leitlinie „Ethische und rechtliche Gesichtspunkte der Klinischen Ernährung“ zurate gezogen werden [92].
Wegen der Gefahr von inneren Drucknekrosen sollten bei Schlaganfallpatienten nasogastrale Ernährungssonden kleinen Durchmessers $(8-12 \mathrm{Ch})$ verwendet werden. Sonden mit größerem Durchmesser sollten nur gelegt werden, wenn eine Magendekompression erforderlich ist. Das Legen nasogastraler Sonden sollte durch ausgebildetes und in dieser Technik erfahrenes medizinisches Personal erfolgen. Wegen der Gefahr einer falschen Platzierung sollte die korrekte Position vor Gabe der Sondennahrung kontrolliert werden. Dies kann entweder durch Röntgenkontrolle oder durch Aspiration von Mageninhalt mit Überprüfung des gastrischen pH-Werts kontrolliert werden [93]. In jedem Krankenhaus sollte eine Richtlinie für die Kontrolle der korrekten Sondenlage erarbeitet und umgesetzt werden.

\subsection{Verringert eine duodenale oder jejunale Sondenlage das Aspirationsrisiko bei Schlaganfallpatienten?}

\section{Empfehlung 17:}

Ernährungssonden sollten vorzugsweise gastral platziert werden. [B (BM); starker Konsens]

Kommentar: Zu diesem Thema gibt es keine Untersuchungen bei Schlaganfallpatienten. In vorliegenden Studien mit anderen Patienten fanden sich keine signifikanten Vorteile einer postpylorischen gegenüber einer präpylorischen Sondenlage [94-97].

\subsection{Sollte die Sondennahrung kontinuierlich oder als Bolus verabreicht werden?}

\section{Empfehlung 18:}

Bei gastroösophagealem Reflux in der Vorgeschichte oder wenn Anzeichen für einen gastroösophagealen Reflux mit Aspiration oder hohem Aspirationsrisiko bestehen, sollte die Ernährung kontinuierlich erfolgen.

[B* (BM); starker Konsens]

\section{Empfehlung 19:}

Bei einer duodenalen oder jejunalen Sondenlage soll eine Dauerapplikation erfolgen.

[KKP; starker Konsens]

Kommentar: *Unter ausschließlicher Berücksichtigung der verfügbaren wissenschaftlichen Studien wäre hier formal der Empfehlungsgrad C angemessen. Unter Berücksichtigung klinischer Expertenerfahrung wurde diese Empfehlung auf Beschluss der Konsensuskonferenz mit Grad B eingestuft.

Ob eine kontinuierliche Sondenernährung zu niedrigeren Komplikationsraten oder besseren Behandlungsergebnissen führt, ist bei Schlaganfallpatienten nicht untersucht worden. Es wurden einige kleinere Studien an kritisch kranken Patienten und an Traumapatienten durchgeführt, die keine abschließende Beurteilung zulassen. Insbesondere die Häufigkeit von Aspirationen und Aspirationspneumonien bei verschiedenen Ernährungstherapien wurde noch nicht ausreichend untersucht. Aufgrund umfassender klinischer Erfahrungen gelten oben angeführte Empfehlungen als „gute klinische Praxis“.

Nur eine retrospektive Studie an 152 Patienten mit traumatischer Hirnschädigung aus dem Jahre 2002 könnte sich in Teilaspekten auf die Situation von Schlaganfallpatienten übertragen lassen [98]. Es fand sich ein signifikanter Vorteil der Dauerernährung in Bezug auf die Nahrungstoleranz (gemessen als Residualvolumen 
$>75 \mathrm{~mL}$ und Blähungen) (37,9 vs. 60,5\%) und die Gesamtzahl der infektiösen Komplikationen (71,2 vs. 82,6\%). Die Zahl der beatmungsassoziierten und nicht beatmungsassoziierten Pneumonien unterschied sich nicht signifikant. Es gab keine Unterschiede bei Funktionsstatus und Ernährungszustand.

In einer Studie mit 28 kritisch kranken Patienten fanden Serpa et al. keine signifikanten Unterschiede zwischen den Komplikationsraten beider Ernährungsregime [99]. In einer Studie mit 105 sondenernährten geriatrischen Patienten mit Diarrhö konnten Lee et al. zeigen, dass die Häufigkeit der Diarrhöen und das gastrale Residualvolumen sich bei Dauerernährung gegenüber intermittierender Bolusgabe nicht unterschieden [100]. Eine Studie mit Manometrie des unteren Ösophagussphinkters (UÖS) zeigte jedoch eine signifikante Drucksenkung des UÖS bei schneller Infusion von $250 \mathrm{~mL}$ Sondennahrung und $100 \mathrm{~mL}$ Flüssigkeit, was den Reflux im Vergleich zur Dauerapplikation begünstigte [101].

Bestehen keine Risikofaktoren für eine Aspiration (s.o.), gilt die intermittierende Bolusapplikation (6-mal täglich) über jeweils eine Stunde als ebenso sicher.

Besonders bei Patienten mit hohem Risiko für eine Sondendislokation, z.B. psychomotorisch unruhige Patienten, die über eine nasogastrale Sonde ernährt werden, sollte eine Bolusapplikation in 6 Portionen mit einer Applikationsspritze verabreicht werden. So können Sondendislokationen und daraus entstehende Komplikationen frühzeitig erkannt werden.

\subsection{Sollte die Sondennahrung mit einer Pumpe oder mittels Schwerkraft verabreicht werden?}

\section{Empfehlung 20:}

Bei Schlaganfallpatienten sollte Sondennahrung vorzugsweise mit einer Pumpe verabreicht werden.

[KKP; starker Konsens]

Kommentar: $\mathrm{Zu}$ diesem Thema liegen keine Daten für Patienten allgemein oder Schlaganfallpatienten vor. Da dysphagische Schlaganfallpatienten einem deutlichen Aspirationsrisiko ausgesetzt sind, ist eine potenziell unkontrollierte Gabe von Sondennahrung mittels Schwerkraft zu vermeiden. Diese kann zu Magenüberfüllung, Regurgitation und Aspiration führen.

\subsection{Beeinträchtigt die nasogastrale Sondenernährung das Schlucktraining und die Rehabilitation?}

\section{Empfehlung 21:}

Sondenernährung beeinträchtigt das Schlucktraining nicht. Somit soll mit dem Schlucktraining auch bei sondenernährten Patienten so früh wie möglich begonnen werden.

[A* (BM); starker Konsens]

\section{Empfehlung 22:}

Bei Symptomen einer ungeklärten Verschlechterung der Dysphagie sollte die Sondenlage endoskopisch überprüft werden.

[B (BM); Konsens]

Kommentar: *Unter ausschließlicher Berücksichtigung der verfügbaren wissenschaftlichen Studien wäre hier formal der Empfehlungsgrad B angemessen. Unter zusätzlicher Berücksichtigung klinischer Expertenerfahrung wurde diese Empfehlung auf Be- schluss der Konsensuskonferenz mit Grad A eingestuft. Sie gilt als „gute klinische Praxis“.

Bei den meisten Patienten verschlimmert nasogastrale Sondenernährung die Schluckstörung nicht und ist somit kein grundsätzliches Hindernis für die Dysphagierehabilitation.

In einer Patientengruppe mit verschiedenen Erkrankungen wurden bei 17,4\% der Patienten mit nasogastraler Sondenernährung Schluckstörungen beobachtet, während diese in der PEG-Gruppe in keinem Fall beobachtet wurden [102]. Zusätzlich zu einer weiteren Studie, die die Veränderungen im Schluckakt bei gesunden Freiwilligen untersuchte [103], führten diese Ergebnisse teilweise zur Annahme, dass eine Dysphagiebehandlung bei nasogastraler Sonde in situ nicht möglich wäre. Drei neuere Studien (2 davon mit Schlaganfallpatienten) bestätigten diese Annahme nicht und ließen keine negativen Auswirkungen der nasogastralen Sondenernährung auf die Schluckfunktion erkennen [52, 104, 105]. Die Dysphagietherapie sollte somit, sowohl bei sondenernährten als auch bei nicht-sondenernährten Patienten, so früh wie möglich beginnen. Dziewas et al. zeigten für die meisten Fälle mit nasogastraler Sonde, in denen eine Verschlechterung der Dysphagie vorlag, dass dies auf eine Dislokation mit Aufrollen der Sonde im Pharynx zurückzuführen war [52]. Eine erneute Positionierung der Sonde oder besser noch eine endoskopische Untersuchung der Sondenlage im Pharynx ist in dieser Situation deshalb ratsam.

\subsection{Sollten sondenernährte dysphagische Schlaganfall- patienten zusätzliche orale Nahrung erhalten?}

\section{Empfehlung 23:}

Abhängig von Art und Schwere der Dysphagie sollte die Mehrheit wacher dysphagischer Schlaganfallpatienten, die über eine Sonde ernährt werden, zusätzlich Nahrung per os erhalten.

[B (BM); starker Konsens]

Kommentar: Es gibt einige Hinweise, dass die Rate an Atemwegsinfekten bei sondenernährten dysphagischen Schlaganfallpatienten höher ist als bei oral ernährten Patienten [9, 106]. Es kann jedoch davon ausgegangen werden, dass dies in den meisten Fällen am höheren Schweregrad der Dysphagie liegt, die der Grund für die Sondenernährung ist. Selbst Patienten ohne orale Nahrungszufuhr müssen pro Tag mehr als $500 \mathrm{~mL}$ Speichel schlucken und haben somit ein hohes Aspirationsrisiko. Eine Aspirationspneumonie wird durch die Bakterienlast des Speichels verursacht und nicht durch den Speichel selbst $[107,108]$. Eine konsequente Mundhygiene trägt daher potenziell zur Verringerung von Atemwegsinfekten bei [109, 110]. Dieses Konzept wird gestützt durch eine Studie von Gosney et al., die einen signifikanten, vorbeugenden Effekt selektiver oraler Dekontamination auf die Inzidenz von Pneumonien bei älteren dysphagischen Schlaganfallpatienten zeigte [111]. Ein ebensolcher Effekt der oralen Dekontamination wurde für die Prävention beatmungsassoziierter Pneumonien nachgewiesen [112].

Obwohl es zu diesem Thema keine systematischen Untersuchungen gibt, empfehlen zahlreiche Experten bei schwer dysphagischen Patienten, kleine orale Nahrungsgaben wie Eisstückchen um die Mundhygiene und auch die Schluckfähigkeit selbst zu fördern. Häufig besteht die Dysphagie nur für bestimmte Konsistenzen. Nach einer gründlichen klinischen und endoskopischen Prüfung der Sicherheit verschiedener Konsistenzen sollte der Patient oral Nahrung der „sicheren“ Konsistenz erhalten, um die Mundhygiene zu fördern und das Schlucken zu üben. 


\subsection{Kann die Sondenernährung dysphagischer Patienten die Lebensqualität erhöhen? \\ Es liegen keine Daten vor.}

\subsection{Kann die Sondenernährung dysphagischer Patienten Gesundheitskosten reduzieren? \\ Es liegen keine Daten vor.}

\subsection{Verbessert parenterale Ernährung die Prognose von Schlaganfallpatienten?}

\section{Empfehlung 24:}

Parenterale Ernährung ist indiziert, sofern enterale Ernährung kontraindiziert oder nicht durchführbar ist. [KKP; starker Konsens]

\section{Empfehlung 25:}

Selbst bei gut ernährten Patienten sollte eine zusätzliche parenterale Ernährung erfolgen, wenn die enterale Ernährung die Ernährungsbedürfnisse über mehr als 7 Tage nicht erfüllen kann.

[KKP; starker Konsens]

\section{Empfehlung 26:}

Ist eine ausreichende Hydratation durch orale oder enterale Ernährung nicht möglich, sollte unverzüglich eine parenterale Hydratation erfolgen.

[KKP; starker Konsens]

Kommentar: Daten zur parenteralen Sicherstellung der Energiezufuhr und Ernährung bei Schlaganfallpatienten sind nicht verfügbar. Die Indikation sollte gemäß den Leitlinien für kritisch kranke Patienten gestellt werden [67].

Einige Studien zeigten bei dysphagischen Schlaganfallpatienten, die oral ernährt werden, eine unzureichende Flüssigkeitsaufnahme $[113,114]$. Demgemäß muss die Flüssigkeitszufuhr bei dysphagischen Schlaganfallpatienten überwacht und, falls erforderlich, ergänzt werden. Dies kann ggf. mit angedickten Getränken sowie mittels intravenöser und subkutaner Hydratation erfolgen [113 -115]. Vor allem in der Akutphase ist die periphere intravenöse Hydratation am besten geeignet.

\subsection{Welche Schlaganfallpatienten sollten orale Nahrungssupplemente erhalten?}

\section{Empfehlung 27:}

Schlaganfallpatienten, die in der Lage sind zu essen, sollten Trinknahrung erhalten, wenn einer der folgenden Punkte zutrifft:

- Risiko einer Mangelernährung

- manifeste Mangelernährung

- Dekubitusrisiko.

[B (BM); Konsens]

Kommentar: Mit Trinknahrung kann die Energie- und Proteinzufuhr bei Schlaganfallpatienten ohne Beeinträchtigung des Schluckakts oder mit einer leichten Form der Dysphagie gesteigert werden [116]. In der Gesamtgruppe der Schlaganfallpatienten ohne Dysphagie verbessern orale Nahrungssupplemente weder den funktionellen Status noch die Überlebensrate [117]. Bei älteren Patienten mit Mangelernährung hingegen verbessert Trinknahrung die Überlebensrate. Dies gilt wahrscheinlich auch für ältere mangelernährte Schlaganfallpatienten [117-119]. Bei mangelernährten Patienten während der Rehabilitation können orale Nahrungssupplemente den funktionellen Status verbessern [120]. Bei Patienten mit Dekubitusrisiko kann Trinknahrung den Anteil der Dekubitusgeschwüre verringern. Dies gilt wahrscheinlich auch für Schlaganfallpatienten [117, 121].

Etwa 24\% der Schlaganfallpatienten weisen eine Mangelernährung auf, wobei Studien eine Prävalenz von 8 und 48\% abhängig vom Patientenkollektiv und der Art der Beurteilung angeben [122]. Die Gründe für die verringerte Nahrungsaufnahme und den in der Folge schlechten Ernährungszustand sind unterschiedlich und reichen von Dysphagie über Funktionsbeeinträchtigungen, getrübtes Bewusstsein, Wahrnehmungsdefizite und kognitive Dysfunktionen bis hin zu Depressionen [122]. Es gibt nur wenige Studien zur Wirkung von oralen Nahrungssupplementen bei Schlaganfallpatienten. Die größte Studie, die den Nutzen von Trinknahrung untersucht ist die FOOD-Studie, eine Multicenterstudie mit 4023 Patienten [65]. In dieser Studie wurde kein signifikanter Einfluss der Zusatznahrung auf Mortalität oder Hilfsbedürftigkeit beobachtet (modifizierte Rankin-Skala 23) (OR 1,03; 95\%-KI 0,91-1,17; n.s.). Bei 119 unterernährten Patienten, die mit Trinknahrung behandelt wurden, zeigte sich ein tendenziell besserer Verlauf (Mortalität oder Hilfsbedürftigkeit: OR 0,78; 95\%-KI 0,46-1,35; p=0,39). Die Daten dieser Studie müssen kritisch interpretiert werden, da die Erfassung des Ernährungszustands der Patienten nicht standardisiert erfolgte (bei 63\% der Patienten wurde er nur subjektiv durch den Arzt beurteilt). Darüber hinaus wurden keine objektiven Einschlusskriterien verwendet: Patienten wurden nur dann eingeschlossen, wenn Ärzte sich „unsicher“ über die beste Ernährungstherapie waren. Während des Krankenhausaufenthalts wurden den Patienten durchschnittlich 14 Liter Trinknahrung zusätzlich zur normalen Krankenhauskost angeboten $(360 \mathrm{~mL} / \mathrm{d}, 1,5 \mathrm{kcal} / \mathrm{mL}, 6 \mathrm{~g}$ Protein $/ 100 \mathrm{~mL}$ ). Da jedoch die Gesamtenergiezufuhr und die orale Nahrungszufuhr nicht erfasst wurden, geht aus diesen Daten nicht hervor, ob die Energie- und Proteinzufuhr durch die Supplementierung tatsächlich erhöht wurde.

Eine Studie von Gariballa et al. mit 42 Schlaganfallpatienten ermöglicht Aussagen über die Steigerung der Energie- und Proteinzufuhr, da hier die normale Nahrungsaufnahme miterfasst und berechnet wurde [116]. Durch die Ergänzung der Krankenhauskost mit Trinknahrung $(400 \mathrm{~mL} / \mathrm{d}, 1,5 \mathrm{kcal} / \mathrm{mL}, 5 \mathrm{~g}$ Protein/ $100 \mathrm{~mL}$ ) über 4 Wochen konnte die tägliche Energie- und Proteinzufuhr signifikant gesteigert werden $(1807 \pm 318$ gegenüber $1084 \pm 343 \mathrm{kcal} / \mathrm{d} ; \quad \mathrm{p}<0,0001 ;$ Protein $65,1 \pm 13,8$ gegenüber $44,1 \pm 12,8 \mathrm{~g} / \mathrm{d} ; \mathrm{p}<0,001)$. Obgleich der Gewichtsverlust in der supplementierten Gruppe nicht geringer war, konnte doch ein Absinken der Serumalbumin- und Eisenspiegel verhindert werden ( $\mathrm{p}=0,025$ bzw. $\mathrm{p}=0,03$ ). Die klinischen Outcomeparameter (Barthel-Index, infektiöse Komplikationen, Verweildauer) waren in der supplementierten Gruppe tendenziell besser. Die Mortalität war tendenziell niedriger $(p=0,066)$. In einer neueren Studie von Rabadi u. Kollegen bei Schlaganfallpatienten während der Rehabilitation [120] erwies sich die Supplementierung mit einer hochkalorischen eiweißreichen Rezeptur ( $2 \mathrm{kcal} / \mathrm{mL}, 9 \mathrm{~g}$ Protein/ $100 \mathrm{~mL}$ ) im Vergleich mit einer Standardtrinknahrung $(1 \mathrm{kcal} / \mathrm{mL}$, $4 \mathrm{~g}$ Protein/100 mL) als effektiver, was die Verbesserung des funktionellen Status unterernährter Schlaganfallpatienten angeht. Während eine höhere Anzahl der Patienten in der Interventionsgruppe mit hochkalorischer eiweißreicher Nahrung früher nach Hause zurückkehrte $(\mathrm{p}=0,05)$, konnte jedoch keine signifikante Gewichtszunahme beobachtet werden, und die kognitive Funktion blieb bei beiden Gruppen gleich. 
In einer weiteren Studie untersuchten Ha u. Kollegen die Auswirkungen einer individualisierten Ernährungstherapie bei unterernährten älteren Patienten mit akutem Schlaganfall [119]. Die Patienten wurden randomisiert und erhielten entweder die hochkalorische eiweißreiche Trinknahrung, Sondenernährung oder Routineversorgung. Nach 3 Monaten hatten weniger Patienten $(p=0,055)$ der Interventionsgruppe mehr als $5 \%$ ihres Körpergewichts verloren. Darüber hinaus verzeichnete die Interventionsgruppe eine signifikante Verbesserung ihrer Lebensqualität $(\mathrm{p}=0,009)$ und ihrer Handkraft $(\mathrm{p}=0,002)$. Leider konnten in dieser Studie der Einfluss der Nahrungssupplemente und der Sondennahrung nicht unterschieden werden.

Eine generelle Empfehlung für die Verwendung von Trinknahrung kann anhand der Daten der FOOD-Studie für Schlaganfallpatienten nicht gegeben werden. Eine orale Nahrungsergänzung kann auch unerwünschte Wirkungen haben. In der FOOD-Studie haben 27,9\% der Patienten die oralen Supplemente nicht bis zum Ende ihres Krankenhausaufenthalts eingenommen. Gründe dafür waren schlechter Geschmack, Übelkeit, Diarrhö und unerwünschte Gewichtszunahme [65]. Diese Nebenwirkungen führten zur Noncompliance der Patienten, nicht jedoch zu einer Verschlechterung ihres Gesundheitszustands. Bei 33 Patienten mit Diabetes mellitus führten die oralen Nahrungssupplemente zu einer verschlechterten Blutzuckereinstellung, weshalb die Einnahme beendet wurde. Dies sollte bei der Verabreichung von Trinknahrung beachtet werden, da Hyperglykämie beim akuten Schlaganfall ein unabhängiger Risikofaktor für eine schlechte Prognose ist [123].

Eine Metaanalyse von Milne et al. zeigte, dass Supplementation das Risiko von Komplikationen bei älteren Patienten im Krankenhaus verringert (OR 0,86; 95\%-KI 0,75-0,99). Die Mortalität war in der Gesamtgruppe unverändert, jedoch bei älteren mangelernährten Patienten signifikant reduziert (OR 0,79; 95\%-KI 0,640,97) [118].

In der FOOD-Studie war das Risiko für Dekubitus bei Patienten, die Trinknahrung erhielten, geringer, verfehlte aber das Signifikanzniveau $(p=0,05)$ [65]. In einer Metaanalyse von Studien bei anderen Patientengruppen (Patienten ohne Schlaganfall) war die Einnahme von Trinknahrung mit einer um 25\% reduzierten Entstehung von Dekubitalgeschwüren verbunden [121]. In 3 der 4 von Stratton et al. untersuchten Studien wurden eiweißreiche Trinknahrungen (ca. $24 \%$ der Energie aus Proteinen) für die Dekubitusprävention verwendet. Vermutlich sind jedoch Standardtrinknahrungen (ca. 15\% der Energie aus Protein) ebenso effektiv.

Von den Ergebnissen der FOOD-Studie und der Metaanalyse ausgehend $[118,121]$, ist es sehr wahrscheinlich, dass bestimmte Patientengruppen von oralen Nahrungssupplementen profitieren können. Dies können auch ältere Schlaganfallpatienten sein, die zum Zeitpunkt der Erkrankung mangelernährt sind, nicht genügend Nahrung aufnehmen oder ein erhöhtes Dekubitusrisiko haben. Ob orale Nahrungssupplemente bei Schlaganfallpatienten zu einer verbesserten Lebensqualität führen können, ist bislang nicht untersucht.

Unter ausschließlicher Berücksichtigung der verfügbaren wissenschaftlichen Studien wäre für die oben aufgeführte Empfehlung formal der Empfehlungsgrad $C$ angemessen. Unter Berücksichtigung klinischer Expertenerfahrung und Extrapolation der Studien bei Patienten ohne Schlaganfall wurde diese Empfehlung auf Beschluss der Konsensuskonferenz mit Grad B eingestuft.

\subsection{Sollte bei Patienten mit Dysphagie die Konsistenz der Nahrung geändert bzw. Flüssigkeit angedickt werden?}

\section{Empfehlung 28:}

Nach Assessment des Schluckakts (z. B. sorgfältige Beurteilung durch den Logopäden und/oder eine videofluoroskopische oder endoskopische Untersuchung) sollte Patienten konsistenzadaptierte Nahrung oder angedickte Flüssigkeit einer sicheren Konsistenz verabreicht werden.

[KKP; starker Konsens]

\section{Empfehlung 29:}

Patienten mit konsistenzadaptierter Nahrung neigen dazu, weniger Nahrung und Flüssigkeiten aufzunehmen, deshalb kann eine Ernährungsfachkraft konsultiert werden und in Fällen mit dauerhaft geringer Nahrungszufuhr eine Ernährungstherapie initiiert werden. [C (BM); starker Konsens]

Kommentar: Schluckstörungen sind eine häufige Begleiterscheinung bei Schlaganfällen und können bis zu 50\% der Patienten betreffen [14]. Zusätzlich zur Schluckstörung haben Patienten, die nicht orientiert sind, ein um $31 \%$ erhöhtes Aspirationsrisiko, wie von Leder et al. in einer retrospektiven Datenanalyse gezeigt wurde [124].

In der klinischen Praxis wird die Konsistenz von Flüssigkeiten und Nahrung verändert, um das Aspirationsrisiko zu verringern, jedoch gibt es dazu nur wenig gesicherte Daten. In einer kleinen Studie mit Schlaganfallpatienten zeigten Diniz et al., dass die Veränderung der Nahrungskonsistenz und das Andicken von Flüssigkeiten Aspiration verhindern kann [125]. Es gibt eine kleine Anzahl von Studien, die den Einfluss von Bolusgröße und Nahrungs- bzw. Flüssigkeitskonsistenz auf die Schluckfunktion von Patienten mit unterschiedlichen Erkrankungen untersuchen. Eine Studie bei Patienten mit 1-seitiger Stimmbandparese zeigte, dass breiige Konsistenzen sicherer als flüssige Konsistenzen waren, da sie weniger häufig zu Penetration oder Aspiration führten [126]. Kuhlemeier et al. zeigten in einer Studie in einer gemischten Patientenpopulation mit milder bis schwerer Dysphagie, dass ultradicke Flüssigkeiten, die mit einem Löffel verabreicht wurden, weniger häufig zu Penetration führten als dünne Flüssigkeiten, die in einem Becher verabreicht wurden (8,9 vs. 27,9\%). Das Aspirationsrisiko war höher bei dünnen Flüssigkeiten im Vergleich zu dicken und ultradicken Flüssigkeiten $(\mathrm{p}=0,001)$ und höher, wenn die Flüssigkeit im Becher statt mit dem Löffel verabreicht wurde $(p<0,001)$ [127]. In einer weiteren Untersuchung bei Patienten mit Hirnschaden oder neurologischen Erkrankungen verbesserte eine erhöhte Bolusviskosität den Schluckakt [128]. Logemann et al. führten eine Studie an 711 Patienten mit Demenz und/oder Morbus Parkinson durch, um zu untersuchen, ob eine spezielle Position des Kinns während des Schluckakts (Kinn runter) oder eine nektar- bzw. honigdicke Konsistenz hilfreich in der Aspirationsprävention sind. Honigdicke Flüssigkeiten waren am effektivsten, während Patienten die Kinn-runter-Position gefolgt von der nektardicken Konsistenz bevorzugten [129]. Basis für die Empfehlung der adäquaten Konsistenz sollte eine klinische oder apparative Untersuchung sein. Abhängig von der Art und dem Schweregrad der Schluckstörung sollte Nahrung in verschiedenen Konsistenzen - von püriert bis breiig - angeboten werden. Trockene, faserige oder krümelige Nahrung sollte vermieden werden, da sie die Bolusformung erschweren. Gemischte 
Konsistenzen erhöhten das Aspirationsrisiko [130]. Es gibt keine Studien, die die Auswirkung von konsistenzadaptierten Kostformen und angedickten Flüssigkeiten auf den Ernährungszustand, den funktionellen Status und die Prognose untersuchen. Obwohl nur wenig empirische Daten vorliegen, scheinen diese diätetischen Maßnahmen jedoch effektiv und werden in verschiedenen nationalen Leitlinien zum Schlaganfallmanagement empfohlen $[131,132]$.

Studien haben gezeigt, dass Patienten mit Dysphagie im Vergleich zu Patienten ohne Schluckstörungen ein erhöhtes Risiko für Mangelernährung haben [133]. Patienten, die eine konsistenzadaptierte Nahrung erhalten, haben eine um ca. $40 \%$ geringere Energie- und Proteinzufuhr als Patienten mit normaler Kost [134]. Das Gleiche gilt für angedickte Flüssigkeiten, wo Studien zeigen, dass Patienten nicht ausreichend Flüssigkeit zu sich nehmen [113, 114]. Somit sollte eine Konsistenzveränderung der Nahrung oder ein Andicken von Flüssigkeiten nur nach entsprechendem Assessment und unter Aufsicht von Fachkräften (z.B. Logopäden) vorgenommen werden. Wright et al. empfehlen eine routinemäßige Konsultation von Ernährungsfachkräften sobald ein Patient konsistenzmodifizierte Kost erhalten soll [134]. Bei unzureichender Nahrungszufuhr über einen längeren Zeitraum sollte eine Ernährungstherapie begonnen werden, um die negativen Folgen einer Mangelernährung zu vermeiden. Zu diesem Thema besteht noch Forschungsbedarf.

\section{Ernährungstherapie bei Patienten mit Parkinson- krankheit}

\subsection{Indikationen und Behandlungsziele ernährungs-} medizinischer Maßnahmen bei Parkinsonkrankheit 4.1.1 Was sind die Indikationen für ernährungsmedizinische Maßnahmen zum Erhalt des Ernährungszustands und zur Prävention und Behandlung von Mangelernährung bei Parkinsonkrankheit?

\section{Empfehlung 30:}

Patienten mit Parkinsonkrankheit weisen bereits in frühen Stadien der Erkrankung ein erhöhtes Risiko für Mangelernährung und Gewichtsverlust auf, deshalb kann empfohlen werden, den Ernährungsstatus von Patienten mit Parkinsonkrankheit regelmäßig zu überprüfen.

[C (BM); starker Konsens]

\section{Empfehlung 31:}

Das Körpergewicht sollte in Abständen von 3 Monaten kontrolliert werden, sofern die Parkinsonerkrankung stabil ist.

[KKP; starker Konsens]

\section{Empfehlung 32:}

Bei Veränderungen der Vigilanz, Fortschreiten des Krankheitsstadiums und Gewichtsverlust kann das Körpergewicht genau festgehalten und mindestens einmal monatlich kontrolliert werden. [C (BM); starker Konsens]

\section{Empfehlung 33:}

Die Beurteilung des Ernährungszustands und die diätetische Schulung können Bestandteil der Routinebetreuung von Parkinsonpatienten sein. Ernährungsmedizinische Maßnahmen in einem multi- disziplinären Ansatz können bei Patienten mit einem Risiko der Mangelernährung oder mit Mangelernährung sinnvoll sein. [C (BM); starker Konsens]

Kommentar: Mehrere Studien geben die Prävalenz von Mangelernährung und das Risiko für Mangelernährung mit etwa 22 $23 \%$ an $[135,136]$. Frauen zeigen offenbar einen ausgeprägteren Gewichtsverlust als Männer [137]. Über Mangelernährung und Gewichtsverlust wird häufig in den Anfangsstadien der Krankheit berichtet [138-141]. Der Gewichtsverlust scheint ein kontinuierlicher Prozess zu sein, der mehrere Jahre vor der Diagnose beginnen kann und nicht nur durch eine verringerte Energiezufuhr verursacht wird [139-141].

Bei Patienten mit Gewichtsverlust ist die Fett- und Energiezufuhr erhöht, was auf eine höhere Stoffwechselrate hindeutet. Der Gewichtsverlust bei der Parkinsonkrankheit ist mehr durch Verlust von Fett- als von Muskelmasse bedingt [135, 139, 142]. In einer Längsschnittstudie mit an Morbus Parkinson erkrankten Patienten über 3 Jahre wurde eine lineare Korrelation zwischen MNAWert (Anamnesebogen Ernährung) und Krankheitsdauer bei abnehmenden diätetischen Punktwerten und Body-Mass-Index gezeigt [138]. Eine Verknüpfung von nicht motorischen Symptomen und Mangelernährung bzw. Mangelernährungsrisiko wurde anhand des MNA in einer Studie mit 177 konsekutiv erfassten ambulanten Patienten mit Parkinsonkrankheit gezeigt. Nicht motorische Symptome der Parkinsonkrankheit, wie Obstipation und Depression, wurden mit einem Bedarf an ernährungsmedizinischer Versorgung assoziiert [136]. Bereits Mangelernährung und Unterernährung an sich führen bei einer Reihe verschiedener Erkrankungen zu erhöhter Mortalität [142].

Das Körpergewicht sollte routinemäßig einmal monatlich kontrolliert werden $[143,144]$.

Es gibt keine kontrollierten prospektiven Studien an Patienten mit Parkinsonkrankheit, die zeigen, dass eine Gewichtüberwachung zu einer Besserung des Verlaufs führt. Daher erhält diese Empfehlung den Empfehlungsgrad C.

\subsubsection{Dysphagie}

\section{Empfehlung 34:}

Das Dysphagieassessment kann ab Stadium III nach Hoehn \& Yahr durchgeführt werden. Alle 12 Monate kann das Dysphagieassessment wiederholt werden, sofern keine klinischen Anzeichen für Dysphagie vorhanden sind und die Parkinsonerkrankung stabil ist. Bei Verschlechterung des klinischen Bildes kann unverzüglich ein Dysphagieassessment durchgeführt werden.

[C; starker Konsens]

\section{Empfehlung 35:}

Dysphagiescreening und -assessment können auch in den Anfangsstadien der Erkrankung durchgeführt werden, da sie möglicherweise schon Folgeprobleme und psychosozialen Stress durch physische Veränderungen des Schluckvorgangs verhindern oder verzögern. [C; starker Konsens]

\section{Empfehlung 36:}

Patienten mit Parkinsonkrankheit und Dysphagie sollten spezialisierten Sprach- und Schlucktherapeuten vorgestellt werden. Ernährungsmedizinische Maßnahmen sollten in Betracht gezogen werden.

[B (BM, QL); starker Konsens] 
Kommentar: Patienten mit Parkinsonkrankheit haben bereits in den Anfangsphasen der Erkrankung ein erhöhtes Risiko für Schluckstörungen [145-147]. Die gastrointestinale Motilität ist beim Parkinsonkranken sehr häufig gestört, was sich vornehmlich durch Dysphagie, gestörte Magenentleerung und Obstipation äußert. All diese Symptome können bereits Jahre vor der Parkinsondiagnose auftreten. Wahrscheinlichste Ursachen sind die Degeneration des dorsalen Vaguskerns und des intramuralen Plexus im gesamten Darm. Vermutlich entwickeln sich diese Degenerationen bereits vor dem Abbau der dopaminergen Neuronen in der Substantia nigra [146]. Die Braak-Hypothese (die auf Postmortem-Untersuchungen basiert) weist darauf hin, dass die ersten pathologischen Anzeichen von M. Parkinson im enterischen Nervensystem, in der Medulla und im Bulbus olfactorius auftreten und erst anschließend über Jahre fortschreitend auch die Substantia nigra und den Kortex betreffen. Nicht motorische Symptome wie Obstipation oder Dysphagie können den typischen motorischen Parkinsonsymptomen um Jahre vorausgehen [147]. Die angegebene Prävalenz der Dysphagie variiert stark von 18,5-100\% [148]. Die meisten Studien beschreiben eine Prävalenz der parkinsonbedingten Dysphagie von 50 und $81 \%$ [145, 149-152]. Schluckstörungen mit multiplen Veränderungen finden sich bereits in den Frühstadien der Parkinsonkrankheit und selbst in asymptomatischen Fällen [145].

Der Zusammenhang zwischen Dysphagie und Schweregrad und Dauer der Parkinsonkrankheit ist umstritten. Das Stadium der Parkinsonkrankheit kann nicht als Prädiktor für das Vorliegen einer Dysphagie und ihrer Komplikationen dienen. Dysphagie bei Parkinsonpatienten ist mit einem erhöhten Aspirationsrisiko verbunden und wird daher mit erhöhter Morbidität und Mortalität assoziiert. Dysphagische Patienten haben ein erhöhtes Risiko für stille Aspirationen ohne offenkundige klinische Zeichen oder Symptome.

Eine videofluoroskopische Studie wies stille Aspirationen bei 21\% der untersuchten Parkinsonpatienten mit Speichelfluss am Tag nach [148]. Eine videofluoroskopische Studie zeigte Aspiration bei 53,6\% und Störungen des Schluckakts bei 100\% der untersuchten Parkinsonpatienten mit Symptomen einer Dysphagie [153]. Aufgrund der Prävalenz der stillen Aspirationen ist ein Dysphagiescreening möglicherweise nicht ausreichend, und ein Dysphagieassessment ist ratsam, um die stillen Aspirationen zu erfassen. Schluckstörungen sind mit einem hohen Risiko für Komplikationen, wie verringerte Wasser- und Energiezufuhr, Aspirationen und Pneumonie, verbunden [148]. Patienten mit Gewichtsverlust leiden im Vergleich zu Patienten ohne Gewichtsverlust häufiger an Dysphagie [139]. Schluckstörungen gestalten das Essen schwieriger; sie verringern den Genuss und beeinträchtigen die soziale Komponente der Mahlzeiten. Schwierigkeiten beim Kauen, Angst vor Verschlucken, Kostveränderungen, langsames Essen und Abhängigkeit von fremder Hilfe beim Essen kann die soziale, psychische und physische Gesundheit von Parkinsonpatienten negativ beeinflussen [148, 154]. Dysphagie kann eine große soziale und psychische Belastung für Betroffene und Angehörige bedeuten. Schluckbeschwerden müssen nicht schwerwiegend sein, um deutliche Belastungen im Leben von Parkinsonpatienten und ihrer Betreuungspersonen darzustellen [145]. Verschiedene Studien haben gezeigt, dass subjektive Patientenangaben ungenau und für die Ermittlung dysphagischer Patienten ungeeignet sind. Objektive Schluckuntersuchungen haben wiederholt bei über 50\% der Parkinsonpatienten Schluckstörungen festgestellt, die keine Schluckstörungssymptome angegeben hatten [148].
Regelmäßiges Dysphagiescreening zur frühzeitigen Erkennung von physischen Veränderungen des Schluckakts und psychosozialem Stress kann Sekundärkomplikationen verhindern oder hinauszögern. Die weitergehende klinische und apparative Untersuchung und eine optimale Behandlung erfordern einen multidisziplinären Ansatz [145, 148].

Die Pathophysiologie der Dysphagie umfasst offenbar einen nicht dopaminergen Anteil. Studien zum Effekt von Levodopa auf Schluckfunktionen zeigen widersprüchliche Ergebnisse. Nagaya et al. zeigten, dass Schlucktraining bei Parkinsonpatienten die Schluckfunktionen verbessert [148]. Eine randomisierte verblindete kontrollierte Studie beschreibt eine Verbesserung der Schlucksicherheit und der hypolaryngealen Funktion während des Schluckakts durch Atem-/Muskeltraining (expiratory muscle strength training, EMST) [155].

\subsubsection{Osteoporose}

\section{Empfehlung 37:}

Eine Supplementierung mit Vitamin D und eine ausreichende Kalziumaufnahme sollten bei M. Parkinson gewährleistet werden, um das Risiko für Osteoporose und Frakturen zu verringern.

[B (BM); starker Konsens]

Kommentar: Patienten mit Parkinsonkrankheit haben einen niedrigeren BMI als entsprechende gesunde Personen (paarweise Zuordnung). Ein niedriger BMI geht mit geringer Knochendichte einher [144].

Parkinsonpatienten haben ein höheres Risiko für Frakturen aufgrund von Haltungsinstabilität, neurologischen Störungen und geringerer Knochenmasse. Ein niedrigerer BMI, hohes Alter, Dauer und Schweregrad der Parkinsonkrankheit korrelieren mit einer schwerwiegenderen Osteoporose [156].

Vitamin-D-Mangel ist bei Parkinsonpatienten signifikant häufiger als bei gleichaltrigen Vergleichspersonen. Eine D-Hypovitaminose ist bereits als Einzelfaktor mit einem erhöhten Sturzund Frakturrisiko verbunden. In einer randomisierten kontrollierten Studie mit 43 Parkinsonpatienten und 43 Probanden in der Kontrollgruppe führte eine Supplementierung mit Vitamin D $(1 \mu \mathrm{g} / \mathrm{d}) \mathrm{zu}$ einer erheblichen Reduzierung nicht vertebraler Frakturen [156, 157]. In der aktuellen DVO-Leitlinie zu Osteoporose wird eine Kalziumsupplementierung nur empfohlen, wenn die Kalziumzufuhr unter 1000 mg pro Tag beträgt. Bei einer geringen Exposition gegenüber Sonnenlicht sollte eine Supplementierung von 800-1000 IE Vitamin D3 täglich in Erwägung gezogen werden [158].

\subsection{Welchen Einfluss haben ernährungsmedizinische} Maßnahmen bei Morbus Parkinson auf den Verlauf der Erkrankung, auf die Morbidität und die Mortalität?

\section{Empfehlung 38:}

Parkinsonpatienten sollen die Levodopamedikation mindestens 30 Minuten vor den Mahlzeiten oder 60 Minuten nach den Mahlzeiten einnehmen.

[A (BM); starker Konsens]

Wenn die Einnahme ohne Essen Übelkeit verursacht, kann das Medikament mit einem kleinen Imbiss eingenommen werden. [C; starker Konsens] 


\section{Empfehlung 39:}

Kommt es bei Parkinsonpatienten während ihrer Behandlung mit Levodopa zu motorischen Fluktuationen, sollte eine Umverteilung der täglichen Proteinzufuhr erwogen werden, sobald motorische Fluktuationen auftreten. Bei einer „Protein-Umverteilungs-Diät“ sollte der Patient den größten Teil seiner täglichen Eiweißzufuhr während des medikationsfreien Intervalls zu sich nehmen, also z. B. abends.

[B (BM); starker Konsens]

\section{Empfehlung 40:}

Eiweißarme Diäten ( $<0,8 \mathrm{~g} / \mathrm{kg}$ Normalgewicht/Tag) sind nicht ausreichend belegt, sie sollten daher nicht empfohlen werden. [B; starker Konsens]

\section{Empfehlung 41:}

Parkinsonpatienten, denen Levodopa per intestinaler Dauerapplikation (Duodopa) verabreicht wird, können gleichzeitig Sondenernährung erhalten.

[C; starker Konsens]

Kommentar: Levodopa ist eine große neutrale Aminosäure und wird vom Körper wie die anderen LNAA (Large Neutral Amino Acids) behandelt, die in der Nahrung vorhanden sind. Sie wird im Magen durch Decarboxylierung verstoffwechselt. Die Magenentleerungsgeschwindigkeit ist dabei ein wichtiger Parameter [159]. Im Dünndarm und im proximalen Ileum wird die Resorption von Levodopa aus dem Darm ins Plasma durch ein sättigungsfähiges Transportsystem erleichtert, das mit den großen neutralen Aminosäuren aus Nahrungseiweißen konkurriert. Ähnliche Transportmechanismen gibt es an der Blut-HirnSchranke. Parkinsonpatienten sollten ihre Levodopamedikation mindestens 30 Minuten vor den Mahlzeiten einnehmen $[143,160,161]$. Einige Patienten ziehen es vor, das Medikament mit einem Imbiss oder einer Mahlzeit einzunehmen, um Nebenwirkungen wie Übelkeit oder Schwindel zu vermeiden. Die Rolle solcher diätetischen Faktoren muss bei der Behandlung des Patienten berücksichtigt werden. Kleine Mengen Eiweiß haben offenbar keine Auswirkungen auf die Pharmakokinetik von Levodopa $[143,160]$.

Eine Studie von Carter et al. zeigte, dass Proteine das klinische Ansprechen auf Levodopa beeinflussen [162]. Bei Parkinsonpatienten mit motorischen Fluktuationen wird von der American Academy of Neurology eine Umverteilung der täglichen eiweißhaltigen Mahlzeiten, eine Protein-Umverteilungs-Diät (PRD, Protein Redistribution Diet), empfohlen [163]. Eine PRD führte zu verbesserten motorischen Funktionen. Die Effizienz ist offenbar höher, wenn die Intervention in den Frühstadien der Parkinsonkrankheit erfolgt. Die Reaktion auf die PRD scheint gut zu sein. Die Diät führte zu verbesserten motorischen Funktionen; jedoch traten Komplikationen auf, wie schwere Dyskinesien durch Reduzierung der Levodopadosierung, Gewichtsverlust, Proteinmangelerscheinungen und Vitaminmangel. In Übereinstimmung mit dem therapeutischen Algorithmus der American Academy of Neurology kann eine solche Diät vorgeschlagen werden, um die motorischen Funktionen von Levodoparespondern zu verbessern; dies betrifft sowohl stationäre als auch ambulante Patienten. Wirksamkeit und Vorteile scheinen in den Frühstadien der Parkinsonkrankheit zu überwiegen. Sobald motorische Fluktuationen auftreten und vermutlich bereits vor Erhöhung der Levo- dopadosis kann die PRD Parkinsonpatienten vorgeschlagen werden, die mental aktiv, motiviert und sehr kooperativ sind. Es müssen noch Auswahlkriterien für die Parkinsonpatienten definiert werden, die am meisten von der Diät profitieren können. $\mathrm{Zu}$ den langfristigen Auswirkungen auf den Ernährungszustand bei Parkinsonkrankheit im Allgemeinen und auf Komplikationen besteht noch Forschungsbedarf [163].

Die Dauerverabreichung von Levodopa in den Dünndarm ist in fortgeschrittenen Stadien der Erkrankung mit schweren motorischen Fluktuationen zugelassen worden, wenn die orale Verabreichung von Levodopa zusammen mit diätetischen Maßnahmen nicht ausreicht.

Levodopa wird in einer speziellen Matrix kontinuierlich über eine PEG in Kombination mit einer Jejunalsonde verabreicht. Diese Verabreichungsform ist unabhängig von der Magenentleerung und sorgt für eine stabile Levodopakonzentration im Blut.

Bei vorliegender Mangelernährung oder einem Mangelernährungsrisiko ist die Anwendung von energiereichen oralen Nahrungssupplementen (eiweißarm, Eiweiße 10\% der Gesamtenergiezufuhr), die für Patienten mit Nierenproblemen entwickelt wurden, eine Option.

Niedrige Plasmaspiegel einiger Spurenelemente wie Eisen, Zink, Vitamin A und E können sowohl die Folge mangelnder Zufuhr als auch von oxidativem Stress sein. Die Erkenntnisse zu Spurenelementen bei Parkinsonkranken sind bisher noch begrenzt. Mangel an Spurenelementen scheint mit Problemen bei der Nahrungsaufnahme verbunden zu sein und tritt vor einer mangelnden Energie- und Proteinzufuhr auf.

Der Ablauf der Magenentleerung kann auf der Zusammensetzung der Mahlzeiten beruhen, wobei Fette und ballaststoffreiche Lebensmittel normalerweise eine Verzögerung bewirken. Hochwertige Kohlenhydrate (Stärke) sollten, aufgrund ihrer Effekte auf die Glukosetoleranz, bei gastrischer Dysfunktion in der Ernährungsführung vorgezogen werden [143]. Viele Faktoren tragen zu Veränderungen des Ernährungszustands im Verlauf einer Erkrankung bei. Die Beurteilung des Ernährungsstatus sollte Teil der Betreuung von Parkinsonpatienten sein. Eine Anpassung der Diät sollte stets in Erwägung gezogen werden [143].

Ernährungsmedizinische Maßnahmen mit Verabreichung ausreichender Mengen an Energie, Hauptnährstoffen und Spurenelementen können zur Verhinderung von Gewichtsverlust, osteoporoseassoziierten Schmerzen und Frakturen beitragen. Dadurch kann die Lebensqualität verbessert werden [143].

\section{Empfehlung 42:}

Bei Dysphagie können konsistenzveränderte Nahrung und Andickungsmittel für eine sicherere Flüssigkeits- und Energiezufuhr empfohlen werden, und zwar üblicherweise nach einem Dysphagieassessment, das von einem Logopäden nach standardisiertem Verfahren durchgeführt wird, und/oder nach apparativer Beurteilung mittels FEES oder VFSS.

[C; starker Konsens]

\section{Empfehlung 43:}

Langfristige Behinderung, bei der keine adäquate Ernährung und Medikation zu erreichen ist, kann eine Indikation für eine PEG sein, sofern künstliche Ernährung gemäß Allgemeinzustand und Willenserklärung des Patienten indiziert ist.

[C (BM); starker Konsens] 
Kommentar: Bei Schluckstörungen können für eine sicherere Flüssigkeits- und Energiezufuhr konsistenzveränderte Nahrung und Andickungsmittel empfohlen werden, üblicherweise nach einer gründlichen apparativen Untersuchung [143]. Bestehen Zweifel hinsichtlich der Vorteilhaftigkeit einer PEG-Sonde, kann vor einer PEG-Anwendung für einige Wochen eine nasogastrale Sonde gelegt werden, sofern diese vom Patienten toleriert wird. Auf diese Weise kann der Effekt von Ernährung und Medikation über die Sonde beobachtet werden. Sind nach einer festgelegten Zeitspanne keine positiven Effekte zu verzeichnen, kann die nasogastrale Sonde entfernt werden. Die Anlage einer nasogastralen Sonde oder einer PEG ist eine individuelle Entscheidung, in die Aspekte wie die Willensfreiheit und die Lebensqualität des Patienten einfließen sollten.

Zum Einfluss des Diätmanagements auf den Krankheitsverlauf liegen noch keine Erkenntnisse vor, und hier besteht noch Forschungsbedarf [164].

\subsection{Welchen Einfluss haben ernährungsmedizinische Maßnahmen auf die Lebensqualität von Parkinson- patienten?}

\section{Empfehlung 44:}

Eine Protein-Umverteilungs-Diät (PRD) führt zur Besserung von motorischen Symptomen bei Patienten mit motorischen Fluktuationen unter Levodopa und kann hier empfohlen werden, weil dadurch die Lebensqualität verbessert werden kann.

[C (QL); starker Konsens]

\section{Empfehlung 45:}

Die Behandlung von Komplikationen wie Dysphagie und Obstipation durch einen multidisziplinären Ansatz mit Diätadaption entsprechend den aktuellen Schluckfunktionen sowie eine ausgewogene ballaststoffreiche Diät mit ausreichender Flüssigkeitszufuhr, kann empfohlen werden, weil so zu einer Verbesserung der Lebensqualität beigetragen werden kann.

[C (QL); starker Konsens]

Kommentar: Alle Symptome der Parkinsonkrankheit haben beträchtliche Auswirkungen auf die Aktivitäten des Alltags und auf die gesundheitsbedingte Lebensqualität. Eine spezifische Arzneimitteltherapie, meist in Kombination mit einem multidisziplinären Ansatz, kann somit die Lebensqualität der Patienten erhöhen.

Der PDQ-39-Bogen zeigt, dass die Lebensqualität signifikant mit der Erkrankungsdauer, dem Stadium nach Hoehn \& Yahr und dem Schweregrad der Erkrankung korreliert. Die Lebensqualität androgyner Männer und besonders von Frauen mit ausgeprägten femininen und maskulinen Charakteristika ist signifikant besser [165]. Störungen der unteren Extremitäten hatten einen größeren Einfluss auf die Lebensqualität als Störungen der oberen Extremitäten [166]. Nicht motorische Symptome (NMS) und PDQ39 korrelieren signifikant mit der Krankheitsdauer. NMS sind unabhängig und negativ assoziiert mit der gesundheitsbezogenen Lebensqualität (HR-QL) bei Parkinsonkranken; eine Verbesserung der NMS spielt eine wichtige Rolle in der Behandlungsführung der Parkinsonkrankheit [167]. Eine bessere kognitive Leistungsfähigkeit wurde unabhängig mit einer besseren HR-QL assoziiert [168].

Dysautonomiesymptome des oberen und unteren Gastrointestinaltrakts, Speichelfluss, Dysphagie und Obstipation treten bei
Parkinsonkranken häufig auf und haben negative Auswirkungen auf die Sicherheit und Lebensqualität der Patienten. Diese Symptome korrelieren u.U. nicht mit anderen motorischen Parkinsonsymptomen. Chronische Obstipation ist das häufigste Symptom einer Beteiligung des vegetativen Nervensystems bei Parkinsonkranken und beeinträchtigt die Lebensqualität [143, 169]. Schluckstörungen müssen nicht schwer sein, um die Lebensqualität von Parkinsonpatienten und ihrer Angehörigen signifikant zu beeinträchtigen. Essen ist eine soziale Aktivität und physische Veränderungen, die das Kauen, das Schlucken und die manuelle Geschicklichkeit beeinflussen, können tiefgreifende psychosoziale Konsequenzen für die Betroffenen haben [145]. Dysphagie beeinträchtigt ebenfalls stark den Genuss und die soziale Komponente von Mahlzeiten. Parkinsonpatienten, die unter Schluckstörungen leiden, berichten über eine stark reduzierte Lebensqualität. In fortgeschrittenen Stadien der Parkinsonkrankheit zeigt ein weiter reduzierter Appetit und eine längere Dauer der Mahlzeiten (zunehmend mit dem Schweregrad der Erkrankung) einen negativen Einfluss auf den Ernährungszustand [170]. Es wurden signifikante Zusammenhänge zwischen schluckbezogener Lebensqualität, allgemeiner gesundheitsbezogener Lebensqualität und Depression gezeigt. Diese Daten zeigen einen Zusammenhang zwischen Schluckfunktion, sozialer Funktion und Depressionen [171].

\subsection{Soziale Aspekte}

Die Parkinsonkrankheit beeinflusst mit ihren motorischen und nicht motorischen Symptomen stark das soziale Leben von Betroffenen und Betreuungspersonen. Psychologische Interventionen, Patientenschulungen und Ergotherapie in Kombination mit einem multidisziplinären Ansatz können die soziale Belastung von Betroffenen und Betreuungspersonen lindern.

Eine randomisierte kontrollierte Studie mit 64 Parkinsonpatienten und 46 Betreuungspersonen zeigt, dass das Patientenschulungsprogramm „Patient Education Program Parkinson“ (PEPP) die gesundheitsbezogene Lebensqualität bei Parkinsonkranken erhöht. Ein signifikanter Effekt wurde bei der Lebensqualität der Betreuungspersonen verzeichnet; bei den Patienten ergab sich ein Trend zur signifikanten Erhöhung der Lebensqualität. Beide Effekte können die psychosozialen Funktionen verbessern [172]. Ergotherapie ist als eine wichtige Ergänzung der pharmakologischen Behandlung anerkannt. Eine Analyse von 8 Studien, keine davon eine Studie der Evidenzklasse I, zeigt, dass die Behandlung während der Therapiedauer Verbesserungen der motorischen Funktionen und der Lebensqualität bewirkt und daher das Potenzial hat, psychosoziale Funktionen zu verbessern [173]. Eine Querschnittsstudie mit 85 Parkinsonpatienten zeigt, dass psychologische Interventionen wie Aufmerksamkeitstraining zur Verringerung von Flucht- und Vermeidungsverhalten eine Verbesserung der motorischen Funktionen und der gesundheitsbezogenen Lebensqualität bei Parkinsonkrankheit erreichen und die psychosozialen Funktionen verbessern kann [174]. Daten einer Studie mit 36 Parkinsonpatienten mit und ohne Dysphagie weisen auf einen möglichen Zusammenhang zwischen der Schluckfähigkeit, sozialen Funktionen und Depressionen hin [171]. Dysphagie kann eine soziale und psychische Belastung für Betroffene und Angehörige darstellen. Eine Studie mit 114 Parkinsonpatienten zeigte, dass Schluckbeschwerden nicht schwerwiegend sein müssen, um eine wesentliche Belastung im Leben von Parkinsonpatienten und ihren Betreuern darzustellen. Essen ist eine soziale Aktivität, und physische Veränderungen, die das Kauen, das Schlucken und die manuelle Geschicklichkeit beein- 
flussen, können tiefgreifende psychosoziale Konsequenzen für die Betroffenen haben [145].

\subsection{Ethische Aspekte}

4.5.1 In welchen Situationen sollten ernährungsmedizinische Maßnahmen bei Parkinsonkranken erfolgen? In welchen Situationen sollten ernährungsmedizinische Maßnahmen abgebrochen werden?

\section{Empfehlung 46:}

Die Entscheidung bei Parkinsonpatienten ernährungsmedizinische Maßnahmen nicht einzuleiten oder ernährungsmedizinische Maßnahmen abzubrechen, kann in Übereinstimmung mit dem Willen oder dem vermuteten Willen des Patienten individuell getroffen werden.

[C; starker Konsens]

Kommentar: Es ist Teil der ärztlichen Kunst zu erkennen, wann eine kurative oder aggressive Behandlung abgebrochen werden sollte zugunsten von Pflege, Wohlbefinden, Linderung der Symptome und Wahrung der Würde. Dazu gehört ein Erkennen des Sterbeprozesses, welcher schnell gehen oder über viele Monate andauern kann. Diese Grundsätze können auch für die Parkinsonkrankheit empfohlen werden [92, 175]. Leser können hierfür auch die aktuelle DGEM-Leitlinie „Ethische und rechtliche Gesichtspunkte der Klinischen Ernährung“" zurate ziehen [92].

Bei jedem Parkinsonpatienten sollte individuell eine ethische Abwägung zwischen dem Nutzen und dem Risiko ernährungsmedizinischer Maßnahmen vorgenommen werden, dies gilt insbesondere bei Sondenernährung. Ein Parkinsonpatient kann seinen Willen über lange Zeit angemessen äußern. Bei der Parkinsonkrankheit als chronisch fortschreitende Krankheit müssen Wille und Geisteszustand des Patienten genau untersucht werden. Die Möglichkeit einer Sondenernährung zur Ernährungs- bzw. Flüssigkeitstherapie sollte nicht erst im Endstadium, sondern frühzeitig im Verlauf der Erkrankung besprochen werden.

\subsection{Ist Obstipation bei Parkinsonkranken eine Indikation für eine Ernährungsumstellung?}

\section{Empfehlung 47:}

Um Obstipation vorzubeugen, sollte bei Parkinsonpatienten mit Obstipation ein multidisziplinärer Ansatz verfolgt werden mit physischer Aktivität, angemessener Ballaststoffzufuhr (mindestens $30 \mathrm{~g}$ pro Tag oder $10 \mathrm{~g}$ pro $1000 \mathrm{kcal}$, sofern dies vertragen wird) und ausreichender Flüssigkeitszufuhr (mindestens $1500 \mathrm{~mL}$ täglich). [B (BM); starker Konsens]

Kommentar: Obstipation kann bereits 10-20 Jahre vor den motorischen Symptomen auftreten. Weniger häufiger Stuhlgang kann auf ein zukünftiges Risiko für Parkinsonkrankheit hinweisen. In den Frühstadien der Erkrankung kommt es zur Lewy-Neuritis und Lewy-Körperchen treten im dorsalen Vaguskern auf und finden sich dann im 3. Stadium im Hirnstamm und schließlich in der Substantia nigra [146, 147]. Eine Dystonie des externen Analsphinkters erschwert die rektale Entleerung. Der Verlust dopaminerger Neuronen verursacht vermutlich Obstipation durch eine verlangsamte Transitzeit. Ernährungsumstellungen, orale Laxativa, Suppositorien und anderes werden häufig verwendet. Es gibt nur wenige Daten zu ihrer Anwendung bei Patienten mit ZNS-Erkrankungen [176].
Eine Studie mit 94 Parkinsonpatienten zeigt keinen signifikanten Unterschied zum Ernährungszustand der Kontrollpersonen, jedoch war die Wasseraufnahme bei Parkinsonpatienten signifikant geringer als in der Kontrollgruppe. Parkinsonpatienten haben häufig keinen Durst. In dieser Studie litten 78,7\% der Parkinsonpatienten an Obstipation (Frauen 82,4\%; Männer 61,9\%). Bei $44,6 \%$ dieser Patienten ging die Obstipation den motorischen Störungen um durchschnittlich 18 Jahre voran [177]. Eine ballaststoffreiche Kost wirkt sich positiv auf die Levodopakonzentration im Blut und die motorischen Funktionen aus. Eine positive Korrelation zeigte sich zwischen der Verbesserung der Obstipation und einer höheren Bioverfügbarkeit von Levodopa [159, 176]. Ballaststoffe spielen eine wichtige Rolle für die Behandlung der Obstipation, und ein ausreichender Verzehr von täglich mindestens 30 $35 \mathrm{~g}$ wird zusammen mit einer entsprechenden Flüssigkeitsaufnahme von täglich mindestens $1500 \mathrm{~mL}$ empfohlen [143].

\subsection{Screening und Beurteilung des Ernährungszustands bei Parkinsonkrankheit}

\section{Empfehlung 48:}

Der Ernährungszustand von Parkinsonpatienten kann regelmäßig, d. h. mindestens im Abstand von 3 Monaten, überprüft werden, bei Veränderungen von Vigilanz, Krankheitsstadium oder Gewichtsverlust einmal monatlich (s. a. 4.1.1).

[C (BM); Konsens]

Kommentar: Studien zum Grundumsatz anhand von indirekter Kalorimetrie zeigten, dass der Kalorienverbrauch sowohl bei unbehandelten als auch bei optimal behandelten Parkinsonpatienten signifikant erhöht ist. Rigor und Dyskinesien können für den erhöhten Energieverbrauch verantwortlich sein, sie können jedoch nicht als einzige Ursache einer extrem negativen Energiebilanz betrachtet werden. Eine geringere Energiezufuhr aufgrund von motorischen und nicht motorischen Symptomen, wie Dysphagie können ebenfalls eine Rolle spielen. Andere Faktoren, wie z.B. Malabsorption, können zu diesem Phänomen beitragen. Eine erhöhte Energiezufuhr zur Kompensierung des erhöhten Energieverbrauchs erwies sich als nicht wirksam in der Verhinderung von Gewichtsverlust [143].

Die Studie von Lorefät aus dem Jahre 2006 mit Befragungen zu regelmäßigen Aktivitäten, Ernährungsgewohnheiten und Energiebedarf mithilfe der von der WHO vorgegebenen Gleichung zur Ermittlung des Grundumsatzes zeigte, dass die Fett- und Energieaufnahme bei Parkinsonpatienten mit Gewichtsverlust höher war als bei Parkinsonpatienten ohne Gewichtsverlust [139]. Eine Studie von Davies mit Ernährungsanalyse, hämatologischen Untersuchungen und anthropometrischen Messungen wies nach, dass Parkinsonpatienten mit Gewichtsverlust eher einen Energieverlust (Körperfettmasse) als einen Proteinverlust (fettfreie Masse) aufweisen [142].

Es liegen keine Untersuchungen zu parkinsonspezifischen Screenings und Assessments des Ernährungsstatus vor. Daher kann auf die ESPEN-Leitlinien für Ernährungsscreenings zurückgegriffen werden.

Wie oben erwähnt, besteht bei Parkinsonpatienten ein besonderes Risiko für Mangelernährung und Gewichtsverlust. Deshalb sollte zusätzlich zur monatlichen Kontrolle des Körpergewichts ein Ernährungsscreening durchgeführt werden, um Risikopatienten zu erfassen und für eine angemessene Ernährungsführung zu sorgen. Des Weiteren wird die Durchführung eines Ernährungsscreenings für Parkinsonpatienten bei Aufnahme ins 
Krankenhaus oder in eine Pflegeeinrichtung empfohlen. Im Krankenhaus wird der NRS-2002 empfohlen. Bei ambulanten Parkinsonpatienten wird häufig der MNA-Bogen verwendet [138]. Die Beurteilung des Ernährungszustands und die diätetische Schulung sollten Bestandteil der Routinebehandlung von Parkinsonpatienten sein. Patienten mit einem Risiko für Mangelernährung oder bestehender Mangelernährung benötigen ernährungsmedizinische Maßnahmen in einem multidisziplinären Ansatz.

\subsection{Screening und Assessment von Schluckstörungen bei Patienten mit Parkinsonkrankheit}

\section{Empfehlung 49:}

Patienten mit Parkinsonkrankheit sollten ein Dysphagiescreening und -assessment zum Zeitpunkt der Diagnose erhalten sowie anschließend in regelmäßigen Abständen von höchstens 12 Monaten und immer wenn sich die Parkinsonkrankheit verschlechtert. [KKP; Konsens]

Kommentar: Dysphagie stellt bei Parkinsonkranken bereits in den Frühstadien der Erkrankung ein häufiges Problem dar. Screening und Assessment zur Früherkennung einer Dysphagie kann bereits in den frühen Stadien der Erkrankung Folgeprobleme und psychosozialen Stress verhindern oder verzögern [145]. Schluckstörungen sind mit einem erhöhten Risiko für Komplikationen wie reduzierte Wasser- und Energieaufnahme, Aspirationen und Pneumonie verbunden [148]. Patienten mit Gewichtsverlust weisen eine höhere Dysphagierate auf als Patienten ohne Gewichtsverlust [139]. Für weitere Informationen über diagnostische Ansätze bei Dysphagie vergleiche Kapitel 3.1.

\subsection{In welchen Situationen sollte die Ernährung von Parkinsonpatienten auf enteralem oder parenteralem Wege erfolgen?}

\section{Empfehlung 50:}

Da parenterale Ernährung ein höheres Komplikationsrisiko birgt als enterale Ernährung, kann die orale oder enterale Ernährung vorgezogen werden, wann immer dies möglich ist.

[C (BM); starker Konsens]

\section{Empfehlung 51:}

Parenterale Ernährung ist indiziert und kann für eine adäquate $\mathrm{Er}$ nährung sorgen, wenn Patienten ihren Energie- und Nährstoffbedarf nicht über enterale Ernährung decken können, und sollte auf Situationen beschränkt bleiben, in denen die enterale Ernährung kontraindiziert ist oder schlecht vertragen wird.

[C (BM); starker Konsens]

Kommentar: Eine akinetische Krise ist eine Indikation für enterale Ernährung. Es liegen keine Untersuchungen zu parkinsonspezifischen Ernährungsprogrammen vor. Parkinson wird hauptsächlich bei älteren Patienten manifest. Hier sollte auf die aktuelle, vor Kurzem publizierte DGEM-Leitlinie für enterale und parenterale Ernährung in der Geriatrie zurückgegriffen werden [178].

\subsection{In welchen Situationen sollte die Ernährung von Parkinsonpatienten über PEG oder nasogastrale Sonde erfolgen?}

\section{Empfehlung 52:}

Eine PEG-Sonde kann bei Parkinsonpatienten empfohlen werden, bei denen abzusehen ist, dass sie enterale Ernährung über Sonde für mindestens 3 Wochen benötigen.

[C (BM); Konsens]

Kommentar: Prospektive klinische Langzeitstudien zeigten eine ausgezeichnete Akzeptanz und Verträglichkeit der enteralen Ernährung mit einem PEG-System seitens der Patienten. In einer prospektiven Studie gaben 3 Monate nach Anlage der PEG über 80\% der Patienten der Ernährung mit einer PEG-Standardsonde die höchste Punktzahl auf einer 4-Punkte-Skala. Prospektive klinische Studien mit gemischten Krankheitsgruppen belegten positive Effekte der PEG-Sondenernährung auf das Körpergewicht und eine Verbesserung der Lebensqualität der Patienten $[179,180]$. In einer prospektiven Studie mit 155 nicht vorausgewählten, chronologisch aufgenommenen Patienten wurde eine signifikante Erhöhung der Lebensqualität nach Ernährung per PEG beobachtet; dies betraf sowohl Patienten mit benignen und malignen Erkrankungen als auch bewusstlose und wache Patienten [181]. Das Assessment eines sicheren Schluckakts und die Eignung des Ernährungsassessments sind entscheidend, um zu bestimmen, welche Patienten mit neurologisch bedingter Dysphagie eine PEG-Anlage erhalten sollen. Allgemeine veröffentlichte Daten befürworten einen individualisierten, aber kritischen und restriktiven Ansatz für die PEG-Ernährung älterer dementer Patienten. Prospektive klinische Studien zeigen deutlich, dass in den meisten Fällen eine unterstützende PEG-Ernährung einen fortschreitenden Gewichtsverlust verhindern und den Ernährungszustand erhalten kann, während ein kompletter Ausgleich des Gewichtsverlustes selbst bei benignen Erkrankungen selten ist. Diese klinischen Daten führen zu einer weiter gefassten und viel frühzeitigeren Diskussion der Vorteile zusätzlicher Nahrungsaufnahme über PEG bei entsprechenden Patienten.

Eine PEG-Anlage ist gegenüber einer nasogastralen Sonde in den meisten Fälle vorteilhaft. Eine pauschale Aussage zum optimalen Zeitpunkt ist schwierig und v.a. von individuellen Bedingungen abhängig [68, 182].

Es liegen keine Untersuchungen zu parkinsonspezifischen Aspekten der PEG-Applikation vor. Bei Parkinsonpatienten bietet die PEG zusätzlich zu ihrem Einfluss auf den Ernährungszustand und die Lebensqualität eine sichere Möglichkeit, Medikamente zu verabreichen. Da es hauptsächlich bei älteren Patienten zur Parkinsonmanifestation kommt, werden die ESPEN-Leitlinien für enterale Ernährung in der Geriatrie und für PEG zitiert. Hierfür kann auch die aktuelle DGEM-Leitlinie „Klinische Ernährung in der Geriatrie“" zu Rate gezogen werden [178].

\subsection{Kontraindikationen für eine Ernährungstherapie bei Patienten mit Parkinsonkrankheit \\ Kontraindikationen für eine Ernährungstherapie bei Patienten mit Parkinsonkrankheit sind bislang noch nicht gründlich unter- sucht. Da diese progressive neurodegenerative Erkrankung vor- wiegend bei älteren Personen auftritt, kann auf die ESPEN-Leitli- nie „Artificial Enteral Nutrition - Percutaneous Endoscopic Gas- trostomy“ [182] sowie auf die aktuellen DGEM-Leitlinien „Ethi- sche und rechtliche Gesichtspunkte der Klinischen Ernährung“}


[92] und „Klinische Ernährung in der Geriatrie“ [178] zurückgegriffen werden.

Orale Nahrungssupplemente oder Sondenernährung können zu einer Verbesserung des Ernährungszustands bei dementen und nicht dementen Patienten mit Parkinson führen. In frühen und mittleren Stadien der Erkrankung können orale Nahrungssupplemente (und manchmal Sondenernährung) zu einer ausreichenden Energie- und Nährstoffzufuhr sowie zur Verhinderung von Unterernährung beitragen. Bei Patienten in den Endstadien der Erkrankung wird wie bei Demenz eine Sondenernährung nicht empfohlen $[68,178]$.

\section{Ernährungstherapie bei Patienten mit Huntingtonkrankheit $\nabla$}

5.1 Indikationen und Behandlungsziele ernährungsmedizinischer Maßnahmen bei der Huntingtonkrankheit 5.1.1 Mangelernährung

\section{Empfehlung 53:}

Ernährungsmedizinische Maßnahmen und Ernährungsberatung sollten ein integraler Bestandteil der Behandlung von Patienten mit Huntingtonkrankheit sein.

[B (BM, QL); starker Konsens]

Kommentar: Unter ausschließlicher Berücksichtigung der verfügbaren wissenschaftlichen Studien wäre hier formal der Empfehlungsgrad C angemessen. Unter Berücksichtigung klinischer Expertenerfahrung wurde diese Empfehlung auf Beschluss der Konsensuskonferenz mit Grad B eingestuft.

Bereits 1909 berichtete George Huntington, der als erster detailliert und umfassend die wesentlichen Merkmale der Huntingtonkrankheit beschrieb, über Malnutrition bei 2 Huntingtonpatienten: „two women, mother and daughter, both tall, thin, almost cadaverous, both bowing, twisting, grimacing“" [183].

Mehrere qualitativ hochwertige Studien haben mittlerweile gezeigt, dass die Huntingtonkrankheit im Verlauf oft von einem erheblichen Gewichtsverlust begleitet wird. Besonders ausgeprägt ist der Gewichtsverlust in der späten hypokinetischen Krankheitsphase der Huntingtonkrankheit [184]. Aber ein unbeabsichtigter Gewichtsverlust tritt auch schon in frühen Krankheitsstadien auf [185]. In einer Studie, in die 517 Patienten mit Huntingtonkrankheit im frühen Stadium eingeschlossen wurden, korrelierte das Ausmaß des Gewichtsverlustes direkt mit der CAG-Repeat-Länge, wohingegen sich keine Korrelationen des Gewichtsverlustes mit motorischen, kognitiven oder Verhaltenssymptomen fanden [186]. Weiterhin konnte gezeigt werden, dass noch asymptomatische Huntington-Gen-Träger einen niedrigeren BMI als gesunde Kontrollprobanden aufweisen [187]. Prämanifeste, klinisch asymptomatische Individuen mit einer CAG-Repeat-Länge von 37 oder höher benötigen eine erhöhte Kalorienaufnahme, um das Körpergewicht konstant zu halten [188]. Mithilfe eines postalischen Fragebogens konnte gezeigt werden, dass Huntingtonpatienten dünner sind als gesunde Kontrollprobanden [189]. Bei gleicher Nahrungsaufnahme entwickeln Huntingtonpatienten in mittleren Krankheitsstadien häufiger eine Mangelernährung als gesunde Kontrollprobanden [190]. Avitaminosen und andere Ernährungsdefizite gehören zu den Haupttodesursachen der Huntingtonkrankheit [191]. Insgesamt komplizieren unbeabsichtigter Gewichtsverlust und Malnutrition oft den Verlauf der Huntingtonkrankheit und tragen wesentlich zu Morbidität und Mortalität bei [184, 192].

Studien, in denen die Pathomechanismen für den Gewichtsverlust bei der Huntingtonkrankheit untersucht wurden, kamen zu widersprüchlichen Ergebnissen [193, 194]. Im Gegensatz zu anderen chronischen Krankheiten mit Gewichtsverlust, haben Huntingtonpatienten häufig einen vermehrten Appetit, der auch nicht abnimmt, wenn große Nahrungsmengen im Tagesverlauf verzehrt werden [187, 190, 195]. Es wird angenommen, dass die Ursachen für den Gewichtsverlust bei der Huntingtonkrankheit multifaktoriell sind und sich zusammensetzen aus einer verminderten Kalorienaufnahme infolge von Schluckstörungen und/ oder Malabsorption, einem erhöhten Energieumsatz aufgrund der motorischen Aktivität (insbesondere choreatiforme und dystone Symptome) oder einem systemischen metabolischen Defekt, der zu einem hypermetabolischen Zustand führt [188].

Eine Beobachtungsstudie in Zusammenarbeit mit der Huntington Study Group verfolgte eine große Patientenkohorte in mehreren Zentren für durchschnittlich 3,4 Jahre. Die Studie ergab, dass Gewichtsverlust und das Ausmaß choreatiformer Symptome nur schwach assoziiert sind und deshalb andere Faktoren eine Rolle spielen müssen [194]. Im Gegensatz dazu erbrachte eine andere Studie, dass der Ruheenergieumsatz bei Patienten mit Huntingtonkrankheit in Abhängigkeit vom Schweregrad der Bewegungsstörung höher ist als bei alters-, geschlechts- und BMI-gematchten Kontrollen [196]. In Übereinstimmung mit diesen Ergebnissen zeigte eine weitere Studie, dass der 24-Stunden-Energieumsatz in frühen und mittleren Stadien der Huntingtonkrankheit abhängig von der willkürlichen und unwillkürlichen körperlichen Aktivität erhöht ist [197]. Nichtsdestotrotz erklären diese Befunde nicht den niedrigen BMI, der bei asymptomatischen Genträgern oder Huntingtonpatienten in sehr frühen Krankheitsstadien gefunden wurde, bei denen unwillkürliche Bewegungen fehlten oder minimal ausgeprägt waren $[185,187]$.

Eine Untersuchung von Probanden, die an der Prospective Huntington At Risk Observational Study (PHAROS) teilnahmen, ergab, dass bei der Huntingtonkrankheit ein gesteigerter metabolischer (prokatabolischer) Zustand bereits vor der Entwicklung von motorischen Symptomen auftritt [188]. Ein intrinsischer Defekt des mitochondrialen Metabolismus trägt möglicherweise ebenfalls zum Gewichtsverlust von Huntingtonpatienten bei. In Hirnbiopsien von Huntingtonpatienten fand sich eine Dysfunktion des elektrischen Transports in der mitochondrialen Atmungskette, insbesondere in den Komplexen II und III [198]. Ein metabolisches Profil bestehend aus Veränderungen in den Fettsäureabbauprodukten, erhöhtem Nukleinsäureabbau und einer Dysregulation des Aminosäurestoffwechsels, war im Mausmodell und in Huntingtonpatienten im Vergleich zu Kontrollen mit einem prokatabolischen Zustand assoziiert [199]. In einer Studie, die 15 prämanifeste Huntingtonpatienten mittels ${ }^{1} \mathrm{H}$-NMR-Spektroskopie untersuchte, fanden sich bei den prämanifesten Huntingtonpatienten im Vergleich zu Kontrollen niedrige Plasmaspiegel verzweigtkettiger Aminosäuren. Die niedrigen Plasmaspiegel korrelierten mit dem Gewichtsverlust und der CAG-Repeat-Länge [200]. Außerdem wurde postuliert, dass eine Reduktion von HAP-1, das stärker an mutantes Huntingtin bindet als an normales Huntingtinprotein und ein die Ernährung stimulierendes Protein ist, möglicherweise mit dem Gewichtsverlust bei der Huntingtonkrankheit assoziiert ist [201]. Eine andere Hypothese nimmt als Ursache des Gewichtsverlustes eine hypothalamische Pathologie an, weil sowohl Neurone, insbesondere Somatostatin enthaltende Zellen, im Nucleus tuberalis lateralis des Hypothala- 
mus als auch Orexin enthaltende Zellen im lateralen Hypothalamus von Huntingtonpatienten untergehen [202, 203]. Zudem konnte gezeigt werden, dass Huntingtonpatienten niedrige Leptinspiegel (Leptin fördert das Sättigungsgefühl) sowie hohe Ghrelinspiegel (Ghrelin steigert den Appetit) aufweisen [204].

Zusammenfassend lassen sich aus der aktuellen Studienlage folgende wesentliche Befunde ableiten:

Unbeabsichtigter Gewichtsverlust und Malnutrition treten bei Patienten mit Huntingtonkrankheit häufig und oft schon im frühesten Krankheitsstadium auf. Unbeabsichtigter Gewichtsverlust und Malnutrition komplizieren den Verlauf der Huntingtonkrankheit und können substanziell zu Morbidität und Mortalität beitragen. In frühen Krankheitsstadien korreliert das Ausmaß des Gewichtsverlustes direkt mit der CAG-Repeat-Länge.

Insgesamt ergibt sich daraus die Empfehlung, dass eine ernährungsmedizinische Untersuchung und Behandlung ein integraler Bestandteil der Therapie von Huntingtonpatienten sein soll [183, 205]. Die Hauptziele ernährungsmedizinischer Maßnahmen bei der Huntingtonkrankheit sind Aufrechterhaltung oder Verbesserung der Ernährungssituation, Vermeidung von Malnutrition, Prävention und Behandlung von Gewichtsverlust, Verbesserung der Lebensqualität und Verlängerung des Zeitraums, in der ein zufriedenstellendes Essen möglich ist [183, 206].

\subsubsection{Dysphagie}

\section{Empfehlung 54:}

Huntingtonpatienten mit Dysphagie sollten eine logopädische Schlucktherapie erhalten.

[B; starker Konsens]

Kommentar: Unter ausschließlicher Berücksichtigung der verfügbaren wissenschaftlichen Studien wäre hier formal der Empfehlungsgrad $C$ angemessen. Unter Berücksichtigung klinischer Expertenerfahrung wurde diese Empfehlung auf Beschluss der Konsensuskonferenz mit Grad B eingestuft.

Eine Dysphagie, die sich im Verlauf der Huntingtonkrankheit typischerweise sehr stark ausbildet, trägt essenziell zu Ernährungsdefiziten und Gewichtsverlust bei, insbesondere in späten Krankheitsstadien [205]. Zudem führt eine zunehmende Dysphagie oft zu akuter respiratorischer Insuffizienz und Aspirationspneumonie, welche mit etwa einem Drittel die häufigste Todesursache bei betroffenen Patienten bei der Huntingtonkrankheit darstellt [207]. Zur Prävalenz der Dysphagie bei der Huntingtonkrankheit liegen keine Daten vor [208]. Es ist auch unbekannt, in welchem Stadium der Huntingtonkrankheit die Dysphagie erstmalig klinisch in Erscheinung tritt [208].

In 3 Beobachtungsstudien, 2 Fallberichten und 1 Übersichtsarbeit wurden Schluckfunktion und Dysphagie bei der Huntingtonkrankheit untersucht [208 - 213]. In der Mehrzahl der Fälle wurden videofluoroskopische Schluckuntersuchungen (VFSS) durchgeführt, um die Schluckfunktion zu evaluieren [208]. In die 5 Studien wurden heterogene Patientengruppen eingeschlossen und keine Studie untersuchte systematisch die Dysphagie innerhalb der aufeinanderfolgenden Stadien der Huntingtonkrankheit [208]. Insgesamt ergibt sich aus diesen Studien, dass die Dysphagie bei der Huntingtonkrankheit besonders die orale Vorbereitungsphase sowie die orale und pharyngeale Phase des Schluckakts betrifft. Hauptprobleme in der oralen Vorbereitungsphase sind posturale Instabilität, schneller und impulsiver Nahrungsverzehr und geringe Zungenkontrolle. In der oralen Phase treten als Hauptprobleme unkoordinierte Schlucke, repetitive Schlucke und Residuen nach dem Schlucken auf. In der pharyngealen Phase sind die Hauptprobleme Husten, Verschlucken und Aspirationen [208]. In einer 16-jährigen, retrospektiven Beobachtungsstudie wurde ein signifikanter Unterschied des Störungsmusters der Dysphagie bei hyperkinetischen und hypokinetisch-rigiden Huntingtonpatienten gefunden. Während die Dysphagie bei den hyperkinetischen Patienten durch unkontrollierte Tachyphagie, choreatiforme Zungenbewegungen, unkontrollierte Initiierung des Schluckens und gestörte Unterbrechung des Atmens während des Schluckens charakterisiert war, zeigte die Gruppe der hypokinetisch-rigiden Huntingtonpatienten ein Störungsmuster, welches dem von Patienten mit Morbus Parkinson ähnlich war. Die wesentlichen Merkmale dieser Dysphagie waren mandibuläre Rigidität, ineffizientes Kauen und verlangsamter oraler Transit [211].

Zusammenfassend lassen sich aus der aktuellen Studienlage folgende wesentliche Befunde ableiten:

Aspirationspneumonien, die aus einer Dysphagie resultieren, sind die häufigste Todesursache bei der Huntingtonkrankheit. Eine Dysphagie trägt essenziell zu Ernährungsdefiziten und Gewichtsverlust bei Huntingtonpatienten bei. Die Dysphagie bei der Huntingtonkrankheit beeinträchtigt besonders die orale Vorbereitungsphase sowie die orale und pharyngeale Phase des Schluckakts.

Obwohl es keine spezifischen Strategien für Prävention und Therapie der Dysphagie bei Huntingtonkrankheit gibt, fand eine Beobachtungsstudie, dass die logopädische Schlucktherapie in der Lage sein kann, Beeinträchtigungen des Schluckens und die Nahrungsaufnahme zu verbessern. In dieser Studie konnten etwa $75 \%$ der Patienten, die eine Schlucktherapie erhielten, zu einer uneingeschränkten Kost zurückkehren. Diese Verbesserung hielt für bis zu 3 Jahre an [209]. Nichtsdestotrotz fehlen bislang randomisierte kontrollierte Studien zum Effekt einer Schlucktherapie bei Patienten mit Huntingtonkrankheit [208].

Insgesamt ergibt sich daraus die Empfehlung, dass Huntingtonpatienten mit Dysphagie eine logopädische Schlucktherapie erhalten sollten.

\subsubsection{Welchen Einfluss haben ernährungsmedizinische Maßnahmen auf den Krankheitsverlauf, die Morbidität und/oder die Mortalität bei Patienten mit Huntington- krankheit?}

\section{Empfehlung 55:}

Orale Nahrungsergänzungen, die zusätzliche Kalorien zur normalen Kost bereitstellen, sollten eingesetzt werden, um den Ernährungsstatus und den funktionellen Status zu erhalten oder zu verbessern. [B (BM); starker Konsens]

Kommentar: Es gibt keine spezifischen Daten zum Einfluss ernährungsmedizinischer Maßnahmen auf Krankheitsverlauf, Morbidität und/oder Mortalität bei Patienten mit Huntingtonkrankheit. Bislang wurden keine prospektiven Studien durchgeführt, die den Effekt ernährungsmedizinischer Maßnahmen auf Krankheitsprogression, Morbidität und/oder Mortalität bei Patienten mit Huntingtonkrankheit untersuchen. Dennoch gibt es indirekte Evidenz, dass ernährungsmedizinische Maßnahmen, d.h. orale Nahrungsergänzungen, anthropometrische Variablen verbessern und den funktionalen Status bei Patienten mit Huntingtonkrankheit stabilisieren können.

Avitaminosen und andere Ernährungsdefizite wurden in den USA als eine der Haupttodesursachen von Huntingtonpatienten 
beschrieben [191]. Bei Patienten mit Huntingtonkrankheit war ein Initial höheres Körpergewicht mit einem langsameren Krankheitsverlauf assoziiert, woraus ein Einfluss des Körpergewichts auf den Krankheitsverlauf abgeleitet werden kann [214]. Huntingtonpatienten waren in einem kontrollierten Setting durch das Angebot adäquater Nahrungsmengen in der Lage, eine positive Energiebilanz aufrechtzuerhalten. Im normalen Lebensumfeld variierte die Nahrungsaufnahme bei den Huntingtonpatienten wesentlich mehr als bei gesunden Kontrollen [197]. Eine experimentelle, longitudinale, prospektive Studie untersuchte den Effekt oraler Nahrungsergänzung auf den Ernährungsstatus bei 30 Huntingtonpatienten. Die Studie ergab, dass eine Nahrungsergänzung, die etwa $500 \mathrm{kcal} /$ Tag zusätzlich zur Verfügung stellt, anthropometrische Variablen, d.h. Körpergewicht, Oberarmumfang, Arm-Muskel-Umfang und Körperfett stabilisieren oder leichtgradig verbessern kann [215].

Die Arbeitsgruppe hat die Empfehlung mit dem Evidenzgrad C eingestuft, da keine Interventionsstudien mit ausreichender Fallzahl vorliegen. Nach Beschluss der Konsensuskonferenz wurde der Empfehlungsgrad auf B hochgestuft, da es sich bei der Empfehlung um „gute klinische Praxis“ handelt.

\subsubsection{Welchen Einfluss haben ernährungsmedizinische Maßnahmen auf die Lebensqualität bei der Huntington- krankheit?}

Es gibt keine spezifischen Daten zum Einfluss ernährungsmedizinischer Maßnahmen auf die Lebensqualität bei Patienten mit Huntingtonkrankheit.

Allgemein wird angenommen, dass ernährungsmedizinische Maßnahmen zur Erhaltung eines akzeptablen Ernährungsstatus bei Huntingtonpatienten mit einer verbesserten Lebensqualität assoziiert sind [205]. Bislang fehlen aber Studien, die den Effekt ernährungsmedizinischer Maßnahmen auf die Lebensqualität bei Huntingtonpatienten untersuchen. Deshalb existieren keine Daten zu dieser Frage und der Effekt einer ernährungsmedizinischen Behandlung auf die Lebensqualität von Huntingtonpatienten ist derzeit ungeklärt.

\subsection{Struktur- und Prozessanforderungen}

5.2.1 Wie oft sollte ein Screening und eine Untersuchung des Ernährungsstatus durchgeführt werden?

\section{Empfehlung 56:}

Das Körpergewicht kann bei klinisch manifester Huntingtonkrankheit monatlich kontrolliert werden.

[C; starker Konsens]

\section{Empfehlung 57:}

Eine Untersuchung des Ernährungsstatus kann bei klinisch manifester Huntingtonerkrankung mindestens alle 6 Monate erfolgen. [C; starker Konsens]

Kommentar: Bei der Untersuchung des Ernährungsstatus von Huntingtonpatienten wurden im Vergleich mit Kontrollen ein signifikant verringertes Körpergewicht, BMI, Armumfang und prozentualer Körperfettgehalt gefunden [187, 205]. Weil Huntingtonpatienten mit einer höheren CAG-Repeat-Zahl ein größeres Risiko für ungewollten Gewichtsverlust haben, sollte das Körpergewicht hier möglicherweise engmaschiger kontrolliert werden [186].
5.2.2 Wie hoch ist der Energiebedarf für einen Patienten mit Huntingtonkrankheit zur Aufrechterhaltung des Körpergewichts?

\section{Empfehlung 58:}

Abhängig vom Krankheitsstadium kann bei Huntingtonpatienten eine tägliche Energiezufuhr von etwa $2500-4000 \mathrm{kcal} / \mathrm{d}$ erforderlich sein, um ein adäquates Körpergewicht aufrechtzuhalten.

[C (BM); starker Konsens]

Kommentar: Eine Studie zeigte, dass der absolute 24-h-Ruheenergieumsatz bei Huntingtonpatienten im Vergleich mit Kontrollen $14 \%$ höher war (2038 \pm 98 vs. $1784 \pm 68 \mathrm{kcal} / 24 \mathrm{~h})$. Dieser erhöhte Ruheenergieumsatz korrelierte mit dem Schweregrad der Bewegungsstörung [196]. In einer anderen Studie ergab sich aus der Harris-Benedict-Formel bei den eingeschlossenen Huntingtonpatienten ein mittlerer Energiebedarf von 2799,2 kcal/ Tag [215]. Eine weitere Studie, welche die Charakteristika von Huntingtonpatienten in der Langzeitbetreuung untersuchte, fand einen täglichen Energiebedarf von etwa $3000-4000 \mathrm{kcal}$, um ein adäquates Körpergewicht aufrechtzuhalten [206]. Eine indirekte 24-h-Kalometrie wurde benutzt, um eine adjustierte Formel für den Faktor der körperlichen Aktivität innerhalb der Harris-Benedict-Formel für Huntingtonpatienten im frühen und mittleren Krankheitsstadium zu bestimmen. Unter Anwendung der adjustierten Formel wurde ein mittlerer täglicher Energiebedarf von $2688 \pm 439 \mathrm{kcal}$ berechnet [216]. Eine Studie zeigte, dass ein höherer BMI zum 1. Untersuchungszeitpunkt ein starker Prädiktor für einen langsameren Krankheitsverlauf war. In dieser Studie hatten Huntingtonpatienten mit einem langsameren Krankheitsverlauf einen mittleren BMI von $23,75 \mathrm{~kg} / \mathrm{m}^{2}$ zum 1 . Untersuchungszeitpunkt verglichen mit $20,20 \mathrm{~kg} / \mathrm{m}^{2}$ in der $\mathrm{Pa}-$ tientengruppe mit schnellerem Krankheitsverlauf [214].

\subsubsection{Wie oft sollten ein Dysphagiescreening und ein Dysphagieassessment durchgeführt werden?}

\section{Empfehlung 59:}

Die erste klinische Schluckuntersuchung kann so früh wie möglich im Verlauf der Huntingtonkrankheit durchgeführt werden, d. h. zum Zeitpunkt der Diagnosestellung. [C (BM); starker Konsens]

\section{Empfehlung 60:}

Klinische Schluckuntersuchungen können bei Patienten mit Huntingtonkrankheit in regelmäßigen Abständen durchgeführt werden, mindestens alle 6 Monate oder im Falle einer signifikanten klinischen Krankheitsprogression.

[C (BM); starker Konsens]

Kommentar: Eine retrospektive Beobachtungsstudie über einen Zeitraum von 16 Jahren ergab, dass dysphagische Huntingtonpatienten dazu neigen, Schwierigkeiten beim Schlucken nicht adäquat wahrzunehmen [211]. Deshalb sollte eine sorgfältige klinische Untersuchung der Schluckfunktion so früh wie möglich im Verlauf der Huntingtonkrankheit durchgeführt und in regelmäßigen Abständen wiederholt werden. Logopäden sollten ein integraler Bestandteil des multidisziplinären Teams sein, dass in die Versorgung von Huntingtonpatienten involviert ist [183]. Huntingtonpatienten mit klinischen Zeichen einer Schluckstörung sollten mindestens einmal mit einem instrumentellen Ver- 
fahren, d.h. fiberoptische endoskopische Evaluation des Schluckakts (FEES) und videofluoroskopische Evaluation des Schluckakts (VFSS), untersucht werden, um detaillierte Informationen über das Störungsmuster und den Schweregrad der Dysphagie zu erhalten (vgl. Kapitel 3.1).

5.2.4 In welchen Situationen sollte eine ernährungsmedizinische Behandlung enteral oder parenteral erfolgen?

\section{Empfehlung 61:}

Bei unzureichender oraler Nahrungsaufnahme kann die ernährungsmedizinische Behandlung von Huntingtonpatienten vorzugsweise enteral erfolgen.

[C (BM); starker Konsens]

\section{Empfehlung 62:}

Eine parenterale Ernährung ist indiziert und ermöglicht eine adäquate Ernährung bei Huntingtonpatienten, die ihren Ernährungsbedarf nicht über den enteralen Weg decken können. Eine parenterale ernährungsmedizinische Behandlung kann auch empfohlen werden, wenn eine enterale Ernährung kontraindiziert ist oder schlecht vertragen wird.

[C (BM); starker Konsens]

Kommentar: Die Indikationen für eine enterale oder parenterale Ernährung bei Huntingtonpatienten unterscheiden sich im Wesentlichen nicht von denen anderer Krankheiten. Entsprechend der ESPEN-Leitlinie für enterale Ernährung geriatrischer Patienten [68] sowie der aktuellen DGEM-Leitlinie „Klinische Ernährung in der Geriatrie“ [178] sollten enterale ernährungsmedizinische Maßnahmen immer die 1. Wahl darstellen. Bei Huntingtonpatienten, die ihren Ernährungsbedarf enteral nicht decken können, wird eine parenterale Ernährung empfohlen und ermöglicht eine adäquate Ernährung. Eine parenterale ernährungsmedizinische Behandlung wird außerdem empfohlen, wenn eine enterale Ernährung kontraindiziert ist oder schlecht vertragen wird [217].

\subsubsection{In welchen Situationen sollte bei der Huntington- krankheit eine Ernährung über PEG erfolgen?}

\section{Empfehlung 63:}

Wenn es für Huntingtonpatienten nicht mehr möglich ist, ihren Energiebedarf substanziell mit einer oralen Ernährung zu decken, kann eine Sondenernährung erwogen werden.

[C; starker Konsens]

\section{Empfehlung 64:}

Sondenernährung kann gegeben werden als Supplement zu einer oralen Ernährung, um zusätzliche Flüssigkeit bei Schluckstörungen zu verabreichen oder als einzige Maßnahme zur Ernährung. [C; starker Konsens]

Kommentar: Es gibt keine spezifischen Daten zu der Frage, in welchen Situationen eine Sonderernährung über eine PEG erfolgen sollte. Allerdings ist eine PEG-Anlage im Spätstadium der Huntingtonkrankheit nur selten eine geeignete Maßnahme. Eine PEG-Anlage sollte vielmehr bereits im mittleren Krankheitsstadium erwogen werden, wenn der Patient Zeichen einer Dysphagie ohne/mit Gewichtsverlust und Aspirationspneumonie entwickelt [183].
5.2.6 In welchen Situationen sollten ernährungsmedizinische Maßnahmen über eine Sonde bei der Huntingtonkrankheit nicht erfolgen?

\section{Empfehlung 65:}

Ernährungsmedizinische Maßnahmen über eine Sonde können im Endstadium der Huntingtonkrankheit nicht empfohlen werden. Die Entscheidung muss jedoch in jedem Einzelfall individuell getroffen werden.

[C; starker Konsens]

Kommentar: Es gibt keine spezifischen Daten zu der Frage, in welchen Situationen bei der Huntingtonkrankheit ernährungsmedizinische Maßnahmen über eine Sonde nicht erfolgen sollen. Die ESPEN-Leitlinie zur enteralen Ernährung bei geriatrischen Patienten sowie die aktuelle DGEM-Leitlinie „Klinische Ernährung in der Geriatrie“ empfehlen eine Ernährung über Sonde nicht bei Patienten mit Demenz im Endstadium [68, 178]. In Übereinstimmung mit dieser Empfehlung sollte auch bei der Huntingtonkrankheit im Endstadium keine ernährungsmedizinischen Maßnahmen über eine Sonde erfolgen (irreversible Abhängigkeit in den Aktivitäten des täglichen Lebens, Immobilität, Unfähigkeit zur Kommunikation, schwere Demenz und unmittelbar vor dem Tod).

\subsubsection{Welche Komplikationen können während der} ernährungsmedizinischen Behandlung von Huntingtonpatienten auftreten?

Es gibt keine spezifischen Komplikationen ernährungsmedizinischer Maßnahmen bei der Huntingtonkrankheit.

\subsubsection{Welche Kontraindikationen gibt es für ernährungs-} medizinische Maßnahmen bei der Huntingtonkrankheit? Es gibt keine spezifischen Kontraindikationen für ernährungsmedizinische Maßnahmen bei der Huntingtonkrankheit.

\section{Ernährungstherapie bei Patienten mit Multipler Sklerose}

$\nabla$

6.1 Indikationen und Behandlungsziele

6.1.1 Behandlung und Prävention von Mangelernährung und Übergewicht/Adipositas

6.1.1.1 Mangelernährung

\section{Empfehlung 66:}

Patienten mit Multipler Sklerose, die durch ihre Erkrankung funktionell beeinträchtigt sind, können einem Screening auf Mangelernährung unterzogen werden.

[C (BM); starker Konsens]

Kommentar: Bei Patienten mit Multipler Sklerose kann eine Mangelernährung u.a. zu einer Beeinträchtigung des Immunsystems, der Gedächtnisfunktion und der Atemmuskulatur führen. Mangelzustände von spezifischen Nährstoffen, Vitaminen und Spurenelementen treten bei mangelernährten Patienten mit Multipler Sklerose häufiger auf als bei normalgewichtigen Patienten [218]. Diese können im Rahmen der Grunderkrankung bestehende funktionelle Einschränkungen und Symptome wie z.B. Muskelabbau, Muskelschwäche, Muskelkrämpfe und Müdigkeit (Fatigue) verstärken [219]. Thomas u. Wiles [220] führten eine Beobachtungsstudie bei Patienten, die wegen Multipler 
Sklerose an ein regionales neurologisches Zentrum überwiesen wurden, durch. Patienten mit Multipler Sklerose klagten häufiger als gesunde Kontrollpersonen über Schluckstörungen und Hustenreiz beim Essen. In dieser Studie korrelierte die gestörte Schluckfunktion allerdings nicht mit dem Ernährungsstatus. Zwischen neudiagnostizierten Patienten und Patienten bei denen die Diagnose vor mehr als 6 Monaten gestellt wurde, bestand kein signifikanter Unterschied beim BMI, beim Körperfettanteil und beim Subjective Global Assessment of Nutrition (SGA). Bei Patienten mit funktionellen Einschränkungen durch Multiple Sklerose ist die Prävalenz von Mangelernährung allerdings höher [221].

Es existieren keine randomisierten Studien zu ernährungsmedizinischen Interventionen bei Patienten mit Multipler Sklerose und Mangelernährung.

\subsubsection{2 Übergewicht und Adipositas}

\section{Empfehlung 67:}

Patienten mit Multipler Sklerose und Übergewicht können eine Ernährungsberatung erhalten, um die Entwicklung einer Adipositas zu verhindern.

[C (BM); starker Konsens]

Kommentar: In einer Studie von Hewson et al. [222] waren 40\% der Frauen und 44\% der Männer übergewichtig. In einer Querschnittsuntersuchung von Veteranen lag die Prävalenz von Übergewicht (BMI $25-30 \mathrm{~kg} / \mathrm{m}^{2}$ ) bei Patienten mit Multipler Sklerose etwas höher (42,3 vs. 39,6\%) als bei Veteranen ohne diese Erkrankung. Die Prävalenz einer Adipositas $\left(\mathrm{BMI}>30 \mathrm{~kg} / \mathrm{m}^{2}\right)$ war bei Veteranen allerdings geringer als bei Veteranen ohne diese Erkrankung [223]. Adipositas kann bei Patienten mit Multipler Sklerose bereits bestehende funktionelle Einschränkungen verschlechtern. Bei Patienten mit bestehendem Übergewicht sollte deshalb die Entwicklung einer Adipositas verhindert werden.

Kontrollierte Studien zu ernährungsmedizinischen Interventionen bei übergewichtigen Patienten mit Multipler Sklerose existieren nicht.

\subsubsection{Können ernährungsmedizinische Interventionen den Krankheitsverlauf beeinflussen?}

Viele Patienten mit Multipler Sklerose glauben, dass spezielle Diäten und Nahrungsergänzungsmittel den Krankheitsverlauf positiv beeinflussen und sie damit eine gewisse Kontrolle über ihre Erkrankung haben [224-227]. Die Hälfte bis zwei Drittel aller Patienten mit Multipler Sklerose wenden neben der wissenschaftlich etablierten Behandlung alternative/komplementäre Heilverfahren an [228].

\subsubsection{Supplementierung mit mehrfach ungesättigten Fettsäuren}

\section{Empfehlung 68:}

Aufgrund limitierter Daten von gut durchgeführten randomisierten Studien sollte eine Supplementierung mit mehrfach ungesättigten Fettsäuren für Patienten mit Multipler Sklerose nicht als eine Standardtherapie empfohlen werden.

[B (BM); starker Konsens]

Kommentar: Die Wirkung von mehrfach ungesättigten Fettsäuren auf den Krankheitsverlauf bei Multipler Sklerose wurde in mehreren Studien untersucht. In einem Cochrane Review [229] wurden 6 zwischen 1972 und 2005 publizierte randomisierte kontrollierte Studien analysiert. In diese Studien wurden insgesamt 699 Patienten eingeschlossen. Die Substitution mit mehrfach ungesättigten Fettsäuren hatte in der Gesamtanalyse keinen signifikanten Einfluss auf die Krankheitsprogression.

Die Einnahme von Fischölkapseln (enthalten Omega-3-Fettsäuren) in Kombination mit einer fettreduzierten (15\% Fettanteil) Diät hatte keinen signifikanten Einfluss auf die Krankheitsprogression nach 12 Monaten [230]. Die Einnahme von Fischölkapseln hatte keinen signifikanten Einfluss auf die Häufigkeit und den Schweregrad von akuten Krankheitsschüben [231]. Der Schweregrad der Rezidive (Relapse Severity Score) wurde bei schubförmig-remittierender Multipler Sklerose in 2 Studien $[232,233]$ bestimmt. Nach 24 Monaten zeigte sich in der Studie von Millar et al. [232] ein signifikanter Vorteil (geringerer Schweregrad der Schübe) zugunsten der mit Linolsäure substituierten Gruppe; in der Studie von Paty [233] zeigte sich dagegen kein signifikanter Unterschied.

In keiner der Studien mit mehrfach ungesättigten Fettsäuren wurden mögliche Nebenwirkungen systematisch erfasst. Wechselwirkungen mit für die Behandlung der Multiplen Sklerose verwendeten immunsuppressiven Therapien mit mehrfach ungesättigten Fettsäuren wurden bisher nicht systematisch untersucht. Alle randomisierten kontrollierten Studien hatten kleine Fallzahlen. Als Placebo wurde in den meisten Studien Olivenöl verwendet. Möglicherweise hat Olivenöl aber auch einen Effekt auf die Krankheitsprogression bei Multipler Sklerose.

Zusammenfassend kann aufgrund der derzeitigen Studienlage nicht entschieden werden, ob mehrfach ungesättigte Fettsäuren einen positiven Effekt auf den Krankheitsverlauf bei Multipler Sklerose haben oder nicht. Eine Supplementierung mit mehrfach ungesättigten Fettsäuren wird deshalb bei Patienten mit Multipler Sklerose nicht generell empfohlen.

\subsubsection{Swank-Diät}

\section{Empfehlung 69:}

Die Swank-Diät kann nicht generell für Patienten mit Multipler Sklerose empfohlen werden.

[C (BM); Konsens]

Kommentar: Die Swank-Diät ist eine häufig von Patienten mit Multipler Sklerose angewandte Diät. Bei der Swank-Diät wird empfohlen, die Aufnahme gesättigter Fette auf $15 \mathrm{~g}$ täglich zu begrenzen sowie 10-15g Pflanzenöl, 5 g Lebertran und ein Multivitaminpräparat (mit den Vitaminen A, B, C und D) täglich einzunehmen. In einer prospektiven Studie schloss Swank 208 Patienten mit mindestens 2 Krankheitsschüben einer Multiplen Sklerose ein. Patienten, die nicht gehfähig waren und arbeitsunfähige Patienten wurden von der Studie ausgeschlossen. Die Patienten wurden über 34 Jahre nachbeobachtet [234]. Patienten, die die Diätempfehlung korrekt beachteten, hatten eine langsamere Krankheitsprogression und eine niedrigere Mortalität als Patienten, die mehr als $20 \mathrm{~g}$ Fett täglich zu sich nahmen. Fünf Jahre nach Beginn der Intervention war die Rezidivrate von 1/Jahr auf 0,1/ Jahr gesunken. Diese Studie ist weder randomisiert noch verblindet, was bei einer Diät ja grundsätzlich nicht möglich ist. Deshalb wurde sie auch nicht in das Cochrane Review von Farinotti et al. [229] aufgenommen. Aufgrund der fehlenden Evidenz wird die Swank-Diät deshalb nicht generell empfohlen. 


\subsubsection{Vitamin-D-Supplementierung}

\section{Empfehlung 70:}

Eine Supplementierung mit Vitamin D kann für Patienten mit Multipler Sklerose nicht generell empfohlen werden.

[C (BM); starker Konsens]

\section{Empfehlung 71:}

Patienten mit Multipler Sklerose, die mit Glukokortikoiden behandelt werden, können entsprechend der bestehenden Leitlinien für die Prävention und Therapie der Osteoporose behandelt werden. [C (BM); starker Konsens]

Kommentar: Vitamin D spielt bei der Myelinproduktion durch Oligodendrozyten und bei anderen neuronalen Prozessen eine Rolle [235]. Epidemiologische Daten zeigen, dass die Prävalenz der Multiplen Sklerose in der Äquatorialzone sehr gering ist. Einige Autoren postulieren, dass die unterschiedliche Versorgung mit Vitamin D ein Grund für die regionalen Unterschiede in der Prävalenz der Multiplen Sklerose sein könnte [236]. Fettreicher Fisch ist eine wichtige Quelle für Vitamin D. In den Küstenregionen Norwegens ist die Prävalenz der Multiplen Sklerose niedriger als im Rest Skandinaviens. Es wird postuliert, dass dies mit einer erhöhten Aufnahme von Vitamin D über Fisch zusammenhängen könnte [237]. Fettreicher Fisch enthält neben Vitamin D allerdings auch Omega-3-Fettsäuren. Neuerkrankungen an Multipler Sklerose treten im Frühjahr häufiger auf. Es wird postuliert, dass dies mit der verminderten Sonnenlichtexposition im vorausgegangenen Winter mit den daraus folgenden niedrigen Serumspiegeln von aktivem Vitamin D zusammenhängen könnte [238]. In dem Cochrane Review [229] wurden 8 Studien zur Gabe von Vitamin D bei Patienten mit Multipler Sklerose gefunden. Die randomisierte und kontrollierte Studie von Mahon [239] wurde vom Cochrane Review [229] ausgeschlossen, da nur Laborwerte und keine klinischen Endpunkte als Outcomeparameter untersucht wurden. Die Studie von Lakatos [240] wurde ausgeschlossen, weil auch Patienten mit anderen Grunderkrankungen unter Kortikoidtherapie in die Studie eingeschlossen wurden. Die übrigen 6 Studien waren Beobachtungs- oder Kohortenstudien und wurden deshalb nicht in das Review eingeschlossen.

Wegen fehlender Evidenz wird deshalb die Supplementierung von Vitamin D bei Patienten mit Multipler Sklerose nicht generell empfohlen. Patienten mit Multipler Sklerose, die mit Glukokortikoiden behandelt werden, sollen entsprechend der Leitlinien zur Prophylaxe und Therapie der Osteoporose Vitamin D erhalten.

\subsubsection{Antioxidanzien}

\section{Empfehlung 72:}

Die Supplementation mit Antioxidanzien im Rahmen der Ernährung bei Patienten mit Multipler Sklerose kann nicht empfohlen werden. [C (BM); starker Konsens]

Kommentar: Patienten mit Multipler Sklerose haben erhöhte Hydroperoxidase-Plasmaspiegel [241]. Es wurde postuliert, dass die antioxidativen Vitamine A, C und E, die durch freie Radikale verursachte Zellschädigung verringern könnten. In 2 Studien [242, 243] wurde der Einfluss einer Supplementierung mit Antioxidanzien auf die Glutathion-Peroxidaseaktivität bei Patienten mit Multipler Sklerose untersucht. Klinische Outcomeparameter wurden allerdings nicht bestimmt. Randomisierte kontrollierte
Studien mit antioxidativen Vitaminen zur Behandlung der Multiplen Sklerose existieren nicht. Auch für andere Substanzen mit antioxidativer Wirkung wie Alphaliponsäure, Selen, Coenzym Q Traubenkernöl und Kieferbaumrinde existieren keine kontrollierten randomisierten Studien bei Patienten mit Multipler Sklerose. Die Supplementierung wird deshalb nicht empfohlen.

\subsubsection{Vitamin $B_{12}$}

\section{Empfehlung 73:}

Eine Supplementierung mit Vitamin $\mathrm{B}_{12}$ kann bei Patienten mit Multipler Sklerose nicht generell empfohlen werden. [C (BM); starker Konsens]

Kommentar: Vitamin $\mathrm{B}_{12}$ spielt eine Schlüsselrolle bei der Myelinbildung und hat immunmodulatorische Effekte. In einer randomisierten kontrollierten Studie [244] erhielten sowohl die Patienten der Behandlungs- als auch die Patienten der Kontrollgruppe $1000 \mu \mathrm{g}$ Vitamin $\mathrm{B}_{12}$ täglich. Die Behandlungsgruppe erhielt zusätzlich Lofepramin und L-Phenylalanin. Bei beiden Gruppen kam es zu einer Verbesserung von 2 Punkten in der Guy's Neurological Disability Scale (GNDS). Die Wirkung von Vitamin $\mathrm{B}_{12}$ kann bei dieser Studie nicht ausreichend beurteilt werden, da keine Kontrollgruppe ohne Vitamin- $B_{12}$-Therapie existiert. Wegen fehlender Evidenz wird deshalb eine generelle Substituierung mit Vitamin $B_{12}$ nicht empfohlen.

\subsubsection{Glutenfreie Kost, allergenarme Kost}

\section{Empfehlung 74:}

Eine glutenfreie Kost zur Behandlung der Multiplen Sklerose kann nicht empfohlen werden.

[C; starker Konsens]

Kommentar: In Regionen mit hohen Prävalenzen von Multipler Sklerose werden mehr Milch und mehr glutenhaltige Nahrungsmittel konsumiert [245, 246]. Es wird postuliert, dass eine kryptogene Glutenunverträglichkeit mit Multipler Sklerose assoziiert sein könnte [247].

In einer Fallkontrollstudie [248] mit allergenarmer Diät wurden nur Laborparameter, aber keine klinischen Outcomeparameter untersucht. In einer nicht kontrollierten Studie wurde der Einfluss allergenarmer Kost auf den Verlauf von Multipler Sklerose untersucht [249]. Eine Kohortenstudie [250] untersuchte den Einfluss von Kuhmilchallergie auf das Risiko einer späteren Entstehung einer Multiplen Sklerose. Eine Kuhmilchallergie im Kindesalter war kein Risikofaktor für die Entstehung einer Multiplen Sklerose im Erwachsenenalter. Es existieren keine randomisierten kontrollierten Interventionsstudien mit kuhmilchfreier Ernährung bei Patienten mit Multipler Sklerose.

\subsubsection{Haben diätetische Interventionen einen Einfluss auf die Lebensqualität von Patienten mit Multipler Sklerose?}

\section{Empfehlung 75:}

Eine Supplementierung mit Eicosapentaensäure (EPA) und Docosahexaensäure in Kombination mit einer fettreduzierten Kost kann nicht zur Verbesserung der Lebensqualität bei Patienten mit Multipler Sklerose empfohlen werden.

[C (QL); Konsens] 
Kommentar: Es existieren mehrere validierte Instrumente zur Beurteilung der Health Related Quality of Life (HRQOL). Ein Instrument ist der Short-Form Health Survey Questionaire (SF36). Dieser enthält 36 Fragen aus 8 Bereichen und misst die generelle HRQOL. Der MSQOL-45 [251] beurteilt gezielt die Lebensqualität von Patienten mit Multipler Sklerose. Die Modified Fatigue Impact Scale (MFIS) wurde entwickelt um den Einfluss von Müdigkeit auf die täglichen Aktivitäten von Patienten mit Multipler Sklerose zu beurteilen. Höhere Werte in dieser Skala sprechen für eine stärkere Wahrnehmung von Müdigkeit durch die Patienten [252]. Das Mental Health Inventory (MHI) misst die generelle Stimmung und deckt dabei ein weiteres Spektrum von positiven und negativen Emotionen ab.

Es existiert eine einzige randomisierte kontrollierte Studie, in der die Lebensqualität von Patienten mit Multipler Sklerose als Outcomeparameter verwendet wird. In der Studie von WeinstockGuttman [230] (Ib) wurden die Physical Component Scale des SF-36, die MFIS und das MHI zum Zeitpunkt des Einschlusses in die Studie sowie nach 1, 6 und nach 12 Monaten erhoben. In die Studie wurden 31 Patienten mit schubförmig-remittierendem Verlauf eingeschlossen. Die Interventionsgruppe erhielt $1,98 \mathrm{~g}$ Eicosapentaensäure (EPA) und 1,32 g Docosahexaensäure täglich. Es wurde eine stark fettreduzierte Diät ( $<15 \%$ der täglichen Kalorienaufnahme in Form von Fett, einschließlich der Supplemente) empfohlen. Die Kontrollgruppe erhielt 6 Kapseln Olivenöl täglich und die Empfehlung, $<30 \%$ der Kalorien in Form von Fett und weniger als $10 \%$ in Form gesättigter Fettsäuren aufzunehmen. Beide Gruppen erhielten folgende Supplemente: 400 IE Vitamin D, 1 Tablette eines Multivitaminpräparates und mindestens $500 \mathrm{mg}$ Kalzium täglich. In der Interventionsgruppe zeigte sich eine geringfügige Verbesserung in der Physical Component Scale des SF-36 nach 6 Monaten. Nach 12 Monaten war dieser Effekt nicht mehr nachweisbar. In der MFIS zeigte sich nach 6 Monaten ein signifikanter Vorteil in der Kontrollgruppe. Nach 12 Monaten erreichte der Unterschied nicht mehr das Signifikanzniveau. Die Zahl der in die Studie eingeschlossenen Patienten $(n=31)$ war sehr gering.

Da der Effekt der Supplementation auf die Lebensqualität gering war und die Kontrollgruppe über weniger Müdigkeit klagte, wird die Supplementierung mit Eicosapentaensäure (EPA) und Docosahexaensäure in Kombination mit einer fettreduzierten Diät nicht zur Verbesserung der Lebensqualität von Patienten mit Multipler Sklerose empfohlen.

\section{Interessenkonflikt}

Gemäß den AWMF-Richtlinien wurden die bestehenden potenziellen Interessenkonflikte zu Beginn der Leitlinienarbeit von allen Autoren bzw. Arbeitsgruppenmitgliedern dargelegt. Die Autoren/Arbeitsgruppenmitglieder haben bei folgenden Punkten entsprechende Angaben gemacht:

Berater- bzw. Gutachtertätigkeit oder Mitglied eines wissenschaftlichen Beirats eines Unternehmens: R. Dziewas, J. Kesselring, S. C. Bischoff, H. Lochs, J. Ockenga, C. Sieber

Vortragshonorare von Unternehmen: R. Wirth, R. Dziewas, R. Beer, E. W. Busch, S. C. Bischoff, H. Lochs, A. Weimann, M. Adolph, J. Ockenga, C. Sieber

Finanzielle Zuwendungen für Forschungsvorhaben vonseiten eines Unternehmens: R. Wirth, R. Beer, E. W. Busch, S. C. Bischoff, A. Weimann, C. Sieber

Eigentümerinteresse an Arzneimitteln/Medizinprodukten: R. Dziewas

Die anderen Autoren haben keinen Interessenkonflikt.

Einzelheiten sind im Leitlinienreport des Leitlinien Updates Klinische Ernährung, der über die Internetseite der AWMF abrufbar ist, hinterlegt.

\section{Hinweis \\ $\nabla$}

Die Tabelle 1c wurde korrigiert.

Institute

${ }^{1}$ St. Marien-Hospital Borken GmbH, Klinik für Geriatrie, Borken, Deutschland 2 Universitätsklinikum Münster, Klinik und Poliklinik für Neurologie, Münster, Deutschland

${ }^{3}$ St. Vinzenz-Hospital Dinslaken, Dinslaken, Deutschland

${ }^{4}$ St. Marien-Hospital Borken GmbH, Ernährungsteam, Borken, Deutschland

${ }^{5}$ Universität Hohenheim, Institut für Ernährungsmedizin, Stuttgart, Deutschland

${ }^{6}$ Alexianer Krefeld GmbH, Klinik für Allgemeine Innere Medizin und Altersmedizin, Krefeld, Deutschland 
Evidenztabelle 1a Screening und Assessment bei Schlaganfallpatienten mit Dysphagie.

\begin{tabular}{|c|c|c|c|}
\hline Referenz & Evidenzgrad & Studientyp & Charakteristika der Studienpopulation \\
\hline $\begin{array}{l}\text { Sellars et al. } \\
2007 \text { [24] }\end{array}$ & III & $\begin{array}{l}\text { Beobach- } \\
\text { tungsstudie }\end{array}$ & $\begin{array}{l}\mathrm{n}=412 \text { konsekutive Patienten mit akutem Schlag- } \\
\text { anfall ( } 94,9 \% \text { mit ischämischem Schlaganfall und } \\
5,1 \% \text { mit hämorrhagischem Schlaganfall) } \\
\text { Einschlusskriterien: Patienten mit erstmaligem } \\
\text { oder wiederholtem ischämischen oder hämor- } \\
\text { rhagischen Schlaganfall innerhalb der ersten } \\
7 \text { Tage nach Aufnahme ins Krankenhaus } \\
\text { Ausschlusskriterien: Patienten, welche nach weite- } \\
\text { ren Untersuchungen eine andere Diagnose hatten } \\
\text { als Schlaganfall }\end{array}$ \\
\hline $\begin{array}{l}\text { Lakshminarayan } \\
\text { et al. } 2010 \text { [25] }\end{array}$ & III & $\begin{array}{l}\text { Beobach- } \\
\text { tungsstudie }\end{array}$ & $\begin{array}{l}\mathrm{n}=18017 \text { Patienten mit ischämischen oder hä- } \\
\text { morrhagischem Schlaganfall, Alter } \geq 18 \text { Jahre } \\
\text { Ausschlusskriterien: Patienten, die während des } \\
\text { Krankenhausaufenthaltes keine orale Nahrungs- } \\
\text { aufnahme erhielten; Patienten, die einen doku- } \\
\text { mentierten Grund aufwiesen sich keiner Dyspha- } \\
\text { gieuntersuchung vor der oralen Nahrungsaufnah- } \\
\text { me zu unterziehen (z. B. Intubation); Patienten, } \\
\text { deren Krankenhausaufenthaltsdauer } \leq 2 \text { Tage und } \\
>120 \text { Tage war }\end{array}$ \\
\hline
\end{tabular}

$\mathrm{n}=2532$ Patienten $>18$ Jahre mit einem akuten

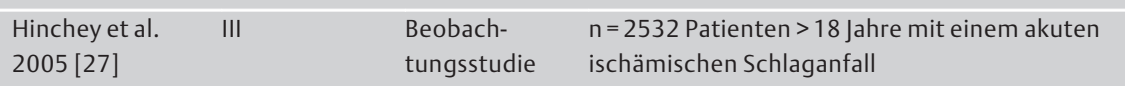

\section{$2005[27$}

tungsstudie

Dziewas et al. III $\quad \begin{aligned} & \text { Beobach- } \\ & \text { tungsstudie }\end{aligned}$
$2004[43]$

$\mathrm{n}=100$ konsekutive Patienten mit akutem Schlag-

Diese prospektive Kohortenstudie zeigt, dass die Implementierung einer systematischen Dysphagieuntersu-
Beobach-
tungsstudie anfall, die wegen Dysphagie Sondennahrung erhielten

Ausschlusskriterien: Zeit zwischen Auftreten des Schlaganfalls und Krankenhausaufnahme: $>24$ Stunden; orale Nahrungsaufnahme von Tag 0 an; Koma bei der Aufnahme; endotracheale Intubation bei Aufnahme

\section{Outcomeparameter}

Empfindlichkeit, Spezifität OR für die Baseline-

Charakteristika; Risiko, eine Pneumonie nach den Mann-Kriterien zu entwickeln. Spezifït eine Pneumoniezuentwickeln $90,9 \%$ bzw. $75,6 \%$ Diese prospektive Beobachtungsstudie zeigt, dass ein Versagen im Wasserschlucktest ein unabhängiges Anzeichen dafür ist, eine Pneumonie zu entwickeln. Abgesehen vom fehlgeschlagenen Wasserschlucktest und anderen

klinischen Variablen, sind Aphasie und Dysarthrie verbunden mit dem Auftreten von Pneumonie.

Pneumonie (definiert als eine dokumentierte nosokomiale Pneumonie, die mindestens $\geq 48$ Stunden nach Krankenhausaufnahme auftrat und mit Antibiotika behandelt wurde)

\section{Ergebnisse}

Unabhängige Prädiktoren einer Pneumonie waren: Alter >65 Jahre, Dysarthrie oder keine Sprache wegen Aphasie, mRS $\geq$ 4, AMTS $<8$ und Versagen im Wasserschlucktest. Lagen 2 $90,9 \%$ bzw. $75,6 \%$.

(n)
Hauptergebnis der Studie ist, dass das Unterlassen der Dysphagieuntersuchung bei akutem Schlaganfall das Risiko einer späten Pneumonie erhöht.

Durchführung eines Screenings für Dysphagie, Art Bei Patienten mit mittlerem Schlaganfallschweregrad (5 vs. der Untersuchung und Entwicklung der Pneumo- $\quad 4 ; p=0,84$ ) gab es keinen Unterschied, ob ein formales Dysnie im Krankenhaus les Dysphagiescreening verhinderte Pneumonie selbst nach Anpassung des Schlaganfallschweregrads. chung mit einer Risikoreduzierung für Pneumonie assoziiert ist.

intermediäre Endpunkte: Pneumonie und künst-

liche Beatmung

Bei $44 \%$ der Patienten mit Sondennahrung wurde eine Pneumonie diagnostiziert. Die meisten Patienten bekamen die Pneumonie am 2. oder 3. Tag nach Auftreten des Schlaganfalls. Patienten mit Pneumonie benötigten häufiger eine endotracheale Intubation und mechanische Beatmung als Patienten ohne Pneumonie. Unabhängige Prädiktoren für die Ausprägung der Pneumonie waren: ein vermindertes Bewusstsein und schwere Gesichtslähmungen. Der NIH-SS-

Score bei Aufnahme war der einzige unabhängige Prädiktor für ein schlechtes Outcome.

In dieser Kohorte dysphagischer Schlaganfallpatienten sind ein vermindertes Bewusstsein und schwere Gesichtslähmungen unabhängig assoziiert mit dem Auftreten von Pneumonie. 


\begin{tabular}{|c|c|c|c|}
\hline Referenz & Evidenzgrad & Studientyp & Charakteristika der Studienpopulation \\
\hline $\begin{array}{l}\text { Falsetti et al. } \\
2009 \text { [44] }\end{array}$ & III & $\begin{array}{l}\text { Beobach- } \\
\text { tungsstudie }\end{array}$ & $\begin{array}{l}\text { n=151 konsekutive Krankenhauspatienten mit } \\
\text { kürzlich eingetretenem ischämischem oder hä- } \\
\text { morrhagischem Schlaganfall } \\
\text { Ausschlusskriterien: Patienten, die in der Vergan- } \\
\text { genheit Hals- und Kopfverletzungen und/oder } \\
\text { andere neurologische Erkrankungen wie zerebro- } \\
\text { vaskuläre Störungen aufwiesen; Patienten mit } \\
\text { bestehender Dysphagie }\end{array}$ \\
\hline $\begin{array}{l}\text { Logemann et al. } \\
1999 \text { [45] }\end{array}$ & III & $\begin{array}{l}\text { Beobach- } \\
\text { tungsstudie }\end{array}$ & $\begin{array}{l}\mathrm{n}=200 \text { (51 Patienten mit einem Schlaganfall, } \\
18 \text { Patienten mit mehreren Schlaganfällen, } 26 \text { Pa- } \\
\text { tienten mit Kopf-Hals-Tumoren, } 21 \text { Patienten mit } \\
\text { Rückenmarksverletzung, } 84 \text { Patienten mit ande- } \\
\text { ren Erkrankungen) }\end{array}$ \\
\hline $\begin{array}{l}\text { Dziewas et al. } \\
2008 \text { [52] }\end{array}$ & III & $\begin{array}{l}\text { Beobach- } \\
\text { tungsstudie }\end{array}$ & $\begin{array}{l}\mathrm{n}=100 \text { Patienten mit akutem Schlaganfall, be- } \\
\text { wertet mit FEES innerhalb } 72 \text { Stunden nach Auf- } \\
\text { nahme. } \\
\text { Ausschlusskriterien: mehrfaches vermindertes Be- } \\
\text { wusstsein und instabiler medizinischer Zustand, } \\
\text { wie Pneumonie oder hydropische Herzdekom- } \\
\text { pensation }\end{array}$ \\
\hline $\begin{array}{l}\text { Warnecke et al. } \\
2009 \text { [50] }\end{array}$ & III & $\begin{array}{l}\text { Beobach- } \\
\text { tungsstudie }\end{array}$ & $\begin{array}{l}\mathrm{n}=153 \text { erster konsekutiver akuter Schlaganfall } \\
\text { bewertet durch FEES innerhalb } 72 \text { Stunden nach } \\
\text { Aufnahme } \\
\text { Ausschlusskriterien: eine Vorgeschichte mit bereits } \\
\text { vorhandener Dysphagie oder anderen Erkrankun- } \\
\text { gen, die möglicherweise Dysphagie verursachen; } \\
\text { eine verminderte Wahrnehmung (z. B. Stupor } \\
\text { oder Koma); endotracheale Intubation }\end{array}$ \\
\hline
\end{tabular}

\section{Outcomeparameter}

Definition der Inzidenz von Dysphagie, Vergleich eines klinischen patientennahen Assessments mit VFS, Definition jeglicher Korrelationen zwischen Dysphagie und klinischen Charakteristika der $\mathrm{Pa}$ tienten.

Diese Studie zeigt, dass einige klinische Variablen mit Dysphagie verbunden sind. Unter anderem wurden Dysarthrie und Aphasie vom Autor identifiziert.

Sensitivität und Spezifität einer 28-Itemliste zur Verschiedene Gruppierungen klinischer Variablen beein-

Erfassung der Atmung, Störung der oralen Phase, flussten die 4 Hauptzielgrößen. Die Sensitivität und Spezifipharyngealen Verzögerung oder Störung der pha- tät war in den meisten Fällen ca. $70 \%$. ryngealen Phase.

Diese Studie zeigt, dass verschiedene klinische Variablen herangezogen werden müssen, um verschiedene Aspekte der Dysphagie zu erfassen.

Penetration und Atmung verschiedener Texturen Die Speichelaspiration war ein starkes Anzeichen für spätere wurden bei akuten Schlaganfallpatienten mit FEES orotracheale Intubation. Die Interraterreliabilität war groß. bewertet. Auf Grundlage dieser Ergebnisse wurde

ein endoskopischer Dysphagiescore entwickelt.

Die Interraterreliabilität wurde eingestuft.

Diese Studie schlägt einen endoskopischen Dysphagiescore vor, der mit den wichtigsten Erkenntnissen des FEES für protektive und rehabilitative Maßnahmen verbunden ist.

Intermediäre Endpunkte waren Pneumonie und Der FEDSS kann den mRS in 3 Monaten genauso gut vorherendotracheale Intubation. Funktionelles Outcome sagen, aber unabhängig vom NIH-SS-Score. Für jeden zusätzwurde mittels mRS nach 3 Monaten gemessen.

lichen Punkt des FEDSS war die Abhängigkeitswahrscheinlichkeit in 3 Monaten ( $\mathrm{mRS} \geq 3$ ) um 50\% gestiegen. Jeder Anstieg um 1 Punkt im FEDSS bewirkte mehr als den 2-fachen Anstieg der Wahrscheinlichkeit, eine Pneumonie zu entwickeln. Die Wahrscheinlichkeit einer notwendigen endotrachealen Intubation stieg fast um den 2,5-fachen Faktor mit jedem zusätzlichen Punkt im FEDSS.

Diese Studie zeigt, dass die endoskopische Einstufung von Dysphagie eng mit den Patientenergebnissen und hinzukommenden Komplikationen verbunden ist. Der FEES und die VFS wurden simultan aufge-

zeichnet. Fünfzehn Sprachtherapeuten stuften die pharyngealen Residuen als nicht vorhanden,

Einschlusskriterien: Ubberweisung an einen oder hohes Risiko der Aspiration
Inter- und Intraraterreliabilität waren für beide Untersuchungen gleich. Es gab signifikante Unterschiede zwischen FEES und dem VFS pharyngeal residue Severity-Score (Varianz, $p<0,001)$. Der FEES residue Score war durchweg höher als der VFS residue Score. Untersuchungen wurden 2-mal von allen bewertet. 


\section{Evidenztabelle 1a (Fortsetzung)}

\begin{tabular}{|c|c|c|c|}
\hline Referenz & Evidenzgrad & Studientyp & Charakteristika der Studienpopulation \\
\hline $\begin{array}{l}\text { Kelly et al. } 2007 \\
\text { [57] }\end{array}$ & III & $\begin{array}{l}\text { Beobach- } \\
\text { tungsstudie }\end{array}$ & $\begin{array}{l}\mathrm{n}=15 \text { Dysphagiepatienten } \\
\text { Ausschlusskriterien: keine orale Aufnahme möglich } \\
\text { oder hohes Risiko der Aspiration bei oraler Auf- } \\
\text { nahme }\end{array}$ \\
\hline
\end{tabular}

\section{Outcomeparameter}

Penetration und Aspiration wurden eingestuft, indem die Penetration Aspiration Skala verwendet wurde.

Intrarater-Reliabilität wurden durch den kappa-Wert festgestellt.

\section{Ergebnisse}

Der Penetration-Aspiration-Skala-Score war signifikant höher für die FEES- als für die VFS-Aufzeichnungen (Varianz $p<0,001)$. Der Hauptunterschied zwischen den FEES- und den VFS-Penetration-Aspiration-Werten für die gleichen Schlucke betrug 1,15 Punkte. Die Interrater- und IntraraterReliabilität reichte von 0,64-0,79 (kappa-Wert). Penetration und Aspiration wurden vom FEES besser erkannt als von der VFS.

Um Penetration und Aspiration zu erkennen, scheint FEES sensitiver zu sein als VFS.

\begin{tabular}{|c|c|c|c|}
\hline $\begin{array}{l}\text { Smithard et al. } \\
1997 \text { [58] }\end{array}$ & III & $\begin{array}{l}\text { Beobach- } \\
\text { tungsstudie }\end{array}$ & $\begin{array}{l}\mathrm{n}=121 \text { konsekutive akute Schlaganfallpatienten } \\
\text { Ausschlusskriterien: } \\
\text { Aufnahme später als } 24 \text { Stunden nach Eintritt des }\end{array}$ \\
\hline
\end{tabular}

spater als 24 Stunden nach Eintritt des Häufigkeit der Dysphagie zu verschiedenen Zeit-
punkten nach dem akuten Schlaganfall (klinische Beurteilung und VFS)

Klinisch wurden $51 \%$ der Patienten eingestuft, ein Aspirationsrisiko bei Aufnahme zu haben. Während den ersten 7 Tage sank diese Zahl auf $27 \%$ der Patienten. Nach 6 Monaten hatten noch $6,8 \%$ eine Dysphagie, außerdem wurden be 2,3\% Schluckbeschwerden beobachtet.

Obwohl die schlaganfallbedingte Dsyphagie bei einer großen Anzahl der Patienten während der ersten 5 Tage zurückgeht, leiden manche Patienten noch nach Monaten nach dem Schlaganfall an Schluckbeschwerden.

Carnaby et al. Ib randomisiert, $n=306$ Patienten mit klinischer Dysphagie, die mit $2006[60]$ kontrolliert

akutem Schlaganfall ins Krankenhaus eingeliefert wurden

$\rightarrow \mathrm{n}=102$ erhielten eine normale Pflege (verordnet vom behandelnden Arzt)

$\rightarrow \mathrm{n}=102$ erhielten eine standardisierte Intervention mit niedriger Intensität (einschließlich

Schluckübungen und Diätverordnungen, 3-mal wöchentlich für 1 Monat)

$\rightarrow \mathrm{n}=102$ erhielten eine standardisierte Intervention mit hoher Intensität (einschließlich Schluckübungen und Diätverordnungen, täglich für $1 \mathrm{Mo}$ nat) primärer Zielparameter war das Überleben unter

normaler Ernährung nach 6 Monaten

60 Patienten starben der 6-Monats-Analyse. Von den Patienten, die die normale Pflege erhielten, lebten $56 \%$ (57/102) nach 6 Monaten ohne besondere Ernährungsform, verglichen mit 67 \% (136/204) in der Gruppe mit standardisierter Schlucktherapie (relatives Risiko 1-19, $95 \%$-KI 0,98-1,45). Die standardisierte Schlucktherapie war verbunden mit einem nicht signifikanten Trend zu einer Verminderung der Todesfälle $(0,80 ; 0,5$ $1,3)$, der Krankenhauseinweisung $(0,69 ; 0,4-1,1)$ und de Abhängigkeit (1,05; 0,8 - 1,3); mit einer signifikanten Reduktion der mit dem Schlucken in Zusammenhang stehenden Komplikationen $(0,73 ; 0,6-0,9)$, Brustinfektionen

$(0,56 ; 0,4-0,8)$ und Tod oder Einweisung $(0,73 ; 0,55-0,97)$ signifikanter Anstieg des Anteils von Patienten, die die Schluckfunktion nach 6 Monaten wiedererlangten $(1,41$; $1,03-1,94)$; verglichen mit der normalen Pflege und der Intervention mit niedriger Intensität war die Intervention mit hoher Intensität einer größeren Anzahl an Patienten verbunden, die wieder zu einer normalen Ernährungsform zurückkehrten $(p=0,04)$ und die die Schluckfähigkeit wiedergewannen.

Diese Daten zeigen einen stetigen Trend zu einem günstigeren Outcome bei dysphagischen Schlaganfallpatienten, welche ein Standardprogramm zur frühen Therapie des Schluckverhaltens bekommen.

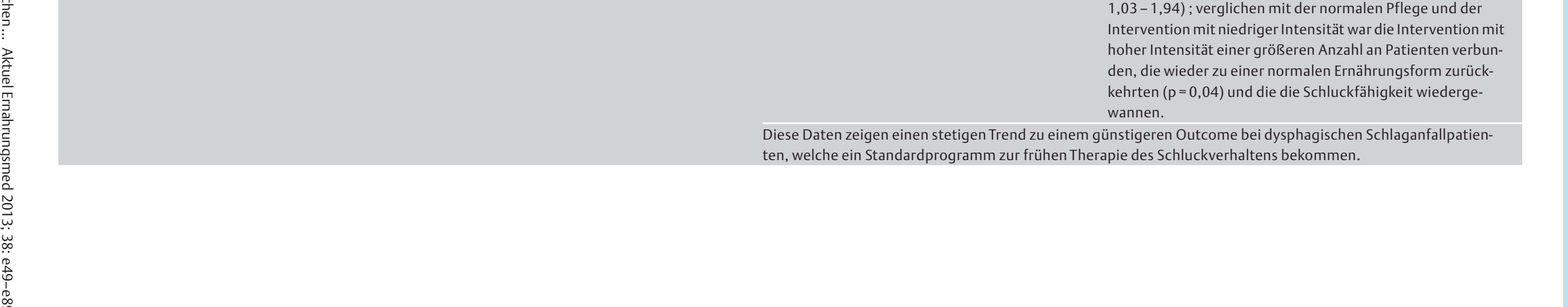




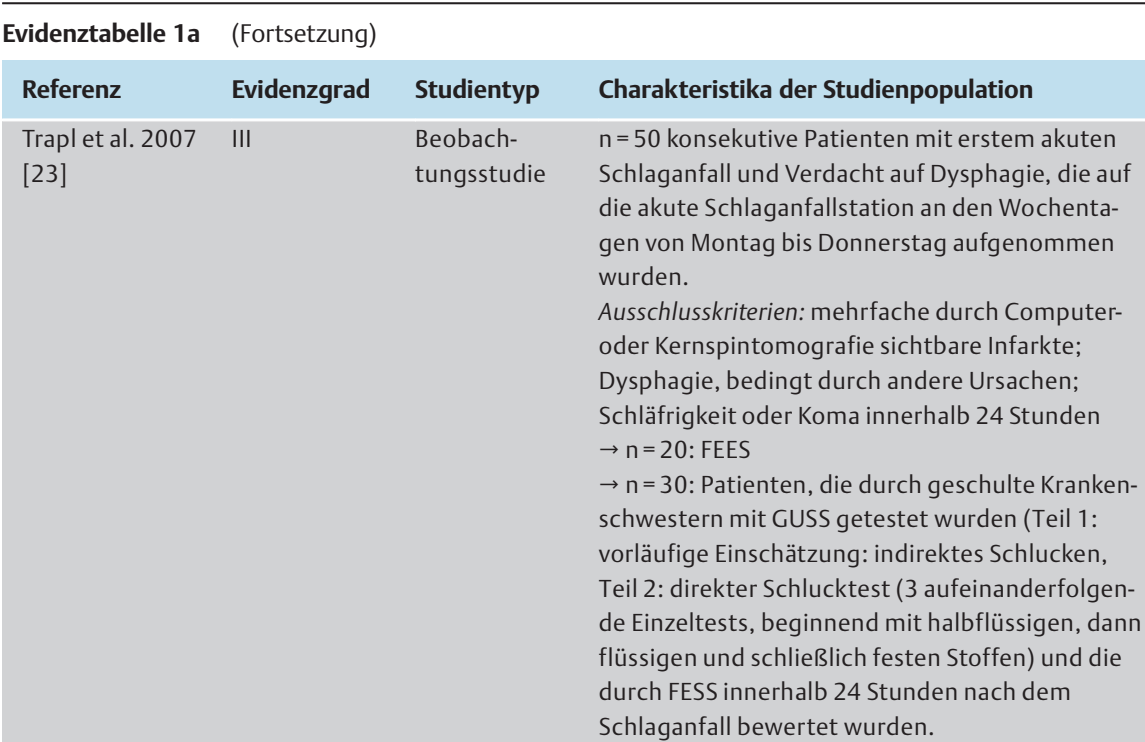

\section{Outcomeparamete}

Die GUSS-Ergebnisse wurden mit den FEES-Ergebnissen hinsichtlich des Aspirationsrisikos verglichen.

\section{Ergebnisse}

Die Inhaltsvalidität zeigte ein signifikant höheres Aspirationsrisiko mit Flüssigkeiten verglichen mit halbflüssigen Stoffen ( $p=0,001)$, was der 2 . Teil des GUSS-Tests bestätigte. GUSS bietet eine schnelle und verlässliche Methode, um

Schlaganfallpatienten mit Dysphagie und Aspirationsrisiko zu identifizieren.

Diese Studie zeigt, dass das Testen von verschiedenen Konsistenzen und Flüssigkeiten im Vergleich zum FEES zu einer hohen Sensitivität führt. Die Methode, die im GUSS-Protokoll beschrieben wird, ermöglicht eine frühe Entscheidung, wie die Patienten ernährt werden sollten.

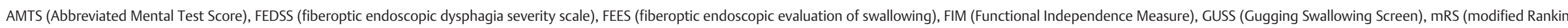
Scale), NIH-SS (National Institutes of Health stroke scale), OR (Odds Ratio), VFS (videofluoroscopy)

\begin{tabular}{|c|c|c|c|c|c|c|c|c|c|c|}
\hline Evidenztabelle 1b & Sondene & hrung bei Schlaganf & all und Dysphagi & & & & & & & \\
\hline Studie & $\begin{array}{l}\text { Evidenz- } \\
\text { grad }\end{array}$ & Studiendesign & Erkrankung & n & Behandlungsarme & Outcome nach & $\begin{array}{l}\text { Outcomemorta- } \\
\text { lität }\end{array}$ & Signifikanz & $\begin{array}{l}\text { andere Outcomepara- } \\
\text { meter }\end{array}$ & Signifikanz \\
\hline $\begin{array}{l}\text { Norton et al. } \\
1996[87]\end{array}$ & Ib & $\begin{array}{l}\text { randomisiert, } \\
\text { kontrolliert }\end{array}$ & $\begin{array}{l}\text { persistierende } \\
\text { Dysphagie } \\
14 \text { Tage nach } \\
\text { Schlaganfall }\end{array}$ & $\begin{array}{l}16 \text { PEG; } \\
14 \text { NGT }\end{array}$ & $\begin{array}{l}\text { Sondenernährung via } \\
\text { PEG oder NGT }\end{array}$ & 6 Wochen & $\begin{array}{l}2(12 \%) \text { vs. } \\
8(57 \%)\end{array}$ & $<0,05$ & $\begin{array}{l}\text { Menge der applizierten } \\
\text { Sondenkost } \\
100 \text { vs. } 78 \%\end{array}$ & $<0,001$ \\
\hline $\begin{array}{l}\text { Dennis et al. } \\
2005 \text { (FOOD II) } \\
\text { [65] }\end{array}$ & $\mathrm{Ib}$ & $\begin{array}{l}\text { randomisiert, } \\
\text { kontrolliert }\end{array}$ & Schlaganfall & $\begin{array}{l}429 \text { frühe Son- } \\
\text { denernährung; } \\
430 \text { Sondener- } \\
\text { nährung vermei- } \\
\text { den }\end{array}$ & $\begin{array}{l}\text { früh (innerhalb von } 7 \\
\text { Tagen nach Schlag- } \\
\text { anfall) vs. späte (Ver- } \\
\text { meidung von) Son- } \\
\text { denernährung }\end{array}$ & 6 Monate & $\begin{array}{l}182(42 \%) \text { vs. } \\
207(48 \%)\end{array}$ & 0,09 & $\begin{array}{l}\text { Tod oder schlechtes Out- } \\
\text { come } \\
339(79 \%) \text { vs. } 344(80 \%)\end{array}$ & 0,7 \\
\hline $\begin{array}{l}\text { Dennis et al. } \\
2006 \text { (FOOD III) } \\
\text { [66] }\end{array}$ & $\mathrm{lb}$ & $\begin{array}{l}\text { randomisiert, } \\
\text { kontrolliert }\end{array}$ & Schlaganfall & $\begin{array}{l}162 \text { PEG; } \\
159 \text { NGT }\end{array}$ & PEG vs. NGT & 6 Monate & $\begin{array}{l}79(49 \%) \text { vs. } \\
76(48 \%)\end{array}$ & 0,9 & $\begin{array}{l}\text { Tod oder schlechtes Out- } \\
\text { come } \\
144(89 \%) \text { vs. } 129(81 \%)\end{array}$ & 0,05 \\
\hline $\begin{array}{l}\text { Nakajoh et al. } \\
2000[75]\end{array}$ & III & $\begin{array}{l}\text { Beobachtungs- } \\
\text { studie }\end{array}$ & Dysphagie & $\begin{array}{l}48 \text { orale Ernäh- } \\
\text { rung; } \\
52 \text { NGT }\end{array}$ & $\begin{array}{l}\text { orale Ernährung vs. } \\
\text { Sondenernährung }\end{array}$ & 12 Monate & nicht gemessen & & $\begin{array}{l}\text { Aspirationspneumonie } \\
54,3 \text { vs. } 13,2 \%\end{array}$ & $<0,001$ \\
\hline $\begin{array}{l}\text { Nyswonger et } \\
\text { al. } 1992 \text { [83] }\end{array}$ & III & $\begin{array}{l}\text { retrospektive Ko- } \\
\text { hortenstudie }\end{array}$ & Schlaganfall & $\begin{array}{l}20(<72 h) \\
32(>72 h)\end{array}$ & $\begin{array}{l}\text { Sondenernährung } \\
\text { innerhalb von } \\
<72 \text { h oder }>72 \mathrm{~h}\end{array}$ & $\begin{array}{l}\text { Krankenhaus- } \\
\text { entlassung }\end{array}$ & nicht gemessen & & $\begin{array}{l}\text { Krankenhausverweildauer } \\
20,14 \text { vs. 29,76 Tage }\end{array}$ & 0,036 \\
\hline
\end{tabular}




\begin{tabular}{|c|c|c|c|c|c|c|c|c|c|c|}
\hline \multirow{2}{*}{$\begin{array}{l}\text { Evidenztabelle 1b } \\
\text { Studie }\end{array}$} & \multicolumn{10}{|c|}{ (Fortsetzung) } \\
\hline & $\begin{array}{l}\text { Evidenz- } \\
\text { grad }\end{array}$ & Studiendesign & Erkrankung & n & Behandlungsarme & Outcome nach & $\begin{array}{l}\text { Outcomemorta- } \\
\text { lität }\end{array}$ & Signifikanz & $\begin{array}{l}\text { andere Outcomepara- } \\
\text { meter }\end{array}$ & Signifikanz \\
\hline $\begin{array}{l}\text { Park et al. } 1992 \\
\text { [82] }\end{array}$ & $\mathrm{Ib}$ & $\begin{array}{l}\text { randomisiert, } \\
\text { kontrolliert }\end{array}$ & $\begin{array}{l}\text { neurogene Dys- } \\
\text { phagie seit min- } \\
\text { destens } 4 \text { Wo- } \\
\text { chen }\end{array}$ & $\begin{array}{l}20 \text { NGT; } \\
20 \text { PEG }\end{array}$ & $\begin{array}{l}\text { Sondenernährung } \\
\text { über NGT oder PEG }\end{array}$ & 4 Wochen & $\begin{array}{l}1 \text { in jeder Gruppe } \\
\text { bevor Beginn der } \\
\text { Sondenernäh- } \\
\text { rung }\end{array}$ & & $\begin{array}{l}\text { Behandlungsabbruch } \\
18 / 19 \text { vs. } 0 / 19 ; \\
\text { Menge der applizierten } \\
\text { Sondenkost } 55 \text { vs. } 93 \%\end{array}$ & $<0,001$ \\
\hline $\begin{array}{l}\text { Kostadima et } \\
\text { al. } 2005 \text { [91] }\end{array}$ & $\mathrm{Ib}$ & $\begin{array}{l}\text { randomisiert, } \\
\text { kontrolliert }\end{array}$ & $\begin{array}{l}\text { künstliche Beat- } \\
\text { mung bei Schlag- } \\
\text { anfall ( } 61 \% \text { oder } \\
\text { Schädel-Hirn- } \\
\text { Trauma }\end{array}$ & $\begin{array}{l}20 \text { PEG; } \\
21 \text { NGT }\end{array}$ & $\begin{array}{l}\text { Sondenernährung via } \\
\text { NGT oder PEG (Anla- } \\
\text { ge innerhalb von } 24 \mathrm{~h} \\
\text { nach Intubation) }\end{array}$ & 3 Wochen & $\begin{array}{l}\text { keine Unter- } \\
\text { schiede }\end{array}$ & n.s. & $\begin{array}{l}\text { durch Beamtmung verur- } \\
\text { sachte Pneumonia } \\
2 / 16(12,5 \%) \text { vs. } \\
8 / 18(44,45 \%)\end{array}$ & 0,041 \\
\hline $\begin{array}{l}\text { Rhoney et al. } \\
2002 \text { [98] }\end{array}$ & III & $\begin{array}{l}\text { retrospektive Ko- } \\
\text { hortenstudie }\end{array}$ & $\begin{array}{l}\text { Schädel-Hirn- } \\
\text { Trauma }\end{array}$ & $\begin{array}{l}86 \text { Bolus; } \\
66 \text { kontinuierlich }\end{array}$ & $\begin{array}{l}\text { kontinuierliche vs. } \\
\text { Bolus-Ernährung }\end{array}$ & nicht bekannt & nicht analysiert & & $\begin{array}{l}\text { Intoleranz gegenüber } \\
\text { Sondenernährung } \\
\text { 60,5 vs.37,9\%; } \\
\text { Erreichen des Zufuhrziels } \\
\text { nach 4,6 vs. 3,3 Tagen }\end{array}$ & $\begin{array}{l}0,009 \\
0,03\end{array}$ \\
\hline $\begin{array}{l}\text { Baeten et al. } \\
1992[102]\end{array}$ & Ib & $\begin{array}{l}\text { randomisiert, } \\
\text { kontrolliert }\end{array}$ & $\begin{array}{l}\text { allgemeine Not- } \\
\text { wendigkeit von } \\
\text { Sondenernäh- } \\
\text { rung }\end{array}$ & $\begin{array}{l}46 \text { NGT; } \\
44 \text { PEG }\end{array}$ & $\begin{array}{l}\text { Ernährung über NGT } \\
\text { oder PEG }\end{array}$ & nicht bekannt & nicht analysiert & & $\begin{array}{l}\text { Aspiration } \\
6,5 \text { vs. } 6,5 \% \\
\text { Nausea, Dekubitus und } \\
\text { Dysphagie } \\
17 \text { vs. } 13 \%\end{array}$ & $<0,05$ \\
\hline $\begin{array}{l}\text { Huggins et al. } \\
1999 \text { [103] }\end{array}$ & $\mathrm{Ib}$ & $\begin{array}{l}\text { randomisiert, } \\
\text { kontrolliert }\end{array}$ & Gesunde & 10 & $\begin{array}{l}\text { keine NGT vs. } \\
\text { dünnlumige NGT vs. } \\
\text { dicklumige NGT }\end{array}$ & & nicht adäquat & & $\begin{array}{l}\text { NGT verlangsamt das Schlu- } \\
\text { cken ohne eigentliche } \\
\text { Schluckstörung }\end{array}$ & \\
\hline $\begin{array}{l}\text { Wang et al. } \\
2006[104]\end{array}$ & Ila & $\begin{array}{l}\text { prospektive Be- } \\
\text { obachtungsstu- } \\
\text { die vorher/nach- } \\
\text { her }\end{array}$ & $\begin{array}{l}\text { Schlaganfall mit } \\
\text { Dysphagie }\end{array}$ & 22 & $\begin{array}{l}\text { Transitzeit in VFES vor } \\
\text { und nach Sondenent- } \\
\text { fernung }\end{array}$ & $\begin{array}{l}20 \text { Tage nach } \\
\text { Schlaganfall }\end{array}$ & nicht adäquat & & $\begin{array}{l}\text { Transitzeit um } 0,2-0,6 \mathrm{~s} \\
\text { nicht signifikant verkürzt }\end{array}$ & $>0,05$ \\
\hline $\begin{array}{l}\text { Leder et al. } \\
2008[105]\end{array}$ & III & $\begin{array}{l}\text { Beobachtungs- } \\
\text { studie }\end{array}$ & $\begin{array}{l}\text { Zuweisung zur } \\
\text { Dysphagiediag- } \\
\text { nostik }\end{array}$ & $\begin{array}{l}\text { 1260; } \\
630 \text { NGT; } \\
630 \text { ohne NGT }\end{array}$ & $\begin{array}{l}\text { FEES bei NGT vs. } \\
\text { FEES ohne NGT }\end{array}$ & & nicht adäquat & & Aspiration & $>0,05$ \\
\hline $\begin{array}{l}\text { Dziewas et al. } \\
2008 \text { [52] }\end{array}$ & Ila & $\begin{array}{l}\text { prospektive Be- } \\
\text { obachtungsstu- } \\
\text { die vorher/nach- } \\
\text { her }\end{array}$ & $\begin{array}{l}\text { akuter Schlagan- } \\
\text { fall mit Dyspha- } \\
\text { gie und Sonden- } \\
\text { ernährung }\end{array}$ & 25 & $\begin{array}{l}\text { FEES mit und ohne } \\
\text { NGT }\end{array}$ & & nicht adäquat & & $\begin{array}{l}\text { Veränderung der Schluck- } \\
\text { funktion }\end{array}$ & $>0,05$ \\
\hline
\end{tabular}

FEES (fiberoptic endoscopic evaluation of swallowing), NGT (nasogastrale Sonde), PEG (perkutane endoskopische Gastrostomie), n. s. (nicht signifikant), VFES (videofluoroscopic examination of swallowing) 
Evidenztabelle 1c Ernährungstherapie bei Schlaganfallpatienten.

\begin{tabular}{|c|c|c|c|c|c|c|c|c|}
\hline Studie & $\begin{array}{l}\text { Evidenz- } \\
\text { grad }\end{array}$ & Studiendesign & Population & $\mathrm{n}^{*}$ & $\begin{array}{l}\text { Studienzeitpunkt/ } \\
\text { Studiendauer }\end{array}$ & Studienarme & Ergebnisse & $\begin{array}{l}\text { statistische } \\
\text { Signifikanz }\end{array}$ \\
\hline $\begin{array}{l}\text { Bhattacharyya et } \\
\text { al. } 2003 \text { [126] }\end{array}$ & III & $\begin{array}{l}\text { randomisiert, } \\
\text { nicht kontrolliert }\end{array}$ & $\begin{array}{l}\text { Patienten mit einseitiger } \\
\text { Stimmbandparalyse }\end{array}$ & 55 & Videofluoroskopie & $\begin{array}{l}\text { - flüssiger Bolus } \\
\text { - breiiger Bolus }\end{array}$ & $\begin{array}{l}\text { flüssiger Bolus: Penetration } 34,5 \% \text {, Aspiration } 20,0 \% \text {; } \\
\text { breiiger Bolus: Penetration 21,8\%, Aspiration 0\% }\end{array}$ & $p<0,001$ \\
\hline $\begin{array}{l}\text { Clave et al. } 2006 \\
\text { [128] }\end{array}$ & III & $\begin{array}{l}\text { kontrolliert, } \\
\text { nicht randomisiert }\end{array}$ & $\begin{array}{l}\text { Patienten mit GS oder } \\
\text { ND }\end{array}$ & 92 & Videofluoroskopie & $\begin{array}{l}\text { - flüssiger Bolus } \\
\text { - nektarartiger Bolus } \\
\text { - puddingartiger Bolus }\end{array}$ & $\begin{array}{l}\text { Aspiration GS: } 21,6 \% \text { flüssig, } 10,5 \% \text { nektarartig, } \\
\text { 5,3\% puddingartig; } \\
\text { Aspiration ND: } 16,2 \% \text { flüssig, } 8,3 \% \text { nektarartig, } \\
2,9 \% \text { puddingartig }\end{array}$ & $p<0,05$ \\
\hline $\begin{array}{l}\text { Dennis et al. } 2005 \\
\text { [66] }\end{array}$ & $\mathrm{lb}$ & $\begin{array}{l}\text { randomisiert, } \\
\text { kontrolliert }\end{array}$ & Schlaganfall & 4023 & $\begin{array}{l}\text { Krankenhausaufent- } \\
\text { halt }\end{array}$ & $\begin{array}{l}\text { - Krankenhauskost } \\
\text { - Krankenhauskost + } \\
\text { Trinknahrung }\end{array}$ & $\begin{array}{l}\text { Tod OR 0,94 (95\%-KI 0,78-1,13); } \\
\text { Tod oder schlechtes Outcome OR 1,03 }(0,91-1,17)\end{array}$ & $\begin{array}{l}\text { n.s. } \\
\text { n.s. }\end{array}$ \\
\hline $\begin{array}{l}\text { Diniz et al. } 2009 \\
\text { [125] }\end{array}$ & $\mathrm{Ib}$ & $\begin{array}{l}\text { randomisiert, } \\
\text { kontrolliert }\end{array}$ & Schlaganfall & 61 & $\begin{array}{l}\text { klinische oder endo- } \\
\text { skopische Beurteilung } \\
\text { des Schluckakts }\end{array}$ & $\begin{array}{l}\text { sondenernährte Patien- } \\
\text { ten erhielten zusätzlich } \\
\text { flüssige Nahrung oder } \\
\text { puddingartige Nahrung }\end{array}$ & $\begin{array}{l}\text { Aspirationsrisiko: } \\
3 \text { puddingartige vs. } 21 \text { flüssige Konsistenz (RR 0,13; } \\
95 \%-K I 0,04-0,39 \text { ) }\end{array}$ & $\mathrm{p}<0,001$ \\
\hline $\begin{array}{l}\text { Gariballa et al. } \\
1998[77]\end{array}$ & $\mathrm{lb}$ & $\begin{array}{l}\text { randomisiert, } \\
\text { kontrolliert }\end{array}$ & $\begin{array}{l}\text { Schlaganfallpatienten } \\
\text { mit Ernährungsrisiko }\end{array}$ & 40 & Wochen & $\begin{array}{l}\text { - Krankenhauskost } \\
\text { - Krankenhauskost + } \\
\text { Trinknahrung }\end{array}$ & $\begin{array}{l}\text { verbesserte Energiezufuhr (geschätzter } \\
\text { Behandlungseffekt } 723 \mathrm{kcal} / \mathrm{Tag}, 95 \%-K \mathrm{l} \text { 498-947); } \\
\text { verbesserte Proteinzufuhr (geschätzter } \\
\text { Behandlungseffekt } 21 \mathrm{~g} / \mathrm{Tag}, 95 \% \text {-KI 11,7-30,3); } \\
\text { Trend zu niedrigerer Mortalität }\end{array}$ & $\begin{array}{l}p<0,0001 \\
p<0,001 \\
\text { n.s. }\end{array}$ \\
\hline $\begin{array}{l}\text { Ha et al. } 2010 \\
\text { [119] }\end{array}$ & $\mathrm{lb}$ & $\begin{array}{l}\text { randomisiert, } \\
\text { kontrolliert }\end{array}$ & $\begin{array}{l}\text { Schlaganfallpatienten } \\
\text { mit Ernährungsrisiko }\end{array}$ & 124 & $\begin{array}{l}\text { während Kranken- } \\
\text { hausaufenthalt, } \\
\text { 3-monatiges Follow- } \\
\text { up }\end{array}$ & $\begin{array}{l}\text { - individualisierte Ernäh- } \\
\text { rungstherapie } \\
\text { - Routineversorgung }\end{array}$ & $\begin{array}{l}\text { geringerer Gewichtsverlust ( } 20,7 \text { vs. } 36,4 \% \text {; } \\
\text { verbesserte Lebensqualität; } \\
\text { verbesserte Handkraft }(2,3 \pm 3,7 \text { vs. }-0,3 \pm 4,9 \mathrm{~kg} \text { ); } \\
\text { Krankenhausaufenthaltsdauer ( } 12 \text { vs. } 13 \text { Tage) }\end{array}$ & $\begin{array}{l}\text { n. } s .(p=0,055) \\
p=0,012 \\
p=0,002 \\
\text { n.s. }\end{array}$ \\
\hline $\begin{array}{l}\text { Kuhlemeier et al. } \\
2001[127]\end{array}$ & III & $\begin{array}{l}\text { Beobachtungsstu- } \\
\text { die }\end{array}$ & $\begin{array}{l}\text { milde bis mittelschwere } \\
\text { Dysphagie }\end{array}$ & 190 & Videofluoroskopie & $\begin{array}{l}\text { Verabreichung mit Be- } \\
\text { cher oder Löffel: } \\
\text { dünne (Saft) vs. dicke } \\
\text { (Nektar) vs. ultradicke } \\
\text { Flüssigkeit (Pudding) }\end{array}$ & $\begin{array}{l}\text { Aspiration häufiger bei Verabreichung mit Becher als } \\
\text { mit Löffel; } \\
\text { Aspiration am häufigsten mit dünnen Flüssigkeiten, } \\
\text { gefolgt von dicken Flüssigkeiten, am seltensten mit } \\
\text { ultradicken Flüssigkeiten }\end{array}$ & $\begin{array}{l}p<0,001 \\
p=0,001\end{array}$ \\
\hline $\begin{array}{l}\text { Logemann et al. } \\
2008[129]\end{array}$ & IIb & $\begin{array}{l}\text { randomisiert, nicht } \\
\text { kontrolliert }\end{array}$ & $\begin{array}{l}\text { Verdacht auf Schluck- } \\
\text { störung }\end{array}$ & 711 & Videofluoroskopie & $\begin{array}{l}\text { Kinn-runter-Position vs. } \\
\text { keine besondere Posi- } \\
\text { tion während der Auf- } \\
\text { nahme von dünnen, } \\
\text { nektar- oder honigarti- } \\
\text { gen Flüssigkeiten }\end{array}$ & $\begin{array}{l}\text { Aspiration mit Kinn-runter Position: } \\
\text { dünn vs. nektarartig ( } 68 \text { vs. } 63 \%) \\
\text { dünn vs. honigartig ( } 68 \text { vs. } 53 \% \text { ) }\end{array}$ & $\begin{array}{l}p<0,001 \\
p<0,0001\end{array}$ \\
\hline $\begin{array}{l}\text { Milne et al. } 2009 \\
\text { [118] }\end{array}$ & la & Metaanalyse & $\begin{array}{l}\text { Senioren (Krankenhaus, } \\
\text { Pflegeheim, selbststän- } \\
\text { dig lebend) mit verschie- } \\
\text { denen Erkrankungen }\end{array}$ & 9187 & & $\begin{array}{l}\text { - Trinknahrung } \\
\text { - Placebo oder keine } \\
\text { Supplementation }\end{array}$ & $\begin{array}{l}\text { weniger Komplikationen bei Krankenhauspatienten } \\
\text { (OR 0,72; } 95 \% \text {-KI 0,53-0,97); } \\
\text { Reduktion der Mortalität bei unterernährten Kranken- } \\
\text { hauspatienten (OR 0,66; } 95 \% \text {-KI } 0,49-0,90 \text { ) }\end{array}$ & \\
\hline $\begin{array}{l}\text { Ozaki et al. } 2010 \\
\text { [130] }\end{array}$ & III & $\begin{array}{l}\text { Beobachtungsstu- } \\
\text { die }\end{array}$ & $\begin{array}{l}\text { Patienten mit Verdacht } \\
\text { auf Dysphagie }\end{array}$ & 229 & Videofluoroskopie & $\begin{array}{l}\text { Verabreichung von } 6 \\
\text { Proben in unterschiedli- } \\
\text { chen Konsistenzen und } \\
\text { Mengen }\end{array}$ & $\begin{array}{l}\text { Aspirationsrisiko bei Speisen mit Mischkonsistenzen } \\
\text { am höchsten ( } 58 \% \text { Mischkonsistenz vs. } 0 \% \text { mit pud- } \\
\text { dingartiger Konsistenz) }\end{array}$ & \\
\hline
\end{tabular}




\begin{tabular}{|c|c|c|c|c|c|c|c|c|}
\hline Evidenztabelle 1c & Fortsetzun & & & & & & & \\
\hline Studie & $\begin{array}{l}\text { Evidenz- } \\
\text { grad }\end{array}$ & Studiendesign & Population & $\mathbf{n}^{*}$ & $\begin{array}{l}\text { Studienzeitpunkt/ } \\
\text { Studiendauer }\end{array}$ & Studienarme & Ergebnisse & $\begin{array}{l}\text { statistische } \\
\text { Signifikanz }\end{array}$ \\
\hline $\begin{array}{l}\text { Rabadi et al. } 2008 \\
\text { [120] }\end{array}$ & $\mathrm{Ib}$ & $\begin{array}{l}\text { randomisiert, kon- } \\
\text { trolliert }\end{array}$ & $\begin{array}{l}\text { unterernährte Schlagan- } \\
\text { fallpatienten }\end{array}$ & 102 & $\begin{array}{l}\text { während der Rehabili- } \\
\text { tation }\end{array}$ & $\begin{array}{l}\text { - Standardtrinknahrung } \\
\text { (1 kcal/mL) } \\
\text { - hochkalorische Trink- } \\
\text { nahrung ( } 2 \mathrm{kcal} / \mathrm{mL})\end{array}$ & $\begin{array}{l}\text { verbesserter funktioneller Status in Gruppe mit hoch- } \\
\text { kalorischer Trinknahrung; } \\
\text { Test für funktionelle Unabhängigkeit ( } 31,49 \text { vs. } 22,94) \text {; } \\
\text { 2-Minuten-Gehtest ( } 101,60 \text { m vs. } 43,98 \text { m); } \\
\text { 6-Minuten-Gehtest ( } 299,28 \text { m vs. } 170,59 \text { m); } \\
\text { mehr Patienten kehrten nach Hause zurück: } 63 \text { vs. } 43 \%\end{array}$ & $\begin{array}{l}p<0,001 \\
p<0,001 \\
p<0,001 \\
p<0,05\end{array}$ \\
\hline $\begin{array}{l}\text { Stratton et al. } \\
2005[121]\end{array}$ & la & Metaanalyse & $\begin{array}{l}\text { Senioren, postoperativ, } \\
\text { Langzeitkrankenhaus- } \\
\text { patienten mit verschie- } \\
\text { denen Erkrankungen }\end{array}$ & 1224 & & $\begin{array}{l}\text { - Trinknahrung } \\
\text { - Routineversorgung }\end{array}$ & $\begin{array}{l}\text { geringere Inzidenz von Dekubiti bei Risikopatienten } \\
\text { mit Trinknahrung (OR 0,75; } 95 \% \text {-KI 0,62-0,89) }\end{array}$ & \\
\hline
\end{tabular}

GS (Gehirnschaden), n. s. (nicht signifikant), ND (neurodegenerative Erkrankung), OR (Odds Ratio); * Anzahl der Patienten, die die Studie beendet haben

\begin{tabular}{|c|c|c|c|c|c|c|c|c|c|}
\hline Referenz & Evidenzgrad & Studientyp & Studienpopulation & $n$ & $\begin{array}{l}\text { Studienarme: Interven- } \\
\text { tion/Kontrollgruppe }\end{array}$ & Studiendauer & Zielparameter & Ergebnisse & $\begin{array}{l}\text { statistische } \\
\text { Signifikanz }\end{array}$ \\
\hline $\begin{array}{l}\text { Lorefält et al. } \\
2006 \text { [141] }\end{array}$ & IIb & $\begin{array}{l}\text { longitudinal, } \\
\text { prospektiv }\end{array}$ & $\begin{array}{l}\text { Parkinsonpatienten } \\
\text { Kontrollgruppe }\end{array}$ & $\begin{array}{l}26 \\
26\end{array}$ & $\begin{array}{l}\text { Beobachtung, Vergleich } \\
\text { Mahlzeitenhäufigkeit }\end{array}$ & 2 Jahre & Essverhalten & $\begin{array}{l}\text { Verminderung Zwischenmahlzeiten } \\
\text { pro Tag } \\
\text { Parkinson: } 0,5 \pm 0,7 \text { auf } 0,3 \pm 0,3 \\
\text { Kontrolle: } 0,6 \pm 0,7 \text { auf } 0,7 \pm 0,9 \\
\text { Verminderung Hauptmahlzeiten pro Tag } \\
\text { Parkinson: } 0,8 \pm 0,3 \text { auf } 0,6 \pm 0,3 \\
\text { Kontrolle: } 0,9 \pm 0,2 \text { auf } 0,8 \pm 0,3\end{array}$ & $\begin{array}{l}\mathrm{p}<0,05 \\
\text { n.s. } \\
\text { p }<0,05 \\
\text { n.s. }\end{array}$ \\
\hline $\begin{array}{l}\text { Durrieu et al. } \\
1992 \text { [137] }\end{array}$ & III & $\begin{array}{l}\text { anthropometrische } \\
\text { Analyse }\end{array}$ & $\begin{array}{l}\text { Parkinsonpatienten } \\
\text { Kontrollgruppe }\end{array}$ & $\begin{array}{l}65 \\
68\end{array}$ & Vergleich Gewicht & 7 Tage & $\begin{array}{l}\text { Gewicht }[\mathrm{kg}] \\
\text { Wadenumfang } \\
{[\mathrm{cm}]}\end{array}$ & $\begin{array}{l}\text { Parkinson Frauen } n=28: 55,3 \pm 2,4 \mathrm{~kg} \\
\text { Kontrolle } n=38: 60,6 \pm 1,2 \mathrm{~kg} \\
\text { Parkinson Frauen } n=28: 33,9 \pm 0,6 \mathrm{~cm} \\
\text { Kontrollen } n=38: 35,2 \pm 0,6 \mathrm{~cm}\end{array}$ & $\begin{array}{l}p<0,05 \\
p<0,05\end{array}$ \\
\hline
\end{tabular}




\begin{tabular}{|c|c|c|c|c|c|c|c|c|c|}
\hline Referenz & Evidenzgrad & Studientyp & Studienpopulation & $\mathbf{n}$ & $\begin{array}{l}\text { Studienarme: Interven- } \\
\text { tion/Kontrollgruppe }\end{array}$ & Studiendauer & Zielparameter & Ergebnisse & $\begin{array}{l}\text { statistische } \\
\text { Signifikanz }\end{array}$ \\
\hline $\begin{array}{l}\text { Leow et al. } 2010 \\
{[170]}\end{array}$ & Ila & prospektiv & $\begin{array}{l}\text { Parkinsonpatienten } \\
\text { Kontrollgruppe }\end{array}$ & $\begin{array}{l}32 \\
32\end{array}$ & $\begin{array}{l}\text { Befragung, Vergleich } \\
\text { Lebensqualität }\end{array}$ & & $\begin{array}{l}\text { Lebensqualitäts- } \\
\text { score }\end{array}$ & $\begin{array}{l}\text { signifikante Differenz in SWAL-QOL-Sub- } \\
\text { sektionen außer Schlaf. } \\
\text { Nahrungsauswahl } \\
\text { Parkinson: } 76,6 ; \text { SD } 20,9 \\
\text { Kontrolle: } 97,7 \text {; SD } 6,98 \\
\text { Krankheitslast } \\
\text { Parkinson: } 71,9 ; \text { SD } 20,2 \\
\text { Kontrolle: } 98,4 \text {; SD } 6,3 \\
\text { Dauer der Mahlzeiten } \\
\text { Parkinson: } 71,1 ; \text { SD } 26,9 \\
\text { Kontrolle: } 94,5 ; \text { SD } 13,7\end{array}$ & $\begin{array}{l}p<0,002 \\
p<0,001 \\
p<0,005\end{array}$ \\
\hline $\begin{array}{l}\text { Markus et al. } \\
1993 \text { [135] }\end{array}$ & $11 \mathrm{~b}$ & $\begin{array}{l}\text { anthropometrische } \\
\text { Analyse }\end{array}$ & $\begin{array}{l}\text { Parkinsonpatienten } \\
\text { Kontrollgruppe aus } \\
\text { UK-Studie Gregory } \\
1990 \text { (Alter und Ge- } \\
\text { schlecht gematched) }\end{array}$ & 95 & Vergleich BMI & & BMI-Status & $\begin{array}{l}\text { Parkinson allgemein: } \\
23,0 \mathrm{~kg} / \mathrm{m}^{2} ; \text { SD } 3,0 \\
\text { Parkinson frühes Stadium: } \\
25,2 \mathrm{~kg} / \mathrm{m}^{2} ; \text { SD } 3,1 \\
\text { Parkinson spätes Stadium: } \\
21,3 \mathrm{~kg} / \mathrm{m}^{2} ; \text { SD } 3,2 \\
\text { Kontrolle: } 25,4 \mathrm{~kg} / \mathrm{m}^{2}\end{array}$ & $p<0,01$ \\
\hline $\begin{array}{l}\text { Wood et al. } \\
2010[148]\end{array}$ & la & Metaanalyse & $\begin{array}{l}148 \text { Artikel inkl. ran- } \\
\text { domisierter kontrol- } \\
\text { lierter Studien, Re- } \\
\text { views und Metaana- } \\
\text { lysen }\end{array}$ & & $\begin{array}{l}\text { Dysphagie, Komplika- } \\
\text { tionen, Therapieansät- } \\
\text { ze }\end{array}$ & $\begin{array}{l}\text { PubMed, } \\
\text { Medline } \\
1966-2010\end{array}$ & & $\begin{array}{l}\text { Dysphagie mit Pneumonie, Malnutrition, } \\
\text { Lebensqualität assoziiert; Zusammen- } \\
\text { hang zwischen Dauer Parkinson und Dys- } \\
\text { phagie kontrovers; Evaluation durch } \\
\text { Sprachtherapeuten und Behandlung in } \\
\text { multidisziplinärem Ansatz sinnvoll }\end{array}$ & \\
\hline $\begin{array}{l}\text { Cereda et al. } \\
2010[163]\end{array}$ & Ila & $\begin{array}{l}\text { Review } \\
\text { aus gut angelegten } \\
\text { Studien (nicht kon- } \\
\text { trolliert oder ran- } \\
\text { domisiert) }\end{array}$ & $\begin{array}{l}16 \text { aus } 28 \text { Artikeln } \\
\text { ausgewählt }\end{array}$ & & $\begin{array}{l}\text { Ergebnisse protein- } \\
\text { reduzierter Diäten } \\
\text { sowie Proteinredistri- } \\
\text { butionsdiäten }\end{array}$ & $\begin{array}{l}\text { Pubmed } \\
1973-2009\end{array}$ & & $\begin{array}{l}\text { proteinreduzierte Diät }<0,8 \mathrm{~g} \text { Protein } / \mathrm{kg} \\
\text { Idealgewicht/Tag nicht empfehlenswert } \\
\text { PRD bei Parkinson mit Fluktuationen und } \\
\text { L-Dopa sinnvoll }\end{array}$ & \\
\hline $\begin{array}{l}\text { Barichella et al. } \\
2009 \text { [143] }\end{array}$ & Ib & Review & $\begin{array}{l}8 \text { große nationale } \\
\text { prospektive Kohor- } \\
\text { tenstudien }\end{array}$ & & $\begin{array}{l}\text { Energie, Flüssigkeit, } \\
\text { Ballststoff- und Mikro- } \\
\text { nährstoffaufnahme }\end{array}$ & & & $\begin{array}{l}\text { wichtige Empfehlungen zu Ernährung } \\
\text { sowie weiteren Therapieansätzen bei } \\
\text { Parkinson, Interaktionen Nährstoffe } \\
\text { und Parkinsonmedikation }\end{array}$ & \\
\hline $\begin{array}{l}\text { Invernizzi et al. } \\
2009[156]\end{array}$ & Ib & Review & $\begin{array}{l}43 \text { Artikel inkl. rando- } \\
\text { misierter kontrollier- } \\
\text { ter Studien }\end{array}$ & & $\begin{array}{l}\text { Parkinson und Osteo- } \\
\text { porose }\end{array}$ & & & $\begin{array}{l}\text { Empfehlungen zu Osteoporosetherapie } \\
\text { und Sturzprävention }\end{array}$ & \\
\hline $\begin{array}{l}\text { Coates et al. } 1997 \\
{[149]}\end{array}$ & IIb & $\begin{array}{l}\text { anthropometrische } \\
\text { Analyse }\end{array}$ & $\begin{array}{l}\text { Parkinsonpatienten } \\
\text { Kontrollgruppe }\end{array}$ & $\begin{array}{l}48 \\
21\end{array}$ & $\begin{array}{l}\text { Vergleich BMI, Körper- } \\
\text { fett }\end{array}$ & & $\begin{array}{l}\text { BMI-Status; } \\
\text { Dysphagiepräva- } \\
\text { lenz bei Parkinson }\end{array}$ & $\begin{array}{l}\text { Parkinson: BMI: } 26,0 \pm 4,9 \mathrm{~kg} / \mathrm{m}^{2} \\
\text { Kontrollgruppe: BMI: } 27,6 \pm 4,2 \mathrm{~kg} / \mathrm{m}^{2} \\
\text { Parkinson: prozentuales Körperfett: } \\
24,3 \pm 7,8 \% \\
\text { Kontrollgruppe: prozentuales Körperfett: } \\
30,9 \pm 8,0 \% \\
\text { Dysphagieprävalenz: } 81 \%\end{array}$ & $\begin{array}{l}p<0,1 \\
p<0,004\end{array}$ \\
\hline
\end{tabular}

BMI (Body-Mass-Index), SD (Standardabweichung), SWAL QOL (dysphagia-specific quality of life), PRD (proteinreduzierte Diät) 


\begin{tabular}{|c|c|c|c|c|c|c|c|c|}
\hline Studie & Evidenzgrad & $\begin{array}{l}\text { Studienart und } \\
\text {-dauer }\end{array}$ & Population & n & Intervention & Kontrollgruppe & Zielparameter & Ergebnisse \\
\hline $\begin{array}{l}\text { Aziz et al. } 2008 \\
\text { [186] }\end{array}$ & IIb & $\begin{array}{l}\text { quasi-experimentell; } \\
3 \text { Jahre }\end{array}$ & $\begin{array}{l}\text { Patienten im Frühsta- } \\
\text { dium der Huntington- } \\
\text { krankheit }\end{array}$ & 517 & - & - & $\begin{array}{l}\text { Gewichtsverände- } \\
\text { rung }\end{array}$ & $\begin{array}{l}\text { Gewichtsverlust korreliert direkt mit CAG- } \\
\text { Repeat-Länge (je länger, desto größer der } \\
\text { Gewichtsverlust) }\end{array}$ \\
\hline $\begin{array}{l}\text { Djousse et al. } 2002 \\
\text { [185] }\end{array}$ & Ila & $\begin{array}{l}\text { kontrolliert, nicht } \\
\text { randomisiert }\end{array}$ & $\begin{array}{l}\text { Patienten mit einer } \\
\text { seit }<4 \text { Jahren beste- } \\
\text { henden Huntington- } \\
\text { krankheit }\end{array}$ & 361 & - & $\begin{array}{l}5 \text { geschlechts- und } \\
\text { altersgematchte ge- } \\
\text { sunde Kontrollperso- } \\
\text { nen pro Patient }\end{array}$ & BMI & $\begin{array}{l}\text { Huntingtonpatienten im Frühstadium haben } \\
\text { einen geringeren BMI als die Allgemeinbevöl- } \\
\text { kerung }\end{array}$ \\
\hline $\begin{array}{l}\text { Edmonds } 1966 \\
\text { [207] }\end{array}$ & Ila & $\begin{array}{l}\text { kontrolliert, nicht } \\
\text { randomisiert; } \\
15 \text { Jahre }\end{array}$ & $\begin{array}{l}\text { verstorbene Patien- } \\
\text { ten mit klinisch und } \\
\text { autoptisch diagnosti- } \\
\text { zierter Huntington- } \\
\text { krankheit }\end{array}$ & 14 & - & $\begin{array}{l}2 \text { verstorbene ge- } \\
\text { schlechts- und alters- } \\
\text { gematchte Demenz- } \\
\text { patienten pro Hun- } \\
\text { tingtonpatient }\end{array}$ & Todesursache & $\begin{array}{l}\text { Aspirationspneumonie infolge einer Dysphagie } \\
\text { ist die häufigste Todesursache }\end{array}$ \\
\hline $\begin{array}{l}\text { Gaba et al. } 2005 \\
\text { [197] }\end{array}$ & Ila & $\begin{array}{l}\text { kontrolliert, nicht } \\
\text { randomisiert; } \\
24 \text { Stunden pro } \\
\text { Studienteilnehmer }\end{array}$ & $\begin{array}{l}\text { Patienten im Frühsta- } \\
\text { dium der Huntington- } \\
\text { krankheit }\end{array}$ & 13 & - & $\begin{array}{l}9 \text { altersgematchte } \\
\text { gesunde Kontrollper- } \\
\text { sonen }\end{array}$ & 24-h-Energieumsatz & $\begin{array}{l}\text { der 24-h-Energieumsatz ist bei der Hunting- } \\
\text { tonkrankheit abhängig von der willkürlichen } \\
\text { und unwillkürlichen körperlichen Aktivität }\end{array}$ \\
\hline $\begin{array}{l}\text { Hamilton et al. } \\
2004[194]\end{array}$ & IIb & $\begin{array}{l}\text { quasi-experimentell, } \\
\text { durchschnittlich; } \\
\text { 3,4 Jahre pro Patient }\end{array}$ & $\begin{array}{l}\text { Patienten mit Hun- } \\
\text { tingtonkrankheit }\end{array}$ & 927 & - & - & $\begin{array}{l}\text { Gewichtsverände- } \\
\text { rung }\end{array}$ & $\begin{array}{l}\text { nur schwache Assoziation von Gewichtsverlust } \\
\text { und zunehmenden choreatiformen Bewegun- } \\
\text { gen }\end{array}$ \\
\hline $\begin{array}{l}\text { Kagel u. Leopold } \\
1992[211]\end{array}$ & III & $\begin{array}{l}\text { retrospektive Beob- } \\
\text { achtungsstudie; } \\
16 \text { Jahre }\end{array}$ & $\begin{array}{l}\text { Patienten mit Hun- } \\
\text { tingtonkrankheit }\end{array}$ & 35 & - & - & $\begin{array}{l}\text { Dysphagie, Evaluation } \\
\text { mittels klinischer } \\
\text { Schluckuntersuchung } \\
\text { und Videofluorosko- } \\
\text { pie }\end{array}$ & $\begin{array}{l}\text { Beeinträchtigungen besonders von oraler Vor- } \\
\text { bereitungsphase sowie oraler und pharyngea- } \\
\text { ler Phase des Schluckakts bei allen Patienten }\end{array}$ \\
\hline $\begin{array}{l}\text { Lanska et al. } 1988 \\
\text { [191] }\end{array}$ & III & $\begin{array}{l}\text { kontrolliert, nicht } \\
\text { randomisiert }\end{array}$ & $\begin{array}{l}\text { verstorbene Patien- } \\
\text { ten mit Huntington- } \\
\text { krankheit }\end{array}$ & 495 & - & $\begin{array}{l}2 \text { alters- und ge- } \\
\text { schlechtsgematchte } \\
\text { verstorbene Kontrol- } \\
\text { len pro Huntington- } \\
\text { patient }\end{array}$ & Todesursache & $\begin{array}{l}\text { Pneumonie sowie Avitaminosen und andere } \\
\text { Ernährungsmangelzustände sind bei Hunting- } \\
\text { tonpatienten häufigere Todesursachen als bei } \\
\text { den Kontrollen }\end{array}$ \\
\hline $\begin{array}{l}\text { Leopold u. Kagel } \\
1985 \text { [209] }\end{array}$ & III & $\begin{array}{l}\text { Beobachtungsstudie; } \\
3 \text { Jahre }\end{array}$ & $\begin{array}{l}\text { Huntingtonpatient } \\
\text { mit videofluoroskopi- } \\
\text { schem Nachweis einer } \\
\text { Dysphagie }\end{array}$ & 12 & $\begin{array}{l}\text { logopädische } \\
\text { Schlucktherapie } \\
\text { bei } 11 \text { Patienten }\end{array}$ & - & Ernährungsform & $\begin{array}{l}8 \text { der } 11 \text { Patienten konnten durch die Schluck- } \\
\text { therapie zu einer Normalkost zurückkehren, } \\
\text { Effekt hielt für bis zu } 3 \text { Jahre an }\end{array}$ \\
\hline $\begin{array}{l}\text { Marder et al. } 2009 \\
\text { [188] }\end{array}$ & Ila & Querschnittsstudie & $\begin{array}{l}\text { prämanifeste Hun- } \\
\text { tington-Gen-Träger }\end{array}$ & 652 & - & - & Kalorienzufuhr, BMI & $\begin{array}{l}\text { Klinisch asymptomatische Huntington-Gen- } \\
\text { Träger mit einer CAG-Repeat-Länge von } 37 \\
\text { oder höher benötigen eine höhere Kalorienzu- } \\
\text { fuhr, um das Körpergewicht konstant zu halten }\end{array}$ \\
\hline $\begin{array}{l}\text { Myers et al. } 1991 \\
\text { [214] }\end{array}$ & III & $\begin{array}{l}\text { Beobachtungsstudie; } \\
\text { mindestens } 3 \text { Jahre } \\
\text { pro Patient }\end{array}$ & $\begin{array}{l}\text { Patienten mit Hun- } \\
\text { tingtonkrankheit }\end{array}$ & 42 & - & - & $\begin{array}{l}\text { Krankheitsprogressi- } \\
\text { on }\end{array}$ & $\begin{array}{l}\text { ein höheres Lebensalter zu Krankheitsbeginn } \\
\text { und ein höherer BMI bei der } 1 \text {. Untersuchung } \\
\text { waren assoziiert mit einer langsameren Krank- } \\
\text { heitsprogression }\end{array}$ \\
\hline $\begin{array}{l}\text { Nance et al. } 1996 \\
\text { [206] }\end{array}$ & III & $\begin{array}{l}\text { retrospektive Beob- } \\
\text { achtungsstudie }\end{array}$ & $\begin{array}{l}\text { Patienten mit Hun- } \\
\text { tingtonkrankheit, die } \\
\text { in Einrichtungen zur } \\
\text { Langzeitbetreuung le- } \\
\text { ben }\end{array}$ & 97 & - & - & $\begin{array}{l}\text { Verhaltensmerkmale, } \\
\text { Gewichtsveränderun- } \\
\text { gen, Pflegeaspekte, } \\
\text { Medikamentenein- } \\
\text { nahme, Hospitalisa- } \\
\text { tionen }\end{array}$ & $\begin{array}{l}\text { Huntingtonpatienten in der Langzeitbetreu- } \\
\text { ung benötigten einen Energiebedarf von } 3000 \\
-4000 \text { kcal, um das Körpergewicht konstant zu } \\
\text { halten }\end{array}$ \\
\hline
\end{tabular}




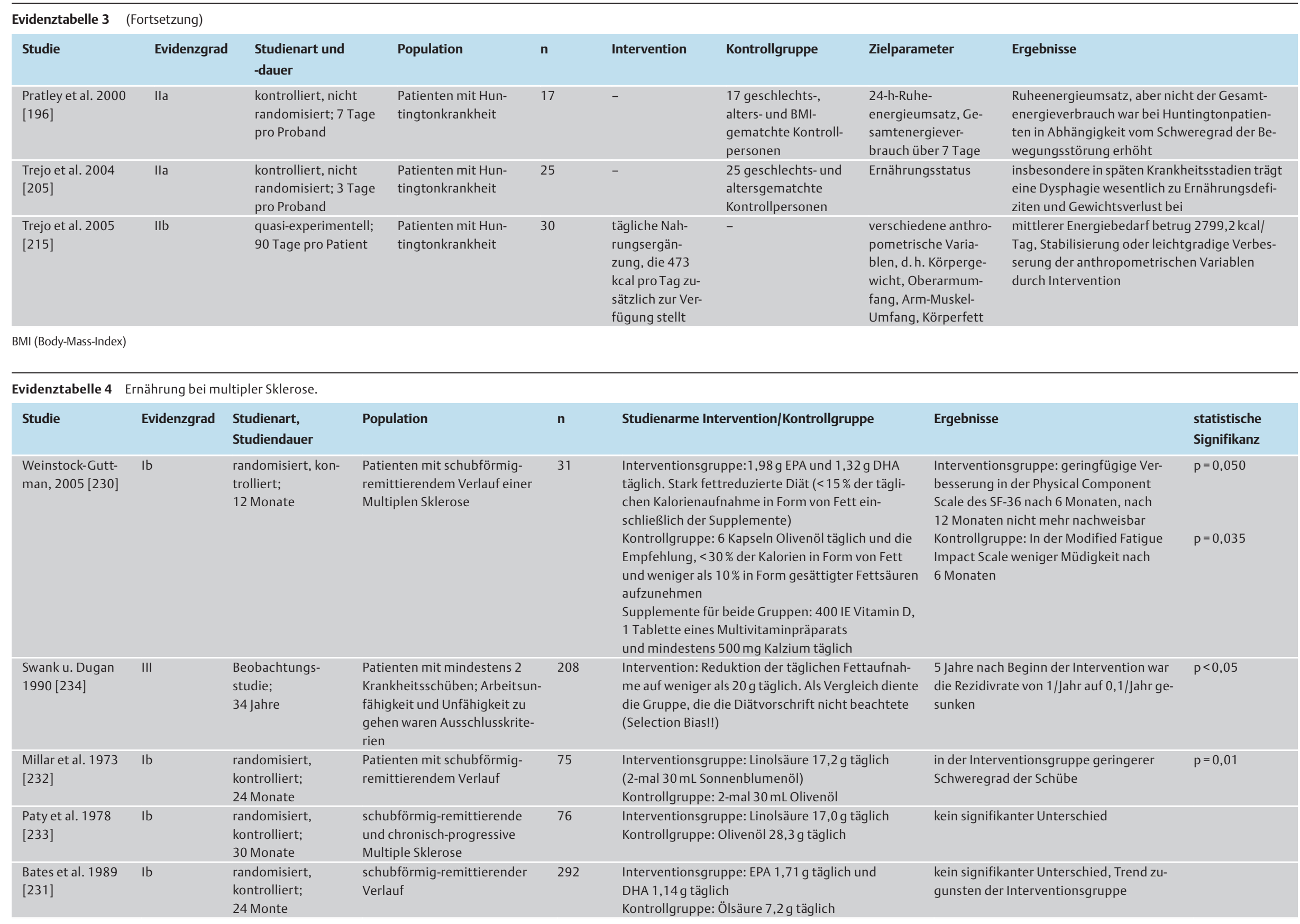

DHA (Docosahexaensäure), EPA (Eicosapentaensäure), SF-36 (Short Form-36) 


\section{Literatur}

1 Leischker A, Wirth R, Busch E et al. Leitlinie „Enterale Ernährung bei Patienten mit Schlaganfall“. Aktuel Ernahrungsmed 2007; 32: 332 348

2 Stingel K, Schütz T, Koller M et al. Leitlinie der Deutschen Gesellschaft für Ernährungsmedizin (DGEM) - Methodik zum Leitlinien-Update Klinische Ernährung. Aktuel Ernahrungsmed 2013; 38: 90-96

3 Koller M, Schutz T, Valentini $L$ et al. Outcome models in clinical studies: Implications for designing and evaluating trials in clinical nutrition. Clin Nutr 2013; 32: 650-657

4 Daniels SK, Brailey K, Foundas AL. Lingual discoordination and dysphagia following acute stroke: analyses of lesion localization. Dysphagia 1999; 14: 85-92

5 Veis SL, Logemann JA. Swallowing disorders in persons with cerebrovascular accident. Arch Phys Med Rehabil 1985; 66: 372 - 375

6 Ertekin C, Aydogdu I, Tarlaci S et al. Mechanisms of dysphagia in suprabulbar palsy with lacunar infarct. Stroke 2000; 31: 1370-1376

7 Martino R, Terrault N, Ezerzer F et al. Dysphagia in a patient with lateral medullary syndrome: insight into the central control of swallowing. Gastroenterology 2001; 121: 420-426

8 Holas MA, DePippo KL, Reding MJ. Aspiration and relative risk of medical complications following stroke. Arch Neurol 1994; 51: 1051 1053

9 Kidd D, Lawson J, Nesbitt $R$ et al. The natural history and clinical consequences of aspiration in acute stroke. QJM 1995; 88: 409-413

10 Smithard DG, O'Neill PA, Parks $C$ et al. Complications and outcome after acute stroke. Does dysphagia matter? Stroke 1996; 27: $1200-$ 1204

11 Mann G, Hankey GJ, Cameron D. Swallowing function after stroke: prognosis and prognostic factors at 6 months. Stroke 1999; 30: $744-748$

12 Hilker $R$, Poetter C, Findeisen $N$ et al. Nosocomial pneumonia after acute stroke: implications for neurological intensive care medicine. Stroke 2003; 34: 975 - 981

13 Wang $Y$, Lim $L L$, Heller RF et al. A prediction model of 1-year mortality for acute ischemic stroke patients. Arch Phys Med Rehabil 2003; 84: $1006-1011$

14 Martino R, Foley N, Bhogal S et al. Dysphagia after stroke: incidence, diagnosis, and pulmonary complications. Stroke 2005; 36: $2756-$ 2763

15 Gordon C, Hewer RL, Wade DT. Dysphagia in acute stroke. Br Med J (Clin Res Ed) 1987; 295: 411-414

16 Wade DT, Hewer RL. Motor loss and swallowing difficulty after stroke: frequency, recovery, and prognosis. Acta Neurol Scand 1987; 76: $50-$ 54

17 Barer $\mathrm{DH}$. The natural history and functional consequences of dysphagia after hemispheric stroke. J Neurol Neurosurg Psychiatry 1989; 52: $236-241$

18 DePippo KL, Holas MA, Reding MJ. Validation of the 3-oz water swallow test for aspiration following stroke. Arch Neurol 1992; 49: $1259-1261$

19 Kidd D, Lawson J, Nesbitt $R$ et al. Aspiration in acute stroke: a clinical study with videofluoroscopy. Q J Med 1993; 86: 825-829

20 Odderson IR, Keaton JC, McKenna BS. Swallow management in patients on an acute stroke pathway: quality is cost effective. Arch Phys Med Rehabil 1995; 76: 1130-1133

21 Hinds NP, Wiles CM. Assessment of swallowing and referral to speech and language therapists in acute stroke. QJM 1998; 91: 829-835

22 Scottish Intercollegiate Guidelines Network. Management of patients with stroke: identification and management of dysphagia, a national clinical guideline. 2010

23 Trapl M, Enderle P, Nowotny $M$ et al. Dysphagia bedside screening for acute-stroke patients: the Gugging Swallowing Screen. Stroke 2007; 38: $2948-2952$

24 Sellars C, Bowie L, Bagg J et al. Risk factors for chest infection in acute stroke: a prospective cohort study. Stroke 2007; 38: 2284-2291

25 Lakshminarayan $K$, Tsai AW, Tong X et al. Utility of dysphagia screening results in predicting poststroke pneumonia. Stroke 2010; 41: $2849-2854$

26 Evans A, Perez I, Harraf $F$ et al. Can differences in management processes explain different outcomes between stroke unit and stroketeam care? Lancet 2001; 358: 1586-1592

27 Hinchey JA, Shephard T, Furie K et al. Formal dysphagia screening protocols prevent pneumonia. Stroke 2005; 36: 1972 -1976
28 Ramsey DJ, Smithard DG, Kalra L. Early assessments of dysphagia and aspiration risk in acute stroke patients. Stroke 2003; 34: 1252-1257

29 Bours GJ, Speyer R, Lemmens J et al. Bedside screening tests vs. videofluoroscopy or fibreoptic endoscopic evaluation of swallowing to detect dysphagia in patients with neurological disorders: systematic review. J Adv Nurs 2009; 65: 477-493

30 Ramsey DJ, Smithard DG, Kalra L. Can pulse oximetry or a bedside swallowing assessment be used to detect aspiration after stroke? Stroke 2006; 37: 2984-2988

31 Teramoto S, Matsuse T, Fukuchi $Y$ et al. Simple two-step swallowing provocation test for elderly patients with aspiration pneumonia. Lancet 1999; 353: 1243

32 Teramoto S, Fukuchi Y. Detection of aspiration and swallowing disorder in older stroke patients: simple swallowing provocation test versus water swallowing test. Arch Phys Med Rehabil 2000; 81: 1517 1519

33 Warnecke T, Teismann I, Meimann W et al. Assessment of aspiration risk in acute ischaemic stroke - evaluation of the simple swallowing provocation test. J Neurol Neurosurg Psychiatry 2008; 79: 312 - 314

34 Zaidi NH, Smith HA, King SC et al. Oxygen desaturation on swallowing as a potential marker of aspiration in acute stroke. Age Ageing 1995; 24: $267-270$

35 Collins MJ, Bakheit AM. Does pulse oximetry reliably detect aspiration in dysphagic stroke patients? Stroke 1997; 28: 1773-1775

36 Sellars C, Dunnet C, Carter R. A preliminary comparison of videofluoroscopy of swallow and pulse oximetry in the identification of aspiration in dysphagic patients. Dysphagia 1998; 13: $82-86$

37 Smith HA, Lee SH, O'Neill PA et al. The combination of bedside swallowing assessment and oxygen saturation monitoring of swallowing in acute stroke: a safe and humane screening tool. Age Ageing 2000; 29: $495-499$

38 Lim SH, Lieu PK, Phua SY et al. Accuracy of bedside clinical methods compared with fiberoptic endoscopic examination of swallowing (FEES) in determining the risk of aspiration in acute stroke patients. Dysphagia 2001; 16: $1-6$

39 Colodny N. Comparison of dysphagics and nondysphagics on pulse oximetry during oral feeding. Dysphagia 2000; 15: 68 - 73

40 Leder SB. Use of arterial oxygen saturation, heart rate, and blood pressure as indirect objective physiologic markers to predict aspiration. Dysphagia 2000; 15: $201-205$

41 Wang TG, Chang YC, Chen SY et al. Pulse oximetry does not reliably detect aspiration on videofluoroscopic swallowing study. Arch Phys Med Rehabil 2005; 86: 730-734

42 Martino R, Pron G, Diamant N. Screening for oropharyngeal dysphagia in stroke: insufficient evidence for guidelines. Dysphagia 2000; 15: $19-30$

43 Dziewas R, Ritter M, Schilling $M$ et al. Pneumonia in acute stroke patients fed by nasogastric tube. J Neurol Neurosurg Psychiatry 2004; 75: $852-856$

44 Falsetti $P$, Acciai $C$, Palilla $R$ et al. Oropharyngeal dysphagia after stroke: incidence, diagnosis, and clinical predictors in patients admitted to a neurorehabilitation unit. J Stroke Cerebrovasc Dis 2009; 18: $329-335$

45 Logemann JA, Veis S, Colangelo L. A screening procedure for oropharyngeal dysphagia. Dysphagia 1999; $14: 44-51$

46 Bartolome G, Buchholz DW, Feussneret H. Schluckstörungen: Diagnostik und Rehabilitation. In: Bartolome G, ed. Klinische Eingangsuntersuchung bei Schluckstörungen. Schluckstörungen: Diagnostik und Rehabilitation. München, Jena: Urban \& Fischer; 2006

47 Gmeinwieser J, Golder W, Lehner K et al. X-ray diagnosis of the upper gastrointestinal tract at risk for aspiration using a nonionic iso-osmolar contrast medium. Rontgenpraxis 1988; 41: 361 - 366

48 Ekberg 0 , Olsson R. Dynamic radiology of swallowing disorders. Endoscopy 1997; 29: 439-446

49 Rosenbek JC, Robbins JA, Roecker EB et al. A penetration-aspiration scale. Dysphagia 1996; 11: $93-98$

50 Warnecke T, Ritter MA, Kroger B et al. Fiberoptic endoscopic Dysphagia severity scale predicts outcome after acute stroke. Cerebrovasc Dis 2009; 28: 283-289

51 Warnecke T, Teismann I, Oelenberg $S$ et al. The safety of fiberoptic endoscopic evaluation of swallowing in acute stroke patients. Stroke 2009; 40: $482-486$

52 Dziewas $R$, Warnecke T, Hamacher $C$ et al. Do nasogastric tubes worsen dysphagia in patients with acute stroke? BMC Neurol 2008; 8: 28 2377-8-28 
53 Leder SB, Sasaki CT, Burrell MI. Fiberoptic endoscopic evaluation of dysphagia to identify silent aspiration. Dysphagia 1998; 13: 19-21

54 Langmore SE. Evaluation of oropharyngeal dysphagia: which diagnostic tool is superior? Curr Opin Otolaryngol Head Neck Surg 2003; 11: 485-489

55 Prosiegel M, Diener HC, Putzki N. Neurogene Dysphagie. Leitlinien für die Diagnostik und Therapie in der Neurologie. Stuttgart: Georg Thieme Verlag; 2008

56 Kelly AM, Leslie P, Beale T et al. Fibreoptic endoscopic evaluation of swallowing and videofluoroscopy: does examination type influence perception of pharyngeal residue severity? Clin Otolaryngol 2006; 31: $425-432$

57 Kelly AM, Drinnan MJ, Leslie P. Assessing penetration and aspiration: how do videofluoroscopy and fiberoptic endoscopic evaluation of swallowing compare? Laryngoscope 2007; 117: 1723-1727

58 Smithard DG, O'Neill PA, England RE et al. The natural history of dysphagia following a stroke. Dysphagia 1997; 12: $188-193$

59 Kleindorfer D, Panagos P, Pancioli A et al. Incidence and short-term prognosis of transient ischemic attack in a population-based study. Stroke 2005; 36: 720-723

60 Carnaby G, Hankey GJ, Pizzi J. Behavioural intervention for dysphagia in acute stroke: a randomised controlled trial. Lancet Neurol 2006; 5: $31-37$

61 Ickenstein GW, Hofmayer A, Lindner-Pfleghar B et al. Standardisation of diagnostic and therapeutic procedures for neurogenic oropharyngeal dysphagia (NOD). Neurol Rehabil 2009; 15: 290-300

62 Dziewas $R$, Warnecke T, Olenberg $S$ et al. Towards a basic endoscopic assessment of swallowing in acute stroke - development and evaluation of a simple dysphagia score. Cerebrovasc Dis 2008; 26: 41-47

63 Ickenstein GW, Riecker A, Hohlig $C$ et al. Pneumonia and in-hospital mortality in the context of neurogenic oropharyngeal dysphagia (NOD) in stroke and a new NOD step-wise concept. J Neurol 2010; 257: $1492-1499$

64 Blackmer J. Tube feeding in stroke patients: a medical and ethical perspective. Can J Neurol Sci 2001; 28: 101 - 106

65 Dennis MS, Lewis SC, Warlow C et al. Effect of timing and method of enteral tube feeding for dysphagic stroke patients (FOOD): a multicentre randomised controlled trial. Lancet 2005; 365: 764-772

66 Dennis $M$, Lewis S, Cranswick G et al. FOOD Trial Collaboration. FOOD: a multicentre randomised trial evaluating feeding policies in patients admitted to hospital with a recent stroke. Health Technol Assess 2006; 10: iii-iv, ix-x, 1-120

67 Kreymann KG, Berger MM, Deutz NE et al. ESPEN Guidelines on Enteral Nutrition: Intensive care. Clin Nutr 2006; 25: 210-223

68 Volkert D, Berner YN, Berry E et al. ESPEN Guidelines on Enteral Nutrition: Geriatrics. Clin Nutr 2006; 25: 330-360

69 Braunschweig $C L$, Levy P, Sheean PM et al. Enteral compared with parenteral nutrition: a meta-analysis. Am J Clin Nutr 2001; 74: 534-542

70 Singh S, Hamdy S. Dysphagia in stroke patients. Postgrad Med J 2006; 82: $383-391$

71 Daniels SK, Brailey K, Priestly DH et al. Aspiration in patients with acute stroke. Arch Phys Med Rehabil 1998; 79: 14-19

72 Broadley S, Croser D, Cottrell J et al. Predictors of prolonged dysphagia following acute stroke. J Clin Neurosci 2003; 10: 300-305

73 Finucane TE, Bynum JP. Use of tube feeding to prevent aspiration pneumonia. Lancet 1996; 348: 1421 - 1424

74 Mamun K, Lim J. Role of nasogastric tube in preventing aspiration pneumonia in patients with dysphagia. Singapore Med J 2005; 46: $627-631$

75 Nakajoh K, Nakagawa T, Sekizawa K et al. Relation between incidence of pneumonia and protective reflexes in post-stroke patients with oral or tube feeding. J Intern Med 2000; 247: 39-42

76 Finestone HM, Greene-Finestone LS, Wilson ES et al. Prolonged length of stay and reduced functional improvement rate in malnourished stroke rehabilitation patients. Arch Phys Med Rehabil 1996; 77: $340-345$

77 Gariballa SE, Parker SG, Taub N et al. Influence of nutritional status on clinical outcome after acute stroke. Am J Clin Nutr 1998; 68: 275 281

78 Kudsk KA, Croce MA, Fabian TC et al. Enteral versus parenteral feeding. Effects on septic morbidity after blunt and penetrating abdominal trauma. Ann Surg 1992; 215: 503 - 511; discussion 511-513
79 Moore FA, Feliciano DV, Andrassy RJ et al. Early enteral feeding, compared with parenteral, reduces postoperative septic complications. The results of a meta-analysis. Ann Surg 1992; 216: 172 - 183

80 Gramlich L, Kichian K, Pinilla J et al. Does enteral nutrition compared to parenteral nutrition result in better outcomes in critically ill adult patients? A systematic review of the literature. Nutrition 2004; 20 : $843-848$

81 Montecalvo MA, Steger KA, Farber HW et al. Nutritional outcome and pneumonia in critical care patients randomized to gastric versus jejunal tube feedings. The Critical Care Research Team. Crit Care Med 1992; 20: $1377-1387$

82 Taylor S. Audit of nasogastric feeding practice at two acute hospitals: is early enteral feeding associated with reduced mortality and hospital stay? Journal of Human Nutrition and Dietetics 1993: 477-489

83 Nyswonger GD, Helmchen RH. Early enteral nutrition and length of stay in stroke patients. J Neurosci Nurs 1992; 24: 220-223

84 Davalos A, Ricart W, Gonzalez-Huix F et al. Effect of malnutrition after acute stroke on clinical outcome. Stroke 1996; 27: 1028-1032

85 Bath PM, Bath FJ, Smithard DG. Interventions for dysphagia in acute stroke. Cochrane Database Syst Rev 2000; (02): CD000323

86 Peschl L, Zeilinger M, Munda $W$ et al. Percutaneous endoscopic gastrostomy - a possibility for enteral feeding of patients with severe cerebral dysfunctions. Wien Klin Wochenschr 1988; 100: 314-318

87 Norton B, Homer-Ward M, Donnelly MT et al. A randomised prospective comparison of percutaneous endoscopic gastrostomy and nasogastric tube feeding after acute dysphagic stroke. BMJ 1996; 312: $13-16$

88 Park RH, Allison MC, Lang J et al. Randomised comparison of percutaneous endoscopic gastrostomy and nasogastric tube feeding in patients with persisting neurological dysphagia. BMJ 1992; 304: $1406-1409$

89 Anderson MR, O'Connor M, Mayer $P$ et al. The nasal loop provides an alternative to percutaneous endoscopic gastrostomy in high-risk dysphagic stroke patients. Clin Nutr 2004; 23: $501-506$

90 Beavan J, Conroy SP, Harwood $R$ et al. Does looped nasogastric tube feeding improve nutritional delivery for patients with dysphagia after acute stroke? A randomised controlled trial. Age Ageing 2010; 39: $624-630$

91 Kostadima E, Kaditis AG, Alexopoulos EI et al. Early gastrostomy reduces the rate of ventilator-associated pneumonia in stroke or head injury patients. Eur Respir J 2005; 26: 106 - 111

92 Oehmichen F, Ballmer PE, Druml C et al. Leitlinie der Deutschen Gesellschaft für Ernährungsmedizin (DGEM) - Ethische und rechtliche Gesichtspunkte der Künstlichen Ernährung. Aktuel Ernahrungsmed 2013; 38: $112-117$

93 National Institute for Health and Clinical Excellence. Nutrition support in adults. Clinical guideline 32, 2006

94 Strong RM, Condon SC, Solinger MR et al. Equal aspiration rates from postpylorus and intragastric-placed small-bore nasoenteric feeding tubes: a randomized, prospective study. JPEN J Parenter Enteral Nutr 1992; 16: 59-63

95 Spain DA, DeWeese RC, Reynolds MA et al. Transpyloric passage of feeding tubes in patients with head injuries does not decrease complications. J Trauma 1995; 39: 1100-1102

96 Lien HC, Chang CS, Chen GH. Can percutaneous endoscopic jejunostomy prevent gastroesophageal reflux in patients with preexisting esophagitis? Am J Gastroenterol 2000; 95: 3439-3443

97 Jabbar A, McClave SA. Pre-pyloric versus post-pyloric feeding. Clin Nutr 2005; 24: 719-726

98 Rhoney DH, Parker D Jr, Formea CM et al. Tolerability of bolus versus continuous gastric feeding in brain-injured patients. Neurol Res 2002; 24: 613-620

99 Serpa LF, Kimura M, Faintuch J et al. Effects of continuous versus bolus infusion of enteral nutrition in critical patients. Rev Hosp Clin Fac Med Sao Paulo 2003; 58: 9-14

100 Lee JS, Auyeung TW. A comparison of two feeding methods in the alleviation of diarrhoea in older tube-fed patients: a randomised controlled trial. Age Ageing 2003; 32: 388 - 393

101 Coben RM, Weintraub A, DiMarino AJJr et al. Gastroesophageal reflux during gastrostomy feeding. Gastroenterology 1994; 106: 13-18

102 Baeten C, Hoefnagels J. Feeding via nasogastric tube or percutaneous endoscopic gastrostomy. A comparison. Scand J Gastroenterol Suppl 1992; 194: $95-98$ 
103 Huggins PS, Tuomi SK, Young C. Effects of nasogastric tubes on the young, normal swallowing mechanism. Dysphagia 1999; 14: 157 161

104 Wang TG, Wu MC, Chang YC et al. The effect of nasogastric tubes on swallowing function in persons with dysphagia following stroke. Arch Phys Med Rehabil 2006; 87: 1270 - 1273

105 Leder SB, Suiter DM. Effect of nasogastric tubes on incidence of aspiration. Arch Phys Med Rehabil 2008; 89: 648-651

106 Langdon PC, Lee AH, Binns CW. High incidence of respiratory infections in 'nil by mouth' tube-fed acute ischemic stroke patients. Neuroepidemiology 2009; 32: $107-113$

107 Abe S, Ishihara K, Adachi $M$ et al. Oral hygiene evaluation for effective oral care in preventing pneumonia in dentate elderly. Arch Gerontol Geriatr 2006; 43: 53-64

108 Bagyi K, Haczku A, Marton I et al. Role of pathogenic oral flora in postoperative pneumonia following brain surgery. BMC Infect Dis 2009; 9: 104

109 Langmore SE, Terpenning MS, Schork A et al. Predictors of aspiration pneumonia: how important is dysphagia? Dysphagia 1998; 13: 69 81

110 Bassim CW, Gibson G, Ward T et al. Modification of the risk of mortality from pneumonia with oral hygiene care. J Am Geriatr Soc 2008; 56: $1601-1607$

111 Gosney M, Martin MV, Wright AE. The role of selective decontamination of the digestive tract in acute stroke. Age Ageing 2006; 35: 42 47

112 Chan EY, Ruest A, Meade MO et al. Oral decontamination for prevention of pneumonia in mechanically ventilated adults: systematic review and meta-analysis. BMJ 2007; 334: 889

113 Whelan $K$. Inadequate fluid intakes in dysphagic acute stroke. Clin Nutr 2001; 20: 423-428

114 Vivanti AP, Campbell KL, Suter MS et al. Contribution of thickened drinks, food and enteral and parenteral fluids to fluid intake in hospitalised patients with dysphagia. J Hum Nutr Diet 2009; 22: 148 - 155

115 Challiner YC, Jarrett D, Hayward MJ et al. A comparison of intravenous and subcutaneous hydration in elderly acute stroke patients. Postgrad Med J 1994; 70: 195-197

116 Gariballa SE, Parker SG, Taub $N$ et al. A randomized, controlled, a single-blind trial of nutritional supplementation after acute stroke. JPEN J Parenter Enteral Nutr 1998; 22: 315 -319

117 Dennis MS, Lewis SC, Warlow C et al. Routine oral nutritional supplementation for stroke patients in hospital (FOOD): a multicentre randomised controlled trial. Lancet 2005; 365: 755 - 763

118 Milne AC, Potter J, Vivanti A et al. Protein and energy supplementation in elderly people at risk from malnutrition. Cochrane Database Syst Rev 2009; (02): CD003288. doi: CD003288

119 Ha L, Hauge T, Spenning AB et al. Individual, nutritional support prevents undernutrition, increases muscle strength and improves QoL among elderly at nutritional risk hospitalized for acute stroke: a randomized, controlled trial. Clin Nutr 2010; 29: 567 - 573

120 Rabadi MH, Coar PL, Lukin $M$ et al. Intensive nutritional supplements can improve outcomes in stroke rehabilitation. Neurology 2008; 71 : $1856-1861$

121 Stratton RJ, Ek AC, Engfer $M$ et al. Enteral nutritional support in prevention and treatment of pressure ulcers: a systematic review and meta-analysis. Ageing Res Rev 2005; 4: $422-450$

122 Stratton RJ, Green CJ, Elia M. Disease-related malnutrition: An evidence-based approach to treatment. CABI Publishing; 2003

123 Williams LS, Rotich J, Qi R et al. Effects of admission hyperglycemia on mortality and costs in acute ischemic stroke. Neurology 2002; 59: $67-71$

124 Leder SB, Suiter DM, Warner HL. Answering orientation questions and following single-step verbal commands: effect on aspiration status. Dysphagia 2009; 24: 290-295

125 Diniz PB, Vanin G, Xavier $R$ et al. Reduced incidence of aspiration with spoon-thick consistency in stroke patients. Nutr Clin Pract 2009; 24: $414-418$

126 Bhattacharyya N, Kotz T, Shapiro J. The effect of bolus consistency on dysphagia in unilateral vocal cord paralysis. Otolaryngol Head Neck Surg 2003; 129: 632-636

127 Kuhlemeier KV, Palmer JB, Rosenberg D. Effect of liquid bolus consistency and delivery method on aspiration and pharyngeal retention in dysphagia patients. Dysphagia 2001; 16: 119-122
128 Clave P, de Kraa M, Arreola $V$ et al. The effect of bolus viscosity on swallowing function in neurogenic dysphagia. Aliment Pharmacol Ther 2006; 24: 1385 - 1394

129 Logemann JA, Gensler G, Robbins J et al. A randomized study of three interventions for aspiration of thin liquids in patients with dementia or Parkinson's disease. J Speech Lang Hear Res 2008; 51: 173-183

130 Ozaki K, Kagaya H, Yokoyama M et al. The risk of penetration or aspiration during videofluoroscopic examination of swallowing varies depending on food types. Tohoku J Exp Med 2010; 220: 41 - 46

131 National Collaborating Centre for Chronic Conditions. Stroke - Diagnosis and initial management of stroke and transient ischaemic attack. July 2008

132 National Stroke Foundation. Clinical Guidelines for Stroke Management. 2010

133 Foley NC, Martin RE, Salter KL et al. A review of the relationship between dysphagia and malnutrition following stroke. J Rehabil Med 2009; 41: 707 - 713

134 Wright L, Cotter D, Hickson $M$ et al. Comparison of energy and protein intakes of older people consuming a texture modified diet with a normal hospital diet. J Hum Nutr Diet 2005; 18: 213-219

135 Markus HS, Tomkins AM, Stern GM. Increased prevalence of undernutrition in Parkinson's disease and its relationship to clinical disease parameters. J Neural Transm Park Dis Dement Sect 1993; 5: 117-125

136 Wang G, Wan Y, Cheng $Q$ et al. Malnutrition and associated factors in Chinese patients with Parkinson's disease: Results from a pilot investigation. Parkinsonism Relat Disord 2010; 16: 119-123

137 Durrieu G, LLau ME, Rascol $O$ et al. Parkinson's disease and weight loss: a study with anthropometric and nutritional assessment. Clin Auton Res 1992; 2: 153-157

138 Barichella M, Villa MC, Massarotto A et al. Mini Nutritional Assessment in patients with Parkinson's disease: correlation between worsening of the malnutrition and increasing number of disease-years. Nutr Neurosci 2008; 11: 128-134

139 Lorefat B, Ganowiak W, Wissing $U$ et al. Food habits and intake of nutrients in elderly patients with Parkinson's disease. Gerontology 2006; 52: $160-168$

140 Chen H, Zhang SM, Hernan MA et al. Weight loss in Parkinson's disease. Ann Neurol 2003; 53: 676-679

141 Lorefalt B, Granerus AK, Unosson M. Avoidance of solid food in weight losing older patients with Parkinson's disease. J Clin Nurs 2006; 15 $1404-1412$

142 Davies KN, King D, Davies H. A study of the nutritional status of elderly patients with Parkinson's disease. Age Ageing 1994; 23: 142 - 145

143 Barichella $M$, Cereda E, Pezzoli $G$. Major nutritional issues in the management of Parkinson's disease. Mov Disord 2009; 24: 1881 1892

144 Bachmann CG, Trenkwalder C. Body weight in patients with Parkinson's disease. Mov Disord 2006; 21: $1824-1830$

145 Miller N, Noble E, Jones D et al. Hard to swallow: dysphagia in Parkinson's disease. Age Ageing 2006; 35: 614-618

146 Jost $W H$. Gastrointestinal dysfunction in Parkinson's Disease. J Neurol Sci 2010; 289: 69-73

147 Hayes MW, Fung VS, Kimber TE et al. Current concepts in the management of Parkinson disease. Med J Aust 2010; 192: 144-149

148 Wood LD, Neumiller JJ, Setter SM et al. Clinical review of treatment options for select nonmotor symptoms of Parkinson's disease. Am J Geriatr Pharmacother 2010; 8: 294-315

149 Coates C, Bakheit AM. Dysphagia in Parkinson's disease. Eur Neurol 1997; 38: $49-52$

150 Johnston BT, Li Q Castell JA et al. Swallowing and esophageal function in Parkinson's disease. Am J Gastroenterol 1995; 90: 1741 - 1746

151 Leopold NA, Kagel MC. Pharyngo-esophageal dysphagia in Parkinson's disease. Dysphagia 1997; 12: 11 -18; discussion 19-20

152 Monte FS, da Silva-Junior FP, Braga-Neto $P$ et al. Swallowing abnormalities and dyskinesia in Parkinson's disease. Mov Disord 2005; 20 : $457-462$

153 Nagaya M, Kachi T, Yamada T et al. Videofluorographic study of swallowing in Parkinson's disease. Dysphagia 1998; 13: 95 - 100

154 Michou E, Hamdy S. Dysphagia in Parkinson's disease: a therapeutic challenge? Expert Rev Neurother 2010; 10: 875-878

155 Troche MS, Okun MS, Rosenbek JC et al. Aspiration and swallowing in Parkinson disease and rehabilitation with EMST: a randomized trial. Neurology 2010; 75: 1912-1919 
156 Invernizzi M, Carda S, Viscontini GS et al. Osteoporosis in Parkinson's disease. Parkinsonism Relat Disord 2009; 15: 339-346

157 Sato Y, Manabe S, Kuno H et al. Amelioration of osteopenia and hypovitaminosis $\mathrm{D}$ by 1alpha-hydroxyvitamin D3 in elderly patients with Parkinson's disease. J Neurol Neurosurg Psychiatry 1999; 66: 64-68

158 Dachverband Osteologie e.V. DVO-Leitlinie 2009 zur Prophylaxe, Diagnostik und Therapie der Osteoporose bei Erwachsenen. Osteologie 2009; 18: 304-328

159 Astarloa R, Mena MA, Sanchez Vet al. Clinical and pharmacokinetic effects of a diet rich in insoluble fiber on Parkinson disease. Clin Neuropharmacol 1992; 15: 375-380

160 Cereda E, Barichella M, Pezzoli G. Controlled-protein dietary regimens for Parkinson's disease. Nutr Neurosci 2010; 13: 29-32

161 Diener H, Weimar C. Leitlinien für Diagnostik und Therapie in der Neurologie. 5. überarbeitete Auflage ed. Stuttgart: Georg Thieme Verlag; 2012

162 Carter JH, Nutt JG, Woodward WR et al. Amount and distribution of dietary protein affects clinical response to levodopa in Parkinson's disease. Neurology 1989; 39: 552-556

163 Cereda E, Barichella M, Pedrolli C et al. Low-protein and protein-redistribution diets for Parkinson's disease patients with motor fluctuations: a systematic review. Mov Disord 2010; 25: 2021 - 2034

164 Cereda E, Gini A, Pedrolli C et al. Disease-specific, versus standard, nutritional support for the treatment of pressure ulcers in institutionalized older adults: a randomized controlled trial. J Am Geriatr Soc 2009; 57: $1395-1402$

165 Moore O, Kreitler S, Ehrenfeld $M$ et al. Quality of life and gender identity in Parkinson's disease. J Neural Transm 2005; 112: 1511 - 1522

166 Stewart KC, Fernandez HH, Okun MS et al. Distribution of motor impairment influences quality of life in Parkinson's disease. Mov Disord 2008; $23: 1466-1468$

167 Li H, Zhang M, Chen $L$ et al. Nonmotor symptoms are independently associated with impaired health-related quality of life in Chinese patients with Parkinson's disease. Mov Disord 2010; 25: 2740-2746

168 Klepac $N$, Trkulja $V$, Relja $M$ et al. Is quality of life in non-demented Parkinson's disease patients related to cognitive performance? A clinic-based cross-sectional study. Eur J Neurol 2008; 15: 128-133

169 Zangaglia R, Martignoni E, Glorioso $M$ et al. Macrogol for the treatment of constipation in Parkinson's disease. A randomized placebocontrolled study. Mov Disord 2007; 22: 1239-1244

170 Leow LP, Huckabee ML, Anderson T et al. The impact of dysphagia on quality of life in ageing and Parkinson's disease as measured by the swallowing quality of life (SWAL-QOL) questionnaire. Dysphagia 2010; 25: 216-220

171 Plowman-Prine EK, Sapienza CM, Okun MS et al. The relationship between quality of life and swallowing in Parkinson's disease. Mov Disord 2009; 24: $1352-1358$

172 A'Campo LE, Wekking EM, Spliethoff-Kamminga NG et al. The benefits of a standardized patient education program for patients with Parkinson's disease and their caregivers. Parkinsonism Relat Disord 2010; 16: 89-95

173 Rao AK. Enabling functional independence in Parkinson's disease: update on occupational therapy intervention. Mov Disord 2010; 25 (Suppl. 01): S146-151

174 Bucks RS, Cruise KE, Skinner TC et al. Coping processes and healthrelated quality of life in Parkinson's disease. Int J Geriatr Psychiatry 2011; 26: 247-255

175 Korner $U$, Bondolfi A, Buhler $E$ et al. Ethical and legal aspects of enteral nutrition. Clin Nutr 2006; 25: 196-202

176 Krogh K, Christensen P. Neurogenic colorectal and pelvic floor dysfunction. Best Pract Res Clin Gastroenterol 2009; 23: 531 - 543

177 Ueki A, Otsuka M. Life style risks of Parkinson's disease: association between decreased water intake and constipation. J Neurol 2004; 251 (Suppl. 07): vII18-23

178 Volkert D, Bauer J, Frühwald T et al. Leitlinie der Deutschen Gesellschaft für Ernährungsmedizin (DGEM) in Zusammenarbeit mit der GESKES, der AKE und der DGG: Klinische Ernährung in der Geriatrie - Teil des laufenden S3-Leitlinienprojekts Klinische Ernährung. Aktuel Ernahrungsmed 2013; 38: e1 - e48

179 Loser C, Wolters S, Folsch UR. Enteral long-term nutrition via percutaneous endoscopic gastrostomy (PEG) in 210 patients: a four-year prospective study. Dig Dis Sci 1998; 43: 2549-2557

180 Bannerman E, Pendlebury J, Phillips $F$ et al. A cross-sectional and longitudinal study of health-related quality of life after percutaneous gastrostomy. Eur J Gastroenterol Hepatol 2000; 12: 1101-1109
181 Loeser C, von Herz U, Kuchler T et al. Quality of life and nutritional state in patients on home enteral tube feeding. Nutrition 2003; 19: 605-611

182 Loser C, Aschl G, Hebuterne X et al. ESPEN guidelines on artificial enteral nutrition - percutaneous endoscopic gastrostomy (PEG). Clin Nutr 2005; 24: $848-861$

183 Phillips W, Shannon KM, Barker RA. The current clinical management of Huntington's disease. Mov Disord 2008; 23: 1491 - 1504

184 Aziz NA, van der Marck MA, Pijl H et al. Weight loss in neurodegenerative disorders. J Neurol 2008; 255: $1872-1880$

185 Djousse L, Knowlton B, Cupples LA et al. Weight loss in early stage of Huntington's disease. Neurology 2002; 59: 1325 - 1330

186 Aziz NA, van der Burg JM, Landwehrmeyer GB et al. Weight loss in Huntington disease increases with higher CAG repeat number. Neurology 2008; 71: 1506-1513

187 Farrer LA, Yu PL. Anthropometric discrimination among affected, atrisk, and not-at-risk individuals in families with Huntington disease. Am J Med Genet 1985; 21: 307-316

188 Marder K, Zhao H, Eberly $S$ et al. Dietary intake in adults at risk for Huntington disease: analysis of PHAROS research participants. Neurology 2009; 73: 385 - 392

189 Robbins AO, Ho AK, Barker RA. Weight changes in Huntington's disease. Eur J Neurol 2006; 13: e7

190 Morales LM, Estevez J, Suarez H et al. Nutritional evaluation of Huntington disease patients. Am J Clin Nutr 1989; 50: 145-150

191 Lanska DJ, Lanska MJ, Lavine L et al. Conditions associated with Huntington's disease at death. A case-control study. Arch Neurol 1988; 45: $878-880$

192 Lanska DJ, Lavine L, Lanska MJ et al. Huntington's disease mortality in the United States. Neurology 1988; 38: 769-772

193 Aziz NA, Swaab DF, Pijl $H$ et al. Hypothalamic dysfunction and neuroendocrine and metabolic alterations in Huntington's disease: clinical consequences and therapeutic implications. Rev Neurosci 2007; 18 : $223-251$

194 Hamilton JM, Wolfson T, Peavy GM et al. Rate and correlates of weight change in Huntington's disease. J Neurol Neurosurg Psychiatry 2004; 75: $209-212$

195 Sanberg PR, Fibiger HC, Mark RF. Body weight and dietary factors in Huntington's disease patients compared with matched controls. Med J Aust 1981; 1: 407-409

196 Pratley RE, Salbe $A D$, Ravussin $E$ et al. Higher sedentary energy expenditure in patients with Huntington's disease. Ann Neurol 2000; 47: $64-70$

197 Gaba AM, Zhang K, Marder K et al. Energy balance in early-stage Huntington disease. Am J Clin Nutr 2005; 81: 1335 -1341

198 Gu M, Gash MT, Mann VM et al. Mitochondrial defect in Huntington's disease caudate nucleus. Ann Neurol 1996; 39: 385-389

199 Underwood BR, Broadhurst D, Dunn WB et al. Huntington disease patients and transgenic mice have similar pro-catabolic serum metabolite profiles. Brain 2006; 129: 877-886

200 Mochel F, Charles $P$, Seguin $F$ et al. Early energy deficit in Huntington disease: identification of a plasma biomarker traceable during disease progression. PLoS One 2007; 2: e647

201 Petersen A, Bjorkqvist M. Hypothalamic-endocrine aspects in Huntington's disease. Eur J Neurosci 2006; 24: 961 -967

202 Petersen A, Gil J, Maat-Schieman ML et al. Orexin loss in Huntington's disease. Hum Mol Genet 2005; 14: 39-47

203 Kremer HP, Roos RA, Dingjan G et al. Atrophy of the hypothalamic lateral tuberal nucleus in Huntington's disease. J Neuropathol Exp Neurol 1990; 49: $371-382$

204 Popovic V, Svetel M, Djurovic $M$ et al. Circulating and cerebrospinal fluid ghrelin and leptin: potential role in altered body weight in Huntington's disease. Eur J Endocrinol 2004; 151: 451 - 455

205 Trejo A, Tarrats RM, Alonso ME et al. Assessment of the nutrition status of patients with Huntington's disease. Nutrition 2004; 20: $192-$ 196

206 Nance MA, Sanders G. Characteristics of individuals with Huntington disease in long-term care. Mov Disord 1996; 11: 542 - 548

207 Edmonds C. Huntington's chorea, dysphagia and death. Med J Aust 1966; $2: 273-274$

208 Heemskerk AW, Roos RA. Dysphagia in Huntington's disease: a review. Dysphagia 2011; 26: 62-66

209 Leopold NA, Kagel MC. Dysphagia in Huntington's disease. Arch Neurol 1985; 42: $57-60$ 
210 Hunt VP, Walker FO. Dysphagia in Huntington's disease. J Neurosci Nurs 1989; 21: 92-95

211 Kagel MC, Leopold NA. Dysphagia in Huntington's disease: a 16-year retrospective. Dysphagia 1992; 7: $106-114$

212 Mochizuki H, Kamakura K, Kumada M et al. A patient with Huntington's disease presenting with laryngeal chorea. Eur Neurol 1999; 41: $119-120$

213 Hamakawa S, Koda C, Umeno $H$ et al. Oropharyngeal dysphagia in a case of Huntington's disease. Auris Nasus Larynx 2004; 31: 171 - 176

214 Myers RH, Sax DS, Koroshetz WJ et al. Factors associated with slow progression in Huntington's disease. Arch Neurol 1991; 48: 800 - 804

215 Trejo A, Boll MC, Alonso ME et al. Use of oral nutritional supplements in patients with Huntington's disease. Nutrition 2005; 21: 889-894

216 Gaba A, Zhang K, Moskowitz CB et al. Harris-Benedict equation estimations of energy needs as compared to measured 24-h energy expenditure by indirect calorimetry in people with early to midstage Huntington's disease. Nutr Neurosci 2008; 11: 213-218

217 Sobotka L, Schneider SM, Berner YN et al. ESPEN Guidelines on Parenteral Nutrition: geriatrics. Clin Nutr 2009; 28: 461-466

218 Pennington $C R$. Disease and malnutrition in British hospitals. Proc Nutr Soc 1997; 56: 393-407

219 Payne A. Nutrition and diet in the clinical management of multiple sclerosis. J Hum Nutr Diet 2001; 14: 349-357

220 Thomas FJ, Wiles CM. Dysphagia and nutritional status in multiple sclerosis. J Neurol 1999; 246: 677-682

221 Slawta JN, Wilcox AR, McCubbin JA et al. Health behaviors, body composition, and coronary heart disease risk in women with multiple sclerosis. Arch Phys Med Rehabil 2003; 84: 1823 - 1830

222 Hewson DC, Phillips MA, Simpson KE et al. Food intake in multiple sclerosis. Hum Nutr Appl Nutr 1984; 38: 355-367

223 Khurana SR, Bamer AM, Turner AP et al. The prevalence of overweight and obesity in veterans with multiple sclerosis. Am J Phys Med Rehabil 2009; 88: 83-91

224 Schwarz S, Leweling $H$. Multiple sclerosis and nutrition. Mult Scler 2005; $11: 24-32$

225 Fawcett J, Sidney JS, Hanson MJ et al. Use of alternative health therapies by people with multiple sclerosis: an exploratory study. Holist Nurs Pract 1994; 8: 36-42

226 Schwartz CE, Laitin E, Brotman S et al. Utilization of unconventional treatments by persons with MS: is it alternative or complementary? Neurology 1999; 52: 626-629

227 Winterholler M, Erbguth F, Neundorfer B. The use of alternative medicine by multiple sclerosis patients - patient characteristics and patterns of use. Fortschr Neurol Psychiatr 1997; 65: 555 - 561

228 Bowling AC, Stewart TM. Current Complementary and Alternative Therapies for Multiple Sclerosis. Curr Treat Options Neurol 2003; 5: 55-68

229 Farinotti M, Simi S, Di Pietrantonj $C$ et al. Dietary interventions for multiple sclerosis. Cochrane Database Syst Rev 2007; (01): CD004192

230 Weinstock-Guttman B, Baier M, Park Y et al. Low fat dietary intervention with omega-3 fatty acid supplementation in multiple sclerosis patients. Prostaglandins Leukot Essent Fatty Acids 2005; 73: $397-$ 404

231 Bates D, Cartlidge NE, French JM et al. A double-blind controlled trial of long chain $n-3$ polyunsaturated fatty acids in the treatment of multiple sclerosis. J Neurol Neurosurg Psychiatry 1989; 52: 18-22
232 Millar JH, Zilkha KJ, Langman MJ et al. Double-blind trial of linoleate supplementation of the diet in multiple sclerosis. Br Med J 1973; 1: $765-768$

233 Paty DW, Cousin HK, Read S et al. Linoleic acid in multiple sclerosis: failure to show any therapeutic benefit. Acta Neurol Scand 1978; 58: $53-58$

234 Swank RL, Dugan BB. Effect of low saturated fat diet in early and late cases of multiple sclerosis. Lancet 1990; 336: 37-39

235 Eyles D, Almeras L, Benech $P$ et al. Developmental vitamin D deficiency alters the expression of genes encoding mitochondrial, cytoskeletal and synaptic proteins in the adult rat brain. J Steroid Biochem Mol Biol 2007; 103: $538-545$

236 Brown SJ. The role of vitamin D in multiple sclerosis. Ann Pharmacother 2006; 40: $1158-1161$

237 Hayes CE. Vitamin D: a natural inhibitor of multiple sclerosis. Proc Nutr Soc 2000; 59: $531-535$

238 Auer DP, Schumann EM, Kumpfel T et al. Seasonal fluctuations of gadolinium-enhancing magnetic resonance imaging lesions in multiple sclerosis. Ann Neurol 2000; 47: 276 - 277

239 Mahon BD, Gordon SA, Cruz J et al. Cytokine profile in patients with multiple sclerosis following vitamin D supplementation. J Neuroimmunol 2003; 134: $128-132$

240 Lakatos P, Nagy Z, Kiss L et al. Prevention of corticosteroid-induced osteoporosis by alfacalcidol. Z Rheumatol 2000; 59 (Suppl. 01): 48 - 52

241 Ferretti G, Bacchetti T, Principi F et al. Increased levels of lipid hydroperoxides in plasma of patients with multiple sclerosis: a relationship with paraoxonase activity. Mult Scler 2005; 11: 677-682

242 Jensen GE, Clausen J. Glutathione peroxidase activity, associated enzymes and substrates in blood cells from patients with multiple sclerosis - effects of antioxidant supplementation. Acta Pharmacol Toxicol (Copenh) 1986; 59 (Suppl. 07): 450-453

243 Mai J, Sorensen PS, Hansen JC. High dose antioxidant supplementation to MS patients. Effects on glutathione peroxidase, clinical safety, and absorption of selenium. Biol Trace Elem Res 1990; 24: 109-117

244 Wade DT, Young CA, Chaudhuri KR et al. A randomised placebo controlled exploratory study of vitamin B-12, lofepramine, and L-phenylalanine (the „Cari Loder regime“) in the treatment of multiple sclerosis. J Neurol Neurosurg Psychiatry 2002; 73: 246 - 249

245 Shatin R. Multiple Sclerosis and Geography. New Interpretation of Epidemiological Observations. Neurology 1964; 14: 338 -344

246 Butcher J. The distribution of multiple sclerosis in relation to the dairy industry and milk consumption. N Z Med J 1976; 83: 427 - 430

247 Ghezzi A, Zaffaroni M. Neurological manifestations of gastrointestinal disorders, with particular reference to the differential diagnosis of multiple sclerosis. Neurol Sci 2001; 22 (Suppl. 02): 117-122

248 Hewson DC. Is there a role for gluten-free diets in multiple sclerosis? Hum Nutr Appl Nutr 1984; 38: 417-420

249 Ehrentheil OF, Schulman MH, Alexander L. Role of food allergy in multiple sclerosis. Neurology 1952; 2: 412-426

250 Ramagopalan SV, Dyment DA, Guimond C et al. Childhood cow's milk allergy and the risk of multiple sclerosis: a population based study. J Neurol Sci 2010; 291: 86-88

251 Vickrey BG, Hays RD, Harooni $R$ et al. A health-related quality of life measure for multiple sclerosis. Qual Life Res 1995; 4: 187-206

252 Fischer JS, LaRocca NG, Miller DM et al. Recent developments in the assessment of quality of life in multiple sclerosis (MS). Mult Scler 1999; 5: $251-259$ 